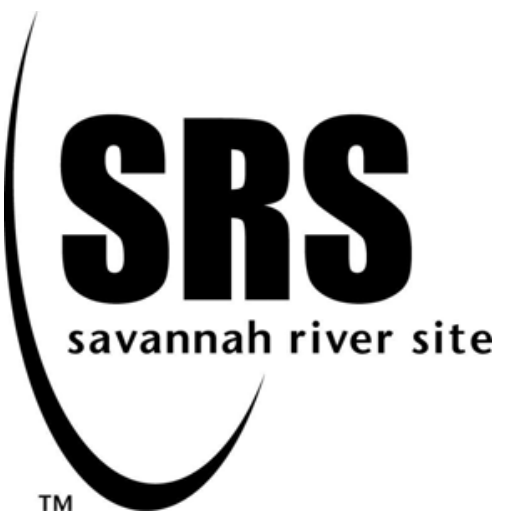

\title{
Effects of Tritium Exposure on UHMW-PE, PTFE, and Vespel ${ }^{\circledR}$
}

\author{
Elliot A. Clark and Kirk L. Shanahan
}

Publication Date: 31 May 2006

\section{Savannah River National Laboratory Washington Savannah River Company Savannah River Site Aiken, South Carolina}

This document was prepared in connection with work done under Contract No. DE-AC09-96SR18500 with the U.S. Department of Energy. By acceptance of this document, the publisher and/or recipient acknowledges the U.S. Government's right to retain a nonexclusive, royalty-free license in and to any copyright covering this document, along with the right to reproduce and authorize others to reproduce all or part of the copyrighted material.

The WSRC Team: Washington Savannah River Company LLC • Bechtel Savannah River, Inc. • BNG America Savannah River Corporation • BWXT Savannah River Company • CH2 Savannah River Company 


\section{DISCLAIMER}

This report was prepared as an account of work sponsored by an agency of the United States Government. Neither the United States Government nor any agency thereof, nor any of their employees, nor any of their contractors, subcontractors or their employees, makes any warranty, express or implied, or assumes any legal liability or responsibility for the accuracy, completeness, or any third party's use or the results of such use of any information, apparatus, product, or process disclosed, or represents that its use would not infringe privately owned rights. Reference herein to any specific commercial product, process, or service by trade name, trademark, manufacturer, or otherwise, does not necessarily constitute or imply its endorsement, recommendation, or favoring by the United States Government or any agency thereof or its contractors or subcontractors. The views and opinions of authors expressed herein do not necessarily state or reflect those of the United States Government or any agency thereof. 


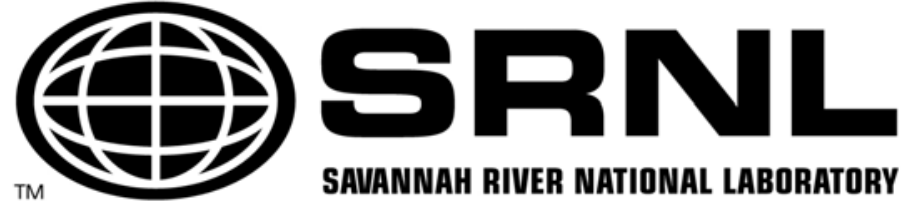

MATERIALS SCIENCE AND TECHNOLOGY

31 May 2006

Keywords: Tritium

Polymers

Radiation Damage

Isotope Exchange,

Retention - Permanent

\title{
Effects of Tritium Exposure on UHMW-PE, PTFE, and Vespel $^{\circledR}$
}

\author{
Elliot A. Clark, Kirk L. Shanahan
}

Materials Science and Technology, ${ }^{\#}$ Hydrogen Technology

Savannah River National Laboratory, Aiken, South Carolina 29808

\section{Washington Savannah River Company}

Prepared for the U. S. Department of Energy under Contract DE-AC09-96SR18500 


\section{APPROVALS}

F.A.Clatk, AITTHÖR

Marsials Compatibility and Joining Technology Grcup MATIRLALS SCILNCE ANIS TICIINOI.OGY

K.L. Shanahan, SUTIIOR

Matcriais Compatihility and Joinine Techrolosy Gucup HYDROGILY ILCHLOLOCIX

T.F. Skidmat. TFCHNTCAI. RFVTFWFR MATERIALS SCIENCE AND TECHNOLOGY

M.R. Dupinit, ACTING MANAGFR

Materials Compuibility and Welding Technology Grou: MATIRIAT.S SCTENCT NNIS TICIINOLOGY

$$
\text { ) }
$$

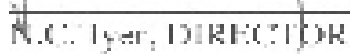

MATERIALS SCIENCE AND TFC.HNOIOGY

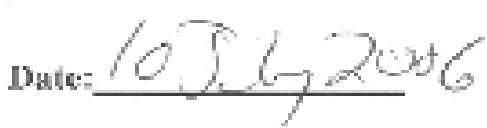

Date: $\angle C D,-2+1 C$

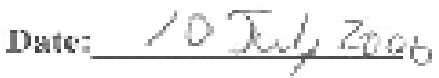

Dute: $\frac{-1 / 10 / 06}{1 / 0}$

Date: $10 v_{b y}=d \tau \&$ 


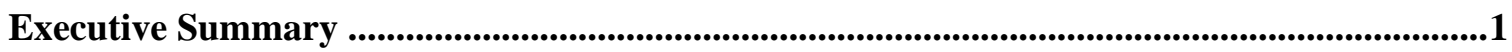

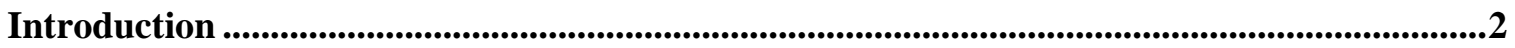

Exposure Program ...............................................................................................................................

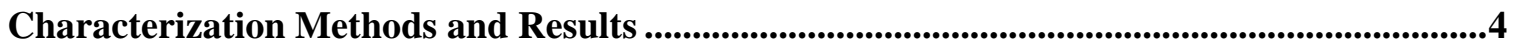

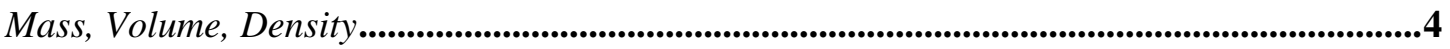

Color- Visual Appearance ........................................................................................................................5

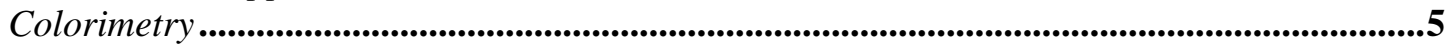

Exposure Gas Pressure, Composition .......................................................................................................6

Dynamic Mechanical Analysis- Overview and Experimental Details .........................................7

Dynamic Mechanical Analysis- Results...................................................................................8

Fourier Transform Infrared Spectroscopy......................................................................11

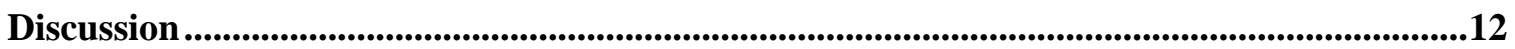

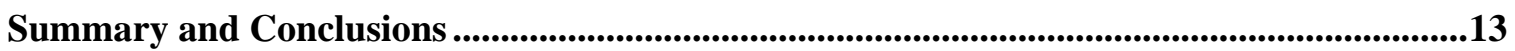

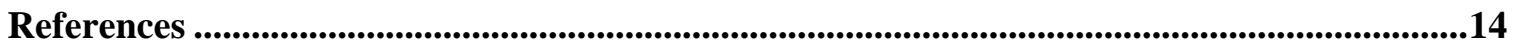

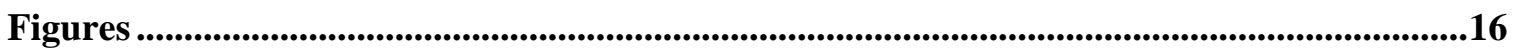

Appendix- Gas/Solid Mass Balance Estimates...............................................................46

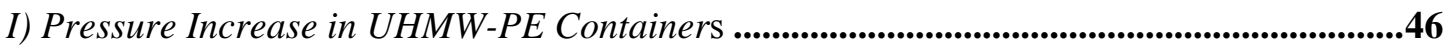

II) Pressure Decrease in PTFE Containers ................................................................................47 


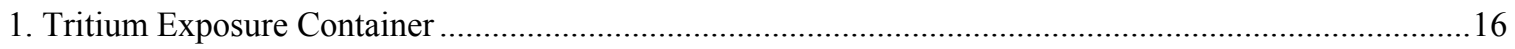

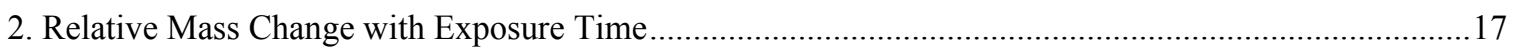

3. Relative Volume Change with Exposure Time …………................................................................. 17

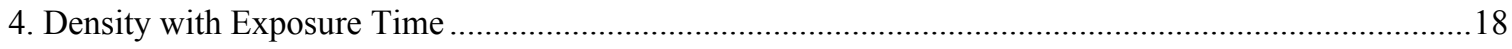

5. Unexposed and Tritium Exposed Samples …………….....................................................................19

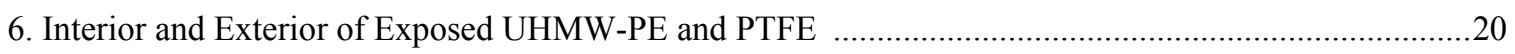

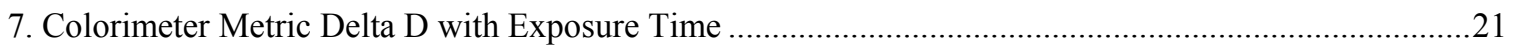

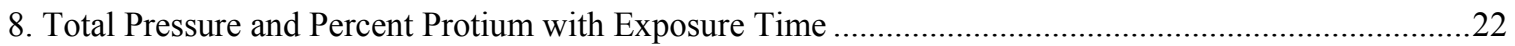

9. Three-Point Bend Dynamic Mechanical Analyzer (DMA) Sample Holder ...............................................23

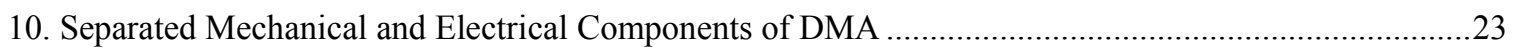

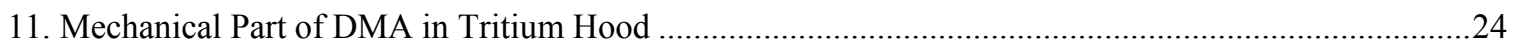

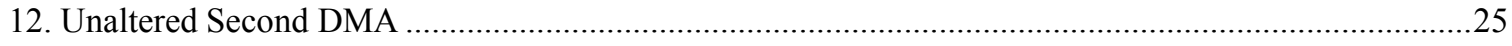

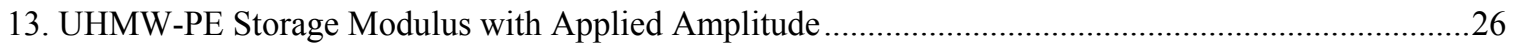

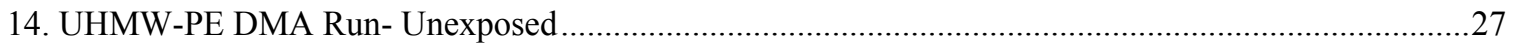

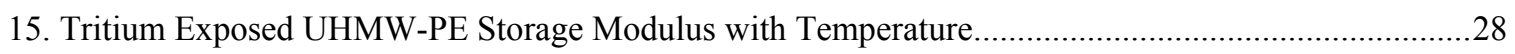

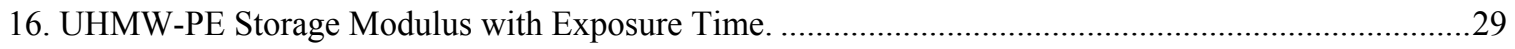

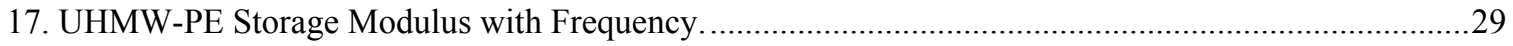

18. Loss Modulus of Exposed UHMW-PE with Temperature ......................................................................

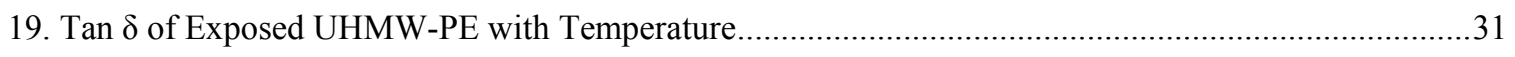

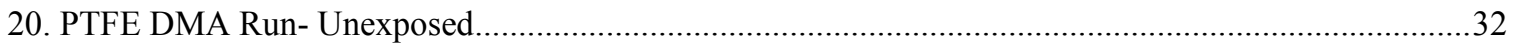

21. Tritium Exposed PTFE Storage Modulus with Temperature …….......................................................3

22. PTFE Storage Modulus with Exposure Time ………......................................................................... 34

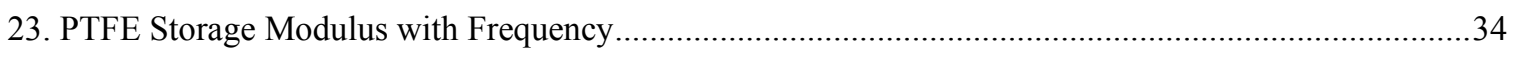

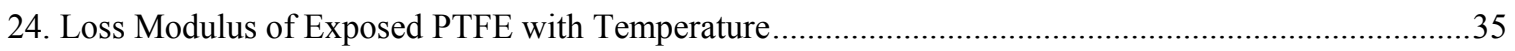

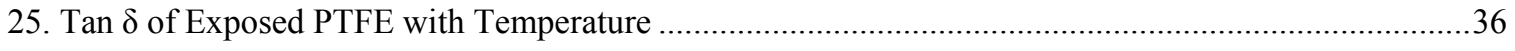

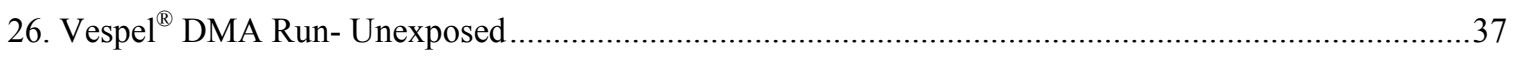

27. Tritium Exposed Vespel ${ }^{\circledR}$ Storage Modulus with Temperature............................................................ 38

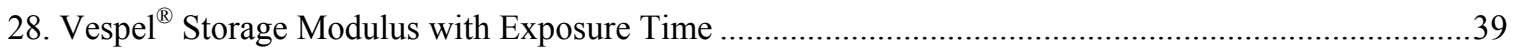

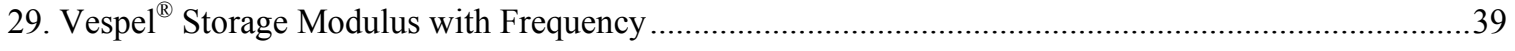

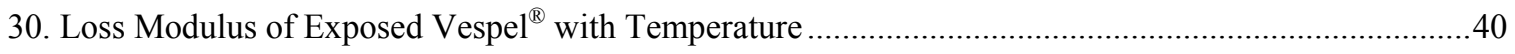

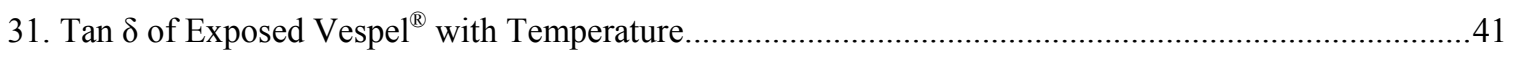

32. Storage Modulus and Tan $\delta$ of Individual Samples- 826 Days Exposure …….......................................42

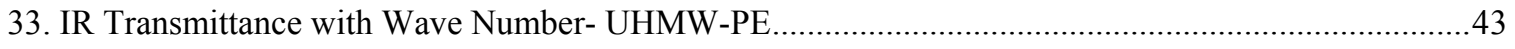

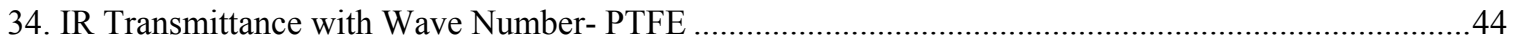

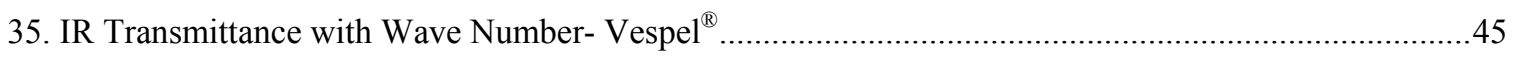




\title{
Effects of Tritium on UHMW-PE, PTFE, and Vespel ${ }^{\circledR}$ -
}

\author{
Elliot A. Clark, Kirk L. Shanahan
}

31 May 2006

\section{EXECUTIVE SUMMARY}

Samples of three polymers, Ultra-High Molecular Weight Polyethylene (UHMW-PE), polytetrafluoroethylene (PTFE, also known as Teflon ${ }^{\mathbb{B}}$ ), and Vespel ${ }^{\mathbb{B}}$ polyimide were exposed to 1 atmosphere of tritium gas at ambient temperature for varying times up to 2.3 years in closed containers. Sample mass and size measurements (to calculate density), spectra-colorimetry, dynamic mechanical analysis (DMA), and Fourier-transform infrared spectroscopy (FT-IR) were employed to characterize the effects of tritium exposure on these samples. Changes of the tritium exposure gas itself were characterized at the end of exposure by measuring total pressure and by mass spectroscopic analysis of the gas composition.

None of the polymers exhibited significant changes of density. The color of initially white UHMW-PE and PTFE dramatically darkened to the eye and the color also significantly changed as measured by colorimetry. The bulk of UHMW-PE darkened just like the external surfaces, however the fracture surface of PTFE appeared white compared to the PTFE external surfaces. The white interior could have been formed while the sample was breaking or could reflect the extra tritium dose at the surface directly from the gas. The dynamic mechanical response of UHMW-PE was typical of radiation effects on polymers- an initial stiffening (increased storage modulus) and reduction of viscous behavior after three months exposure, followed by lowering of the storage modulus after one year exposure and longer. The storage modulus of PTFE increased through about nine months tritium exposure, then the samples became too weak to handle or test using DMA. Characterization of Vespel ${ }^{\circledR}$ using DMA was problematic- sample-to-sample variations were significant and no systematic change with tritium exposure could be discerned. Isotopic exchange and incorporation of tritium into UHMW-PE (exchanging for protium) and into PTFE (exchanging for fluorine) was observed by FT-IR using an attenuated total reflectance method. No significant change in the Vespel ${ }^{\circledR}$ infrared spectrum was observed after three months exposure.

Protium significantly pressurized the UHMW-PE containers during exposure to about nine atmospheres (the initial pressure was one atmosphere of tritium). This is consistent with the well-known production of hydrogen by irradiation of polyethylene by ionizing radiation. The total pressure in the PTFE containers decreased, and a mass balance reveals that the observed decrease is consistent with the formation of small amounts of ${ }^{3} \mathrm{HF}$, which is condensed at ambient temperature. No significant change of pressure occurred in the Vespel ${ }^{\circledR}$ containers; however the composition of the gas became about $50 \%$ protium, showing that Vespel ${ }^{\mathbb{R}}$ interacted with the tritium gas atmosphere to some degree.

The relative resistance to degradation from tritium exposure is least for PTFE, more for UHMW-PE, and the most for Vespel ${ }^{\circledR}$, which is consistent with the known relative resistance of these polymers to gamma irradiation. This qualitatively agrees with the concept of equivalent effects for equivalent absorbed doses of radiation damage of polymers. Some of the changes of different polymers are qualitatively similar; however each polymer exhibited unique property changes when exposed to tritium.

Information from this study that can be applied to a tritium facility is: 1) the relative resistance to tritium degradation of the three polymers studied is the same as the relative resistance to gamma irradiation in air (so relative rankings of polymer resistance to ionizing radiation can be used as a relative ranking for assessing tritium compatibility and polymer selection); and 2) all three polymers changed the gas atmosphere during tritium exposure- UHMW-PE and Vespel ${ }^{\circledR}$ exposed to tritium formed $\mathrm{H}_{2}$ gas (UHMW-PE much more so), 
and PTFE exposed to tritium formed ${ }^{3} \mathrm{HF}$. This observation of forming ${ }^{3} \mathrm{HF}$ supports the general concept of minimizing chlorofluorocarbon polymers in tritium systems.

\section{INTRODUCTION}

All polymers degrade when exposed to ionizing radiation. The amount of degradation depends on several factors including polymer type, specific formulation, total dose, dose rate, and presence of oxygen. Because of this, it is desirable to fabricate tritium processing systems using tritium compatible metals and alloys and to avoid using polymers where possible. However, there are inevitably specific applications for which polymers are uniquely suited because of either unique properties or cost. The degradation of properties by tritium exposure in these situations can be mitigated by prudent materials selection and by regular maintenance and replacement. In the tritium processing facility at the Savannah River Site, stem tips of some valves are made of Ultra-High Molecular Weight polyethylene (UHMW-PE). UHMW-PE is an excellent choice for this application because of its outstanding impact and abrasion resistance. Initially the lifetime of this stem tip was estimated to be five years, however the actual lifetime in the facility was found to be significantly less (one or two years), based on routine valve testing in the facility. There is little or no oxygen in the tritium process, so the common diffusion-limited oxidation-enhanced radiation damage of polymers is not a plausible explanation. Because of this unexpectedly short lifetime and lack of a technical understanding of tritium exposure effects on polymers, funding for a research program to study tritium effects on polymers was sought. The goal of this program is to provide the technical basis for the lifetime of UHMW-PE stem tips in particular, and to advance understanding of the behavior of polymers exposed to tritium in general. This report documents the initial phase of the program.

Three materials were chosen for study- UHMW-PE, polytetrafluoroethylene (PTFE, also known as Teflon ${ }^{\circledR}$ ), and Vespel ${ }^{\circledR}$ polyimide. PTFE is known to rapidly degrade when exposed to tritium (and other forms of ionizing radiation), and so was included in this study to provide a basis for comparison of property changes with time. There are also some parts in the tritium facility that employ glass-filled PTFE. Vespel ${ }^{\mathbb{R}}$ is a pseudo-thermoplastic polyimide (manufactured by Du Pont) that has outstanding high temperature properties and that has been successfully employed as valve stem tips in tritium systems, initially at Los Alamos National Laboratory and later at Savannah River. Vespel ${ }^{\mathbb{B}}$ is among the most radiation-resistant polymers.

When polymers are exposed to ionizing radiation (for example gamma rays, alpha particles, or beta particles from tritium decay), highly reactive "free radical" groups form when the energy of the ionizing photon or particle is absorbed [1]. These free radical groups continue to react in turn, in many complicated ways, and the initial overall response of any given polymer can be thought of as being either cross-linking or degradation by chain-scission. Materials that cross-link initially become stiffer, stronger and less pliable and those that degrade initially become weaker and then finally decompose to a form that has no mechanical strength, such as a powder or a liquid. Some polymers undergo one dominant mode of degradation, while others exhibit a mixed mode of both cross-linking and chain-scission. The degradation mode can also vary depending on the absorbed dose rate and presence of oxygen during irradiation.

Experience at SRS shows that given sufficient time, PTFE exposed to tritium in air decomposes and forms $\mathrm{HF}$ and (likely) other fluorinated compounds. HF is very undesirable because it can combine with water vapor in the air to form hydrofluoric acid, which in turn corrodes any stainless steel that is in contact with PTFE. It can also form many other compounds, depending on other chemical species present.

There is a large amount of data regarding the exposure of polymers to gamma irradiation in air, which has been gathered to support use of polymeric materials and components in nuclear power reactors, such as pumps, motors, valves, cable insulations and protective coatings. Though also involving ionizing radiation, using polymers in a tritium processing system is a specialized area, with little scientific data extant. For tritium service, it is generally assumed that polymers more resistant to gamma radiation in air are preferred - 
that is, the relative resistance or sensitivity of a given polymer to tritium is similar to that of gamma ray exposure.

Several factors differentiate exposure to gamma irradiation in air from tritium exposure. The energy of tritium beta particles (5.7 keV average, $18.6 \mathrm{keV}$ maximum) is very low compared to that typical for gamma irradiation in nuclear environments. Normally the penetration depth of low energy beta radiation is quite small ( $\sim 10$ microns), however tritium can cause radiation damage throughout the polymer bulk because it permeates throughout the material. In fact, tritium can isotopically exchange with protium atoms that comprise the polymer, actually becoming part of the polymer. Oxygen has been shown to be an important factor that accelerates radiation damage of polymers [2], and in tritium systems there is normally little or no oxygen, except that bound in water.

For these reasons, using well-published radiation resistance data for polymers irradiated with gamma rays in air may indicate relative stability but cannot predict detailed behavior or predict lifetime in oxygen-free tritium exposure. Published radiation resistance data for polymers almost always employ very high dose rate exposure $(\sim 1 \mathrm{Mrad} / \mathrm{hr})$ tests that tend to minimize oxidation effects. Such data are also of limited value for predicting service life of polymers irradiated by gamma rays in air, and many studies have shown these limitations even for polymers qualified for nuclear service [3]. Thus there is the need for basic understanding of polymer aging in tritium gas that this program will address, because polymers are used as structural materials in tritium handling systems.

This report documents the initial phase of this program. Sheet samples of UHMW-PE, PTFE, and Vespel ${ }^{\mathbb{R}}$ were cut, weighed and their dimensions were measured. They were then placed in stainless steel exposure containers. The containers were evacuated and filled with pure tritium gas to a pressure of 1 atmosphere. After exposing the samples in each container for times up to 2.3 years, the gas in the containers was sampled and removed. The samples from a specific container were removed (and exposed to air) only when they were to be characterized, to minimize air exposure and the effects of oxygen that might interfere with characterization. The samples were weighed and dimensions measured. The sample color was quantified using a spectra-colorimeter. Dynamic mechanical analysis (DMA) measured various elastic and viscoelastic properties, and the infrared radiation absorption properties were characterized by Fourier Transform Infrared Spectroscopy (FTIR) using an Attenuated Total Reflectance (ATR) technique. The pressure and composition of the container gas at the end of exposure were also determined.

\section{EXPOSURE PROGRAM}

Sheets of UHMW-PE, PTFE, and Vespel ${ }^{\circledR}$ were procured from Professional Plastics (Austin, TX). All sheets were nominally 0.062 ” thick. The PTFE was “virgin" TFE, and the Vespel ${ }^{\circledR}$ grade was SP-1 (without fillers). Fourier Transform Infrared (FT-IR) spectroscopy of the as-procured sheets (performed by SRNL Analytical Development) confirmed that the supplier sent the desired generic material in all three cases. The sheets were stored in drawers, away from direct fluorescent lighting, to avoid exposure to ultraviolet light. Rectangular samples were cut to nominally $3 / 8$ " by $1 \frac{1 / 4}{4}$. Four such samples of each polymer were chosen for each exposure time. One of these pieces was cut again prior to exposure to form two pieces nominally $3 / 8$ " by 0.42 " ("small" sample) and $3 / 8$ " by 0.83 " ("medium" sample). Of the total of five samples of each

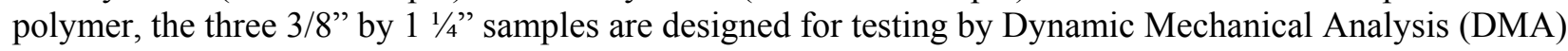
and the small and medium samples were sized differently to allow the volume and mass of each to be measured before and after exposure. All five samples of each polymer were then inserted in a stainless steel tubular exposure container having double valves and qualified for tritium service (Fig.1). Three containers were employed for each exposure time, each containing only one type of polymer.

The exposure containers were evacuated overnight in the Experimental Tritium Manifold (ETM) in the Materials Test Facility in the now deactivated Building 232-H, achieving less than 1 micron per minute rate 
of rise (over 10 minutes). The containers were then pressurized to 760 torr tritium gas, and then both valves were closed, and the container were removed from the manifold. The exposure temperature for all polymers and times investigated was the ambient temperature of the hood where the exposure took place, which normally was about $20-25^{\circ} \mathrm{C}$. Table I. shows the planned and actual exposure times.

\begin{tabular}{|c|c|}
$\begin{array}{c}\text { Planned } \\
\text { Exposure (d) }\end{array}$ & $\begin{array}{c}\text { Actual Tritium } \\
\text { Exposure Time (d) }\end{array}$ \\
\hline 91 & 108 \\
\hline 182 & 185 \\
\hline 273 & 276 \\
\hline 365 & 377 \\
\hline 545 & 568 \\
\hline 790 & 826 \\
\hline
\end{tabular}

Table I. Planned and Actual Exposure Times (days) to Tritium Gas.

After exposure, each container was remounted on a calibrated portion of the tritium manifold, and the total pressure in each container was measured. Prior to tritium exposure, the empty container volumes were measured, and the volume of the polymer samples in each container was calculated using the measured mass and assumed density of the polymers. The actual pressure at the end of exposure was calculated knowing the manifold volume and the measured final pressure which includes gas expansion into the pressure measurement part of the manifold. After the total pressure measurement, the remaining gas in each sample container was expanded into a gas sample bottle for mass spectroscopy using the tritium facility mass spectrometers.

The exposure containers were then evacuated overnight, until no offgassing was detectable by a ten-minute rate of rise test. The evacuated containers were then removed from the manifold and stored until each was opened for testing. Because of the known significant effects of oxygen on radiation damage of polymers, each exposure container remained evacuated to prevent unnecessary exposure to air until just before the samples in a given container were characterized. Each container was opened by slowly opening the top fitting, while minimizing the hood ion chamber ("Kanne") alarm. Immediately after the container was completely opened, the $3 / 8$ " by 0.42 " and $3 / 8$ " by 0.83 "samples were weighed using a laboratory scale and dimensions measured using an electronic caliper (length, width, thickness). These samples remained in the Experimental Tritium Manifold hood for FT-IR spectroscopy. The three 3/8" by 1 1/4" DMA samples were then placed in one plastic vial with holes pierced through the top. The plastic containers were then transferred in plastic bags and paint cans to an air hood in another room for dynamic mechanical analysis and colorimetry testing.

\section{CHARACTERIZATION METHODS AND RESULTS}

Mass, Volume, Density

Measurements of mass before and after exposure allowed the relative mass change to be calculated (Fig. 2). Dimensional measurements before and after exposure allowed calculation of sample volume and relative volume change (Fig. 3). The sample volume was calculated from dimensional measurements rather than measured directly by fluid displacement (more accurate than dimensional measurement) to avoid producing tritium contaminated liquid waste. The average bulk density of each sample was calculated by dividing measured mass by calculated volume (Fig. 4). No systematic change of mass, volume, or density was 
observed for any of the polymers studied. The measured densities were consistent with product literature values for these materials, $0.93 \mathrm{~g} / \mathrm{cc}$ for UHMW-PE, $2.20 \mathrm{~g} / \mathrm{cc}$ for PTFE, $1.41 \mathrm{~g} / \mathrm{cc}$ for Vespel ${ }^{\mathbb{B}}$.

The mass and dimension measurements were made within 30 minutes after the samples were removed from the containers, so it is unlikely that air (oxygen) influenced these results. Polymers can exhibit density decreases or increase when exposed to ionizing radiation [4]. Density decreases can be interpreted as stemming from a decrease in degree of crystallinity during irradiation, and density increases can be interpreted as being caused by cross-linking. UHMW-PE tends to cross-link initially during irradiation, and PTFE generally breaks down by chain scission or degradation. Both UHMW-PE and PTFE are highly crystalline polymers, and the results observed in this study suggest that the net effect on bulk density cancels. Therefore, although the mechanisms of degradation for each polymer may differ the net effect on density is negligible during tritium exposure.

\section{Color-Visual Appearance}

The most obvious effect of tritium exposure was the significant discoloration of the UHMW-PE samples, even after the shortest tritium exposure time, 108 days (Fig. 5). PTFE also discolored somewhat during the shortest exposure- the discoloration was more apparent to the eye than in photographs (Fig. 5). The discoloration of PTFE increased with time (Fig. 6c.). Unexposed Vespel ${ }^{\circledR}$ SP-1 is brown (Fig. 5) and so changes from tritium exposure were difficult to observe visually.

UHMW-PE discolored through the entire sample thickness, and PTFE appeared discolored only at the surface (Fig. 6). Tritium exposure did influence PTFE through the bulk- samples exposed to tritium for more than 9 months were extremely weak (discussed further below) and broke while handling, and so they did not need to be cut to observe the interior (Fig. 6d.). There are several plausible explanations for the white appearance in PTFE. First, the whiteness could have been formed while the sample broke, essentially a type of crazing that is a well-known feature of deformed polymers. Although crazing is normally associated with amorphous polymers (PTFE is normally highly crystalline), it is possible the white appearance of the interior reflects the voids and microcracks formed during the fracture. Another possible explanation of the lack of discoloration in the PTFE bulk is that the constant dose at the surface from tritium gas discolored the surface preferentially, and the amount of tritium permeating into the bulk was far less than that required to cause significant color change. A third explanation could be oxygen from the air rapidly interacting with tritium damaged material near the surface of the polymer within the half hour or so it took to remove the samples after air was admitted to the exposure container. However, the measured surface discoloration of PTFE increased continuously with exposure time (see Colorimetry below), and the oxygen dose when the container is opened would be about the same for each experiment. It is considered more likely that either a type of crazing or the continuous exposure to tritium gas at the surface caused the surface to appear discolored compared to the bulk. In either case, the side and end surfaces of the samples that were exposed when the samples were originally cut from sheet discolored the same as the large flat surfaces, indicating that no surface film was present on the original manufactured sheet that could have discolored preferentially.

\section{Colorimetry}

The sample color was measured using a Spectra-Colorimeter (Photo Research model PR-650, Chatsworth CA). A three-hundred-watt xenon light illuminated the flat samples at a 45-degree angle and the colorimeter was aimed normal to the surface. This arrangement eliminated specular reflection. The correlated color temperature (CCT) of a reflectivity standard illuminated by the lamp was measured to be about $4936 \mathrm{~K}$ as compared to a CCT for sunlight of $4874 \mathrm{~K}$. The outputs of the colorimeter are two numbers that together uniquely describe the color, termed " $x$ " and " $y$ ". These $\mathrm{x}$ and $\mathrm{y}$ values are coordinates in what is known as the 1931 CIE chromaticity diagram and represent the hue and saturation of the specimen. There are several 
color measurement scales, and the 1931 CIE chromaticity scale was chosen to be the most appropriate for this study.

The sample colors were measured shortly after they were removed from the exposure containers, to minimize the influence of air (especially oxygen). The color of each of the three DMA samples was measured, both on the front and back sides. The results of $\mathrm{x}$ and $\mathrm{y}$ were averaged. Also, the color of a matte white PTFE standard was also measured before and after each set of samples. If the average color parameters of samples of a given polymer and tritium exposure time are $\mathrm{x}$ and $\mathrm{y}$, and the color parameters of the standard on the day $\mathrm{x}$ and $\mathrm{y}$ are measured are $\mathrm{x}_{\text {std }}$ and $\mathrm{y}_{\text {std, }}$, the metric

$$
\text { DeltaD }=\sqrt{\left(x-x_{\text {std }}\right)^{2}+\left(y-y_{\text {std }}\right)^{2}}
$$

is a scalar measure of the color change between the measured color and the standard. A graph of DeltaD reveals the change of color of the surface of the samples with tritium exposure (Fig. 7). The change of color using colorimetry is greatest for PTFE, however both PTFE and UHMW-PE changed color drastically during the first six months of exposure. The UHMW-PE color changes less during longer exposure times, however the PTFE color continues to darken until about 18 months exposure. The Vespel ${ }^{\circledR}$ metric initially was constant, then decreased, and subsequently increased with tritium exposure (Fig. 7). The detection area of the colorimeter was too large to measure color changes on the cut (UHMW-PE) or broken (PTFE) surfaces that reveal the bulk color.

\section{Exposure Gas Pressure, Composition}

All containers were filled with 760 torr $\mathrm{T}_{2}$ at the beginning of exposure, discussed earlier. The total pressure inside the closed exposure containers of the UHMW-PE samples increased steadily with time up to a pressure of about 7000 torr (9.2 atm.) after 2.3 years (Fig. 8). The protium $\left({ }^{1} \mathrm{H}_{2}\right)$ composition of the gas in the containers of UHMW-PE increased to about $90 \%$ protium after about a year and then remained constant. The pressure in the PTFE containers gradually decreased to about 440 torr after 2.3 years exposure (Fig. 8). The percent protium in the PTFE containers was very small except for the three month case, which is considered to be an anomaly (based on longer time exposure data in Fig. 8). The total pressure inside the containers of Vespel $^{\circledR}$ samples remained approximately at 760 torr (Fig. 8), and the protium composition quickly rose to about $50 \%$ of the gas after only three months exposure and remained the same upon longer exposures. For all three polymers, in no case was any other significant molecular species detected by mass spectroscopy, including low molecular weight hydrocarbons and HF. The background noise of the spectrometer was about $0.5 \%$, so any smaller concentration of gas produced would not have been observed. The mass spectroscopy system used in this study is not normally used for research and especially does not normally scan for unknown species; although such mass scans were performed, it is entirely possible that small amounts of hydrocarbon molecules were formed but not detected.

Polyethylene is known to emit hydrogen, methane and other hydrocarbon gases upon exposure to ionizing radiation [5], and the production of protium observed in this study is consistent with this. A mass balance estimate reveals that over 2.3 years if roughly $4 \%$ of the hydrogen available in the polymer becomes gas the observed pressure increase would take place (Appendix I). Since the molecular weight of UHMW-PE is so high, it is estimated that the number of cross-links equals the number of hydrogen molecules produced. A literature $\mathrm{G}$ value for producing $\mathrm{H}_{2}$ by irradiating polyethylene is 3.1 molecule/100 eV [5], and tritium decays with an average beta particle energy of $5.7 \mathrm{keV}$ per decay. An estimate of hydrogen production using these values with the observed pressure increase over 2.3 years implies that the average tritium decay produces 44 molecules of ${ }^{1} \mathrm{H}_{2}$ (Appendix II).

Tritium can react with PTFE to form ${ }^{3} \mathrm{HF}$ (TF). Although thermodynamically a gas, HF is known to form linear molecular aggregates of hydrogen bonded HF molecules below $200^{\circ} \mathrm{C}$. [6]. This implies that HF 
could form and condense as a molecular aggregate and so not be detected by either a total pressure gage or by a sample of gas. This would explain the drop in pressure observed over time during exposure of PTFE to tritium. A mass balance estimate shows that the observed pressure drop over 2.3 years in this study can be consistent with the formation of $13 \mathrm{mg}$ TF (Appendix II), which amounts to about $0.83 \%$ of the repeat units being affected. Infrared spectroscopy indicates that at least some tritium replaces fluorine in the polymer structure (discussed below), so this estimated quantity of TF $\left({ }^{3} \mathrm{HF}\right)$ produced is probably an upper limit- the rest possibly being $\mathrm{HF}\left({ }^{1} \mathrm{HF}\right)$.

The Vespel ${ }^{\circledR}$ container pressure exhibited no significant change during any exposure up to 2.3 years, however the gas composition changed rapidly to a $50 \%$ protium $/ 50 \%$ tritium mix and then remained approximately constant (Fig. 8). This isotope exchange shows that although Vespel ${ }^{\circledR}$ is resistant to tritium degradation, it is not inert when exposed to tritium.

\section{Dynamic Mechanical Analysis- Overview and Experimental Details}

Dynamic Mechanical Analysis (DMA) refers to a group of techniques that measure the elastic and viscoelastic properties of materials. When a force small enough to not cause permanent deformation is applied to a material, there is an instantaneous elastic response or displacement and a time-dependent or viscoelastic displacement. The elastic and viscoelastic displacements are both reversible- when the force is removed, the polymer reverts to the original shape, again with an instantaneous and a time-dependent response [7]. Thermodynamically, work done by the force on the material is stored and recovered as elastic energy during both the elastic and viscoelastic displacements, and some work is dissipated as heat because of the viscoelastic deformation.

DMA is a useful tool to study polymers because the elastic and viscoelastic properties are significantly affected by morphological changes, such as glass and crystallographic transitions, cross-linking and chain scission, and approaching the melting point. In addition, there is a strong variation of elastic and viscoelastic properties of polymers with temperature, especially compared to metals and inorganic ceramics. This large temperature dependence is based on the huge influence thermal vibration of the various polymer chains has on the properties of the material. Other factors influencing the mechanical response of polymers to forces, such as fillers, polymer blends and copolymerization, and degree of crystallinity also affect both the elastic and viscoelastic behavior. Because of the sensitivity of elastic and viscoelastic properties to many basic polymer structural changes, DMA was chosen to characterize effects of tritium exposure on polymers in this program.

A TA Instruments model 2980 dynamic mechanical analyzer was used for this study. This device applies a forced vibration on a sample and detects the resulting deflection. The sample configuration was the threepoint bend configuration (Fig. 9). This configuration is appropriate for the relatively stiff thermoplastics studied here. In addition, the three-point bend sample holder, or "clamp", requires no screws to hold the sample when the sample is mounted, which eased mounting the samples in the DMA. (Other common sample holders include single and double cantilever beam, in which the sample must be secured by tightening screws.) The DMA used for testing these tritium exposed polymers was altered by the manufacturer to separate the mechanical part (including the furnace, sample holder, sample, loading system, and position detection) from the electronic part (Fig. 10). This reduced the amount of equipment in the tritium hood and facilitated operation in the radioactive environment (Fig. 11). Preliminary calibration and tests of this system before and after being moved to the tritium hood showed that the DMA operated identically to another Model 2980 that had the normal configuration (Fig. 12). The force is applied using a so called "air bearing" to reduce friction, and in all experiments pure argon was used as the bearing gas.

The DMA applies a sinusoidal force at specified frequencies, and the resulting displacement amplitude and phase angle $\delta$ between the load and displacement are measured. From the measured load, displacement 
amplitude, phase angle and knowing the specimen geometry (rectangular slab used in this study) and sample holder type, the system calculates the various quantities that describe the elastic and viscoelastic properties. The quantities reported here are the storage modulus, loss modulus, and $\tan \delta$. A modulus is the ratio of the applied force per unit area, or stress, to the resulting displacement per unit length, or strain. Because of the viscoelastic (time-dependent) deformation, the modulus is represented as a complex number. The real part of the complex modulus is called the storage modulus, and the imaginary part is called the loss modulus. The storage modulus is a measure of the elastic (or instantaneous) deformation of the polymer, and the loss modulus viscoelastic (or time-dependent) deformation. Tan $\delta$ is the loss modulus divided by the storage modulus. The three quantities storage modulus, loss modulus, and tan $\delta$ are thus not independent.

The DMA was operated in constant amplitude mode, using the so-called "Force Track" feature. For three point bend samples, two locations (near the two ends) of the sample are fixed and the force is applied downward in the middle (Fig. 9). The amplitude is the magnitude of the sinusoidal sample displacement at the point where the force is applied; the amplitude is the time-varying displacement at the applied frequency. Preliminary experiments with unexposed samples of each polymer were performed to determine the range of acceptable amplitudes that provide valid DMA data- both large enough to obtain modulus data that did not vary with amplitude, but also within the limit of linear viscoelasticity (Fig. 13). The amplitudes used in this study were: UHMW-PE $50 \mu \mathrm{m}$, PTFE $80 \mu \mathrm{m}$, $\operatorname{Vespel}^{\circledR} 30 \mu \mathrm{m}$. The DMA applies the sinusoidal force necessary to maintain the chosen amplitude at all sample temperatures and for all applied frequencies. In addition, the Force Track feature applies a constant force in addition to the sinusoidal force to maintain contact between the moving part of the sample holder and the sample- this is specified as a percentage of the amplitude in Force Track mode. This feature prevents the sample holder from separating from the sample and then impacting it during each cycle of the set applied frequency. Preliminary testing of unexposed samples led to choosing the force track settings that were used: UHMW-PE 200\%, PTFE 150\%, and Vespel ${ }^{\circledR} 200 \%$. The Force Track feature is useful because the modulus of polymers lowers significantly with increasing temperature, and so the force required to maintain the set constant amplitude becomes much lower at increasing temperature, and the constant force needed to maintain contact between the moving part and the sample becomes much lower as well.

DMA data was taken using frequencies of $1,3,10$, and $30 \mathrm{~Hz}$ (or cycles per second). The DMA was not stable above $30 \mathrm{~Hz}$ for the polymers studied, and the acquisition time for frequencies below $1 \mathrm{~Hz}$ was too long for the temperature scan rate used (discussed below). The DMA continuously acquired data at each of the frequencies in sequence during the increasing temperature scans. The sampling rate was set at 3.0 sec/point, which specifies the time over which data is acquired for each set frequency.

Each DMA experiment involved stabilizing the temperature at $-60^{\circ} \mathrm{C}$. for 10 minutes and then increasing the sample temperature at $1^{\circ} \mathrm{C}$. per minute until the samples softened for UHMW-PE and PTFE or until $270^{\circ} \mathrm{C}$. for Vespel ${ }^{\circledR}$. (The Vespel ${ }^{\circledR}$ upper temperature was chosen to be able to finish one scan during an eight hour work day). The TA 2980 has both electrical resistance heating and cooling by evaporated cold nitrogen gas from a liquid nitrogen container called the Gas Cooling Accessory (GCA) which is a part of the DMA system. The control software enables optimized control of cooling and heating for a given temperature and heating rate. The system was regularly calibrated before each set of measurements and additionally at least once a month.

\section{Dynamic Mechanical Analysis- Results}

The DMA characterization of each sample, that is each sample experiment or run, consisted of measuring the force, displacement, and temperature in a manner to calculate the storage modulus, loss modulus, and $\tan \delta$ for the four chosen frequencies continuously as the temperature increased. Samples were not tested more than once, because the polymer structure irreversibly changes at elevated temperature. For each polymer and time of exposure, three samples were tested. For UHMW-PE and PTFE exposed under the same conditions, 
results were consistent from sample to sample and so one representative sample result is shown in this report. The sample-to-sample variation of Vespel ${ }^{\mathbb{R}}$ is discussed separately (below).

\section{- $U H M W-P E$}

A graph of results from a run using a sample of UHMW-PE not exposed to tritium illustrates the information obtained during each DMA experiment, or run (Fig. 14). The storage modulus of UHMW-PE decreases continuously as the temperature increases, until the softening point of the sample is reached. At this point, the modulus is very low and the sample begins to undergo permanent deformation and the test is discontinued. Many thermoplastics exhibit this behavior. The storage modulus increases with frequency at a given temperature, meaning the sample is stiffer at increased applied frequency (Fig. 14). This implies that the polymer chains resist force more at the higher frequencies.

The loss modulus of unexposed UHMW-PE changes significantly with temperature, and the changes differ strongly at different frequencies (Fig. 14). The loss modulus appears to have a broad maximum, or "peak", at different temperatures (about $49^{\circ} \mathrm{C}$., $61^{\circ} \mathrm{C}$. $67^{\circ} \mathrm{C}$. and $73^{\circ} \mathrm{C}$.) for the four applied frequencies $(1,3,10,30$ $\mathrm{Hz}$ respectively). There is another loss modulus peak in the $30 \mathrm{~Hz}$ loss modulus data at about $-5^{\circ} \mathrm{C}$. These loss modulus peaks are interpreted as a maximum of the viscoelastic deformation, or energy dissipation, because of coupling between the applied vibration with polymer chain segments at the specific frequency and temperature. The four peaks having differing peak temperatures are considered to be caused by the same physical chain segment coupling. The physical chain segment motion is presumably thermally activated, leading to differing peak temperatures at each frequency. The second peak at low temperature at $30 \mathrm{~Hz}$ is interpreted as a different physical coupling mechanism. It is the ability of polymer chain segments to dissipate the mechanical energy of the applied force that causes the peaks in the loss modulus. These results illustrate the advantage of testing at multiple frequencies.

The $\tan \delta$ of unexposed UHMW-PE reveals the features of the loss modulus represented in a different way. The peaks observed in the loss modulus are also observed as either peaks or slope changes (Fig. 14). In addition, a significant general increase in $\tan \delta$ is observed for all applied frequencies beginning at $12^{\circ} \mathrm{C}$. for $1 \mathrm{~Hz}, 25^{\circ} \mathrm{C}$. for $3 \mathrm{~Hz}, 35^{\circ} \mathrm{C}$. for $10 \mathrm{~Hz}$, and $50^{\circ} \mathrm{C}$. for $30 \mathrm{~Hz}$ (Fig. 14). The tan $\delta$ continues to increase until the softening point is reached, which reflects the ever increasing viscous deformation of the unexposed polymer as the temperature is increased. The decrease in $\tan \delta$ at all frequencies between $130^{\circ} \mathrm{C}$. and $140^{\circ}$ C. likely reflects permanent deformation or creep. The samples appeared permanently deformed when removed from the DMA after each experiment.

Up to and including 276 days exposure to tritium gas raises the storage modulus of UHMW-PE at every temperature (Figs. 15, 16). Longer tritium exposure decreases the storage modulus, especially at low temperature (Fig. 16). This is consistent with the general idea of radiation damage of polymers that crosslink- initially the storage modulus increases because of radiation-induced cross linking, and at longer times degradation products increase relative to the number of cross-links, resulting in a net weakening of the material. It is notable that after about 18 months exposure, the storage modulus at $-50^{\circ} \mathrm{C}$. is lower than the unexposed modulus and this reduction continues with exposure at least through 2.3 years. At $100^{\circ} \mathrm{C}$. the storage modulus decreases with exposure after 18 months, but even after the longest exposure (2.3 years) is still greater than the unexposed storage modulus. The large storage modulus increase with applied frequency at $100^{\circ} \mathrm{C}$. is reduced significantly by tritium exposure (Fig. 17b); there is little effect of frequency on the storage modulus at $-50^{\circ} \mathrm{C}$. for both exposed and unexposed UHMW-PE (Fig. 17a). This can be explained by the reduction of the chain segment vibrations at low temperature that interact with the applied load to change the elastic response as a function of frequency for unexposed UHMW-PE compared to high temperatures [8].

Tritium exposure rapidly diminishes and eliminates the peaks and frequency dependence of the loss modulus (Fig. 18) and all temperature and frequency dependence of $\tan \delta$ (Fig. 19) for UHMW-PE. After the minimum exposure time of 108 days, the frequency and temperature dependent peaks and features are 
drastically reduced for both the loss modulus and $\tan \delta$, and longer exposure eliminates these peaks. At temperatures near the softening point, the $\tan \delta$ does not diminish for any tritium exposure, contrasting with that of unexposed UHMW-PE. These changes can be explained by radiation induced cross linking eliminating the vibration of polymer chain segments that couple with the applied load at a given frequency and causes the peaks and temperature dependence in unexposed UHMW-PE (above). The general decrease in the loss modulus with increasing temperature remains for the UHMW-PE loss modulus (Fig. 18).

\section{- PTFE}

Dynamic mechanical analysis of unexposed PTFE reveals some similar and some differing features compared to UHMW-PE (Fig. 20). In addition to the normal general decrease of storage modulus with increasing temperature, there is an abrupt change of the storage modulus at about $22^{\circ} \mathrm{C}$. and again at $34^{\circ} \mathrm{C}$. This abrupt decrease corresponds to significant peaks in both the loss modulus and $\tan \delta$ (Fig. 20). The peak in the loss modulus occurs at about $27^{\circ} \mathrm{C}$. for all four applied frequencies. The tan $\delta$ peak occurs at $31^{\circ} \mathrm{C}$. at $1 \mathrm{~Hz}, 32^{\circ} \mathrm{C}$. at $3 \mathrm{~Hz}, 35^{\circ} \mathrm{C}$. at $10^{\circ} \mathrm{Hz}$, and $37^{\circ} \mathrm{C}$. at $30 \mathrm{~Hz}$. PTFE undergoes multiple crystallographic transitions in this range of temperature [9], and these transitions are reflected in the observed modulus features. The lack of frequency dependence indicates that the nature of the coupling of the cyclic mechanical load with the transition is not based on a thermally activated vibration of polymer chains segments. There is another series of peaks in $\tan \delta$ at about $140^{\circ}$ C. (Fig. 20), and an associated change of the loss modulus at similar temperatures. These peaks are considered to reflect interaction of the applied cyclic stress with some of the PTFE chain segments, similar to UHMW-PE (above). (Since PTFE is normally a highly crystalline polymer, these chain segments are believed to be in the crystalline region.) Other features of the storage modulus are similar to UHMW-PE-- the storage modulus generally decreases significantly with temperature, and the storage modulus increases with increasing frequency at a given temperature. At about $169^{\circ} \mathrm{C}$. the PTFE sample softened enough so that the run ended, which is higher than the $140^{\circ} \mathrm{C}$. softening point of UHMW-PE.

The storage modulus of tritium-exposed PTFE increased with tritium exposure at every temperature (Fig. 21). Apart from this general stiffening, the shape of the storage modulus versus temperature curve remained the same. In particular, the change of storage modulus between $22^{\circ} \mathrm{C}$. and $34^{\circ} \mathrm{C}$. was unaffected by tritium exposure (Fig. 21), indicating little effect of tritium on the crystallographic transitions. The most important observation of PTFE behavior during tritium exposure was that beyond 276 days tritium exposure the samples were too weak to handle and test without breaking (Fig. 6). For those exposures that were able to be tested, 276 days and less, the storage modulus at a given frequency increased with tritium exposure at both $-50^{\circ} \mathrm{C}$. and $+100^{\circ} \mathrm{C}$. (Fig. 22), similar to the initial behavior of UHMW-PE discussed above. Tritium exposure significantly reduced the increase of storage modulus with increased frequency at $+100^{\circ} \mathrm{C}$. (Fig. 23 b), similar to UHMW-PE (above). There was no change of the small frequency dependence of storage modulus at $-50^{\circ} \mathrm{C}$. with tritium exposure (Fig. 23 a). Tritium decay-induced degradation and free radical formation causing pinning of polymer chain motion with applied stress at elevated temperature, leading to an increased modulus and reduced frequency dependence, is consistent with these observations.

The loss modulus of PTFE was not strongly influenced by tritium exposure up to 276 days (Fig. 24). There appears to be an increase in the loss modulus below the crystallographic transition, below about $25^{\circ} \mathrm{C}$., after the longest exposure for PTFE (276 days), but the temperature of the peak in loss modulus remains constant with increasing tritium exposure. The peak height of the loss modulus increases with tritium exposure (Fig. 24). Similar observations are made concerning the $\tan \delta$ with the additional observation of the reduction of the higher temperature peaks at $140^{\circ}$ C. (Fig. 25). Again, the reduction of loss modulus and tan $\delta$ peaks, and values in general, is interpreted as radiation-induced degradation and free radical formation reducing polymer chain segment vibration that leads to the peaks in loss modulus at $140^{\circ} \mathrm{C}$. in unexposed PTFE. 


\section{- Vespel ${ }^{\circledR} S P-1$}

The polyimide Vespel ${ }^{\circledR}$ maintains its properties at very high temperatures compared to most other polymers. Dynamic mechanical analysis of unexposed Vespel ${ }^{\circledR}$ SP-1 grade reveals this high temperature stability (Fig. 26). Vespel ${ }^{\circledR}$ has a storage modulus of $2700 \mathrm{MPa}$ at $270^{\circ} \mathrm{C}$., while the other two polymers become unable to carry virtually any load at much lower temperatures, $140^{\circ} \mathrm{C}$. for UHMW-PE and $170^{\circ} \mathrm{C}$. for PTFE. The magnitude of $\tan \delta$ (Fig. 26) is generally smaller than that for UHMW-PE (Fig. 14) and is comparable to that of PTFE (Fig. 20). Like the other polymers, the storage modulus of unexposed Vespel ${ }^{\circledR}$ increases with applied frequency, albeit slightly (Fig. 26). There appears to be a peak in both the loss modulus and $\tan \delta$ at about $240^{\circ} \mathrm{C}$. that is greater at $30 \mathrm{~Hz}$ than at 1,3 , and $10 \mathrm{~Hz}$. Unlike the other two polymers studied, DMA characterization of Vespel ${ }^{\circledR}$ was terminated at $270^{\circ} \mathrm{C}$. to enable one run per work shift, not because the polymer became too soft to test.

The storage modulus varied with tritium exposure, but not in a systematic way (Figs. 27, 28). The storage modulus varied little with frequency, and this was not changed by tritium exposure (Fig. 29 a. and b.). This contrasts with reduction of frequency dependence at $+100^{\circ} \mathrm{C}$. for both UHMW-PE (Fig. 17b) and PTFE (Fig. 23b). There appears to be no systematic change of either loss modulus (Fig. 30) or tan $\delta$ (Fig. 31) with tritium exposure. In fact, a plot of DMA results of all three samples exposed for 826 days (Fig. 32) reveals very inconsistent data- this observation holds for other exposure times as well. These samples were cut from the same sheet, handled the same way, and exposed in the same container. These data show that Vespel ${ }^{\circledR}$ is difficult to characterize by DMA- especially the viscoelastic quantities loss modulus and $\tan \delta$.

\section{Fourier Transform Infrared Spectroscopy (FT-IR)}

Fourier transform infrared (FT-IR) spectrometry was performed using the Attenuated Total Reflectance (ATR) technique. A Bruker Vector 22 FT-IR instrument was equipped with a Pike MiRacle ATR attachment, using a ZnSe ATR crystal. This instrument has the advantage of being small enough to fit in the Experimental Tritium Manifold hood. The flat polymer sample is clamped in the ATR apparatus, which presses it onto the ATR crystal surface. Infrared light impinges on the crystal and probes the sample surface. The sampling depth is wavelength dependent but ranges between about 0.5 and $2.0 \mu \mathrm{m}$. All spectra were recorded at $2 \mathrm{~cm}^{-1}$ resolution. The instrument and associated software analyze the data to provide a spectrum showing transmittance versus wave number. The smaller and medium sized samples were analyzed as soon after exposure to air as possible.

Overall, the spectra of both UNMW-PE and PTFE generally show evidence for the substitution of tritium for protium in the UHMW-PE (Fig. 33) and of tritium for fluorine in PTFE (Fig. 34). The resultant C-T stretching vibrational bands in the exposed PTFE were almost identical to those observed in exposed UHMW-PE, indicating a nearly identical chemical environment. The C-T bands observed in exposed UHMW-PE fell at the expected point based on Hooke's Law considerations, indicating that direct exchange had occurred, that is the tritium was located at the same location protium occupied originally. In addition, the peaks appear to broaden and are reduced with increased tritium exposure for both UHMW-PE and PTFE (Fig. 34). The broadening and weakening may reflect radiation damage of the polymers, increased infrared absorption generally (recall the significant visual color changes observed above), or perhaps tritium exposure of the ZeSe crystal. The inside of the PTFE samples was examined by placing the samples 'end-on' in the ATR sample holder, and the spectra obtained in this configuration appeared the same as those obtained from the exposed faces. This is additional support for tritium influencing PTFE through the thickness of the sample (in addition to the brittleness after nine months exposure discussed above). 
Vespel ${ }^{\circledR}$ infrared spectra revealed no change with tritium exposure after three months (Fig. 35). No C-H stretch was observed at about $2900 \mathrm{~cm}^{-1}$ for either unexposed or three months exposure, which was unexpected. The optical properties of Vespel ${ }^{\circledR}$ may prevent this vibration from being optically active.

\section{DISCUSSION}

There are similarities and differences comparing a previous study [10] of exposure of high-density polyethylene (HDPE) to tritium gas at ambient temperature with the UHMW-PE observations in this study. In the previous study, a sample enclosed in a glass container was exposed to initially $1 \mathrm{~atm}$. tritium, and protium gas was produced continuously during the exposure, which lasted 217 days. Unlike in the current study, the total pressure in the container remained at about $1 \mathrm{~atm}$ - the significant increase of total pressure by production of large amounts of protium apparently was not observed (it is unknown whether the protium produced was pumped away in the previous study). The color of the sample became "yellowish" after 70 days, "dull orange" after 120 days, and became "dark red-brown" after 150 days. This color change seems less severe at a given time than that observed here.

After the exposure was completed, the sample was cut and the interior appeared to be a pale yellow with a darker surface. This observation differs from that found in this study for UHMW-PE- a uniform darkening throughout the bulk of the sample. The sample in the earlier study also cracked in several locations. Raman spectroscopy revealed a significant increase in the background fluorescence, with no new peaks appearing. The analysis of the previous study concluded that tritium was being incorporated into the polymer by isotopic exchange, and that the production of hydrogen was consistent with the expected G-value of hydrogen production by polyethylene- both of these ideas are consistent with observations of this study. Laser fluorescence measurements in the earlier study indicated that the damage of the sample was roughly 1000 times greater near the surface than in the bulk. Also, the previous study claimed that damage near the surface somehow protected the bulk from further tritium exposure, creating some kind of barrier to further tritium permeation into the sample. This differs significantly from the uniform color in the bulk of the samples in this study.

Previous investigations of radiation effects on polymers in general and UHMW-PE in particular involve irradiating in air. Continuous oxygen permeation into polymers and its reaction with free radicals and other species formed during irradiation form the basis of explaining various effects observed, including dose-rate effects $[8,11,12]$. Although some oxygen was certainly dissolved in the samples before tritium exposure, the overnight evacuation and long-term exposure to tritium gas without oxygen implies that the effects observed in this study are peculiar to tritium exposure without the effects of oxygen.

The increase storage modulus at a given temperature with tritium exposure for PTFE is similar to that of UHMW-PE. The loss of integrity of PTFE after 9 months exposure is consistent with the classification of PTFE as a degrading type of polymer when initially irradiated, different than the cross-linking mode dominant for polyethylene. This reinforces the idea that the modulus is not a predictor of strength or ductility- strength must be determined directly. During mounting of one of the UHMW-PE samples exposed for 2.3 years, the sample was impulsively loaded and it broke. So, 2.3 years exposure to tritium gas has significantly degraded the strength and ductility of UHMW-PE.

Hydrogen fluoride, HF, is a very undesirable impurity in tritium systems. In this work, the drop in total pressure with increasing tritium exposure for PTFE is evidence that some amount of HF or TF was generated (Appendix II). If any water exists, HF can dissociate and the $\mathrm{F}^{+}$is very reactive, even with the passive oxide surface film on stainless steel. In the past, corrosion and pitting have been observed in the SRS Tritium Facilities caused by degradation of PTFE. This reinforces the idea that halogenated polymers (fluoro- or chloro-carbon based) should be employed as little as possible in tritium systems. 
It is difficult to explain the large variation of the viscoelastic properties (loss modulus, $\tan \delta$ ) for different Vespel® samples exposed to tritium in the same container for the same time. The storage modulus for Vespel ${ }^{\circledR}$ was significantly greater than that for UHMW-PE or PTFE; however the force exerted was within the range of the DMA instrument and the force behaved similar to the other materials throughout each run. The amplitude, which is controlled by the instrument to the setting input by the operator, appeared noisier than for the other materials but otherwise well behaved. The displacement is a measure of the movement of the average location of the sample (not the cyclic amplitude) during the entire DMA run. The variation of displacement during each Vespel ${ }^{\circledR}$ run was as expected. The amplitude used for Vespel ${ }^{\circledR}, 30 \mu \mathrm{m}$, was lower than that used for UHMW-PE and PTFE, to enable the modulus of Vespel ${ }^{\circledR}$ to be measured from $-60^{\circ} \mathrm{C}$. upwards. Perhaps this chosen amplitude was too low for the loss modulus and $\tan \delta$ to be reproducible.

The evolution of protium $\left({ }^{1} \mathrm{H}\right)$ by polyethylene when exposed to tritium results in the loss of isotopic purity of deuterium or tritium gas streams. This has a much greater impact in small volume systems, and less so in long lengths of pipe or in large tanks. Isotopic pollution can be very important in mass spectroscopy inlet manifolds, where small volumes are used. Isotopic pollution can be minimized by avoiding using polyethylene parts in critical small-volume systems (such as mass spectroscopy inlet systems), and by contacting tritium with polyethylene only for the minimum time required.

The immediate and continuously smooth change of color of PTFE with tritium exposure (Fig. 7) suggests using PTFE as a color-based sensor for tritium. For at least up to one year, the color continued to smoothly change. If validated for low levels of tritium in air, it is possible that this effect could be developed as a chronic tritium (or other ionizing radiation) sensor. Being otherwise resistant to practically all chemicals and oxidation, PTFE is a reasonable choice for such an application. Other materials not studied in this case may be equally sensitive to tritium-induced color changes.

While the change of modulus with tritium exposure described here is useful in monitoring the change of molecular structure with tritium exposure and decay, no conclusions about service life of a particular component can be drawn. The general resistance to tritium of the polymers studied in order of increasing resistance was PTFE, UHMW-PE, Vespel ${ }^{\circledR}$; this is the same order as when the polymers are exposed to gamma irradiation. The modulus of UHMW-PE is a maximum at about one year exposure, but it is impossible to say whether any UHMW-PE part would successfully function for this or another time period. The samples studied here were not exposed to any mechanical load during exposure- this would almost certainly not be the case for any conceivable part used in a gas processing system. In addition, the modulus changes give no indication about the changes of yield or breaking strength or ductility with tritium exposure.

\section{SUMMARY and CONCLUSIONS}

Samples of ultra-high molecular weight polyethylene (UHMW-PE), polytetrafluoroethylene (PTFE), and the polyimide Vespel ${ }^{\circledR}$ SP-1 were exposed to initially pure tritium at one atmosphere pressure, ambient temperature in closed containers for up to 2.3 years. There was no significant change of sample mass, volume, or density for any of the polymers with tritium exposure.

UHMW-PE behaved as expected for a prototypical polymer exposed to radiation: initially the storage modulus increased (sample became stiffer) and lost its viscoelastic nature (decreased loss modulus and tan $\delta$ ). After a year of exposure, the storage modulus began to lower with tritium exposure. At $100^{\circ} \mathrm{C}$ it actually became less stiff than unexposed UHMW-PE. The reduction of storage modulus continued with longer tritium exposure. Significant hydrogen gas was generated in the closed container (about nine atmospheres after 2.3 years), which is consistent with the behavior of polyethylene when exposed to other types of ionizing radiation. UHMW-PE darkened severely upon initial exposure, continued to darken with longer exposure, and the darkening occurred throughout the material, not just at the surface. Infrared spectroscopy 
provided evidence for isotope exchange of tritium and incorporation into the UHMW-PE molecular structure- a C-T stretch was observed both on the exposed surface and in the cross-section of the samples.

The storage modulus of PTFE initially increased with tritium exposure, similarly to that of UHMW-PE. The crystallographic transitions of PTFE determined many of the observed features of the dynamic mechanical properties (storage modulus, loss modulus, and $\tan \delta$ ), and these transitions were not significantly affected by tritium exposure. Samples of PTFE exposed for more than nine months became extremely brittle and too weak to handle. This loss of integrity reveals the expected severe degradation of PTFE when exposed to ionizing radiation. The reduction of pressure to about half an atmosphere after 2.3 years in the closed containers is consistent with formation of tritium fluoride, TF $\left({ }^{3} \mathrm{HF}\right)$, which forms linear molecular aggregates of hydrogen bonded TF molecules below $200^{\circ} \mathrm{C}$. The observation of TF formation in these experiments reinforces the well-known concept of minimizing use of fluorinated polymers in tritium systems. The exterior of the PTFE darkened significantly, however the interior remained white or became white when and where the samples broke. The weakness of the samples and the presence of C-T stretches in the infrared spectrum of the sample cross-section revealed that despite the lack of discoloration inside the sample the effects of tritium exposure occurred throughout the material. Infrared spectroscopy provided evidence for incorporating tritium into the polymer molecular structure replacing fluorine- a C-T stretch was observed on exposed samples.

Effects of tritium exposure on Vespel ${ }^{\circledR}$ SP-1 were less than those of UHMW-PE and PTFE. No significant change of dynamic mechanical properties was observed, although there was a significant sample-to-sample variation of the loss modulus and $\tan \delta$. The total pressure in the container remained constant; however the isotopic composition became about $50 \%$ protium after only three months exposure and then remained at about $50 \%$ protium for longer tritium exposures. This observation indicates that Vespel $^{\circledR}$ is not inert to tritium. No color change was observed, and colorimetry showed much smaller color changes than the other two polymers. After three months exposure no change of infrared spectrum was noted.

\section{REFERENCES}

1) D.C. Phillips. "Effects of Radiation on Polymers". Materials Science and Technology, Vol. 4, pp. 85-91 (January 1988).

2) K.T. Gillen, R.L. Clough. "A Kinetic Model for Predicting Oxidative Degradation Rates in Combined Radiation-Thermal Environments". J. of Polymer Science: Polymer Chemistry Edition, Vol. 23, pp. 2683-2707 (1985).

3) K.T. Gillen, R.L Clough, “Accelerated Aging Methods for Predicting Long-term Mechanical Performance of Polymers", Chapter 4 in Irradiation Effects on Polymers, ed. D.W. Clegg and A.A. Collyer. Elsevier Applied Science, New York, pp 157-223 (1991).

4) A. Chapiro. Radiation Chemistry of Polymeric Systems. Vol. XV of series High Polymers, WileyInterscience, New York, Chapter IX (1962).

5) W.W. Parkinson, O. Sisman. "The Use of Plastics and Elastomers in Nuclear Radiation". Nuclear Engineering and Design, vol. 17 pp 247-280 (1971).

6) P. Patnaik. Handbook of Inorganic Chemicals. McGraw-Hill, New York pp 366-370 (2003).

7) F.W. Billmeyer, Jr. Textbook of Polymer Science ( $2^{\text {nd }}$ edition $)$. Wiley-Interscience, New York pp 199207 (1971). 
8) P. O’Neill, C. Birkenshaw, J.J. Leahy, R Barklie. "The Role of long lived free radicals in the ageing of irradiated ultra high molecular weight polyethylene”. Polymer Degradation and Stability vol. 63 pp 3139 (1999).

9) P.J. Rae, E.N. Brown. "The Properties of Poly(tetrafluoroethylene) (PTFE) in Tension". Polymer vol. 46, pp 8128-8140 (2005).

10) J.T. Gill. "Interaction of polyethylene and tritium gas as monitored by Raman spectroscopy". Fusion Technology, vol. 8. pp 2318-2329 (1985).

11) João Carlos Miguez Suarez, Ronaldo Sergio de Biasi. "Effect of gamma irradiation on the ductile-tobrittle transisiton in ultra-high molecular weight polyethylene". Polymer Degradation and Stability vol. 82 pp 221-227 (2003).

12) F.J. Medel, F. García-Álvarez, E. Gómez-Barrena, J.A. Puértolas. "Microstructure changes of extruded ultra high molecular weight polyethylene after gamma irradiation and shelf-aging". Polymer Degradation and Stability vol. 88 pp 435-443 (2005).

13) E.A. Evans. Tritium and its Compounds. D. Van Nostrand Co., p 1, (1966).

14) DOE Handbook: Tritium Handling and Safe Storage. US Department of Energy Handbook DOEHDBK 1129-99 (1999).

\section{ACKNOWLEDGEMENTS}

It is a pleasure to acknowledge: Wanda Britt for sample characterization before testing, sample tracking and handling, mass and volume measurements, and DMA operation; Mike Thomas for initial DMA installation in the Materials Test Facility, facility interface, and sample exposure vessel procurement; David Bell for sample exposure gas handling; and Martin Pechersky for colorimetry measurements and analysis. 


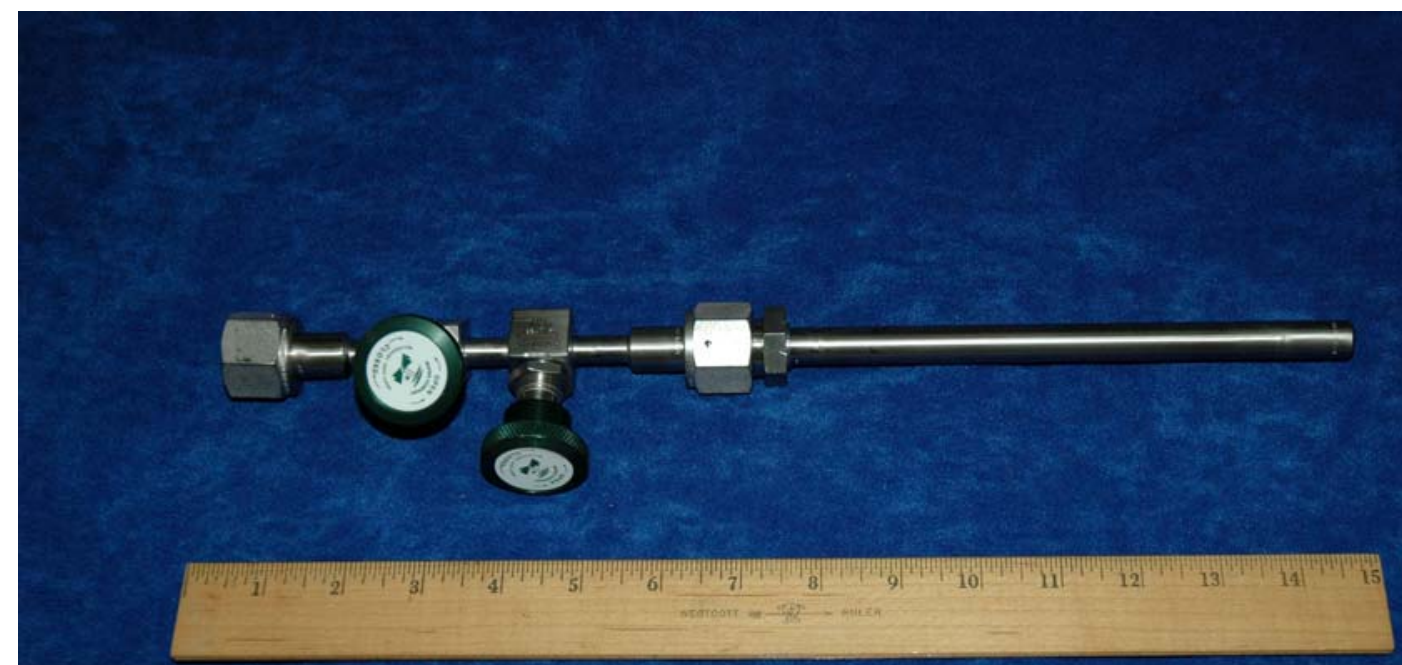

Figure 1. Photograph of Tritium Exposure Container. 


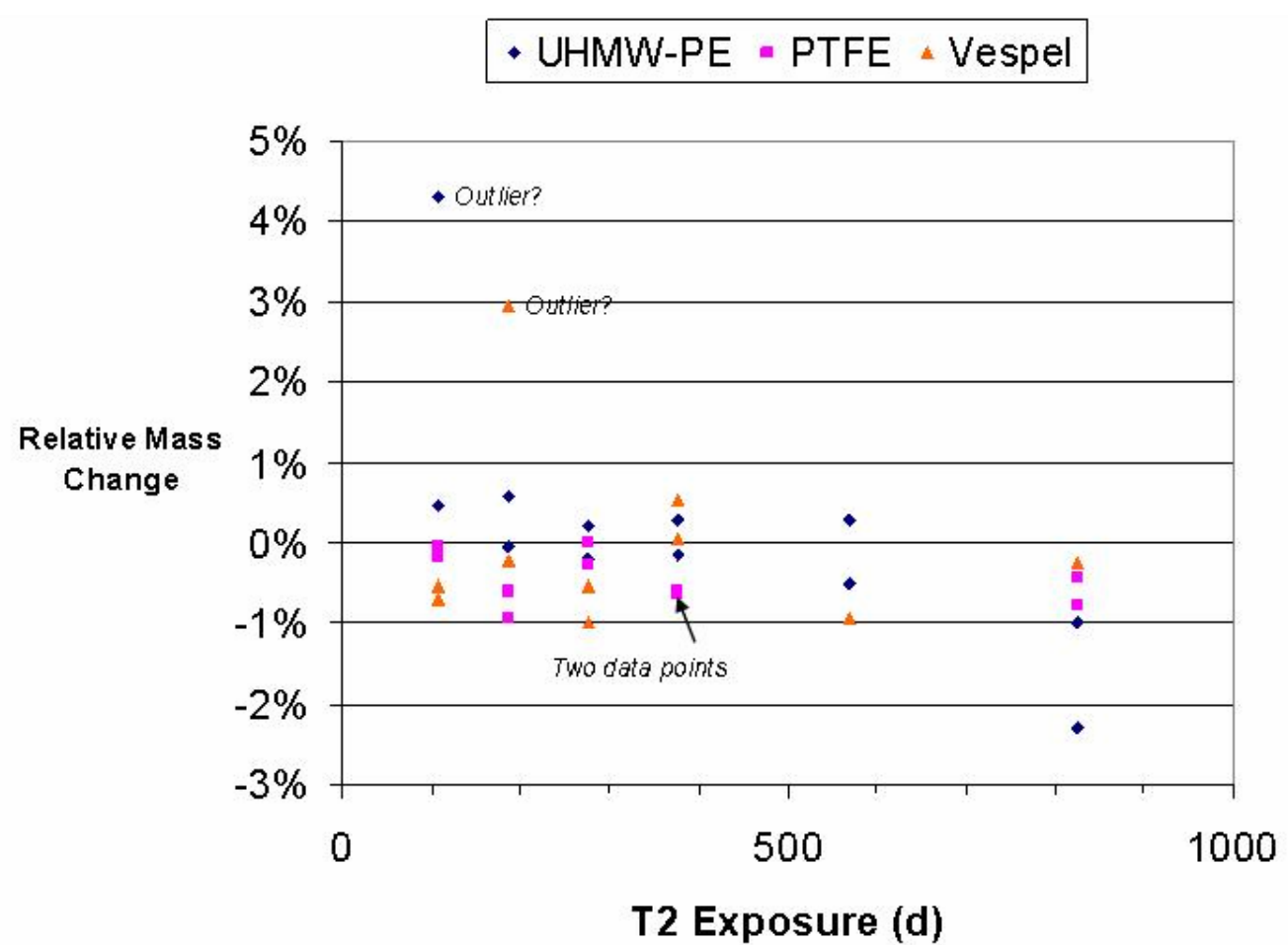

Figure 2. Relative Mass Change of Each Sample as Function of Tritium Exposure Time.

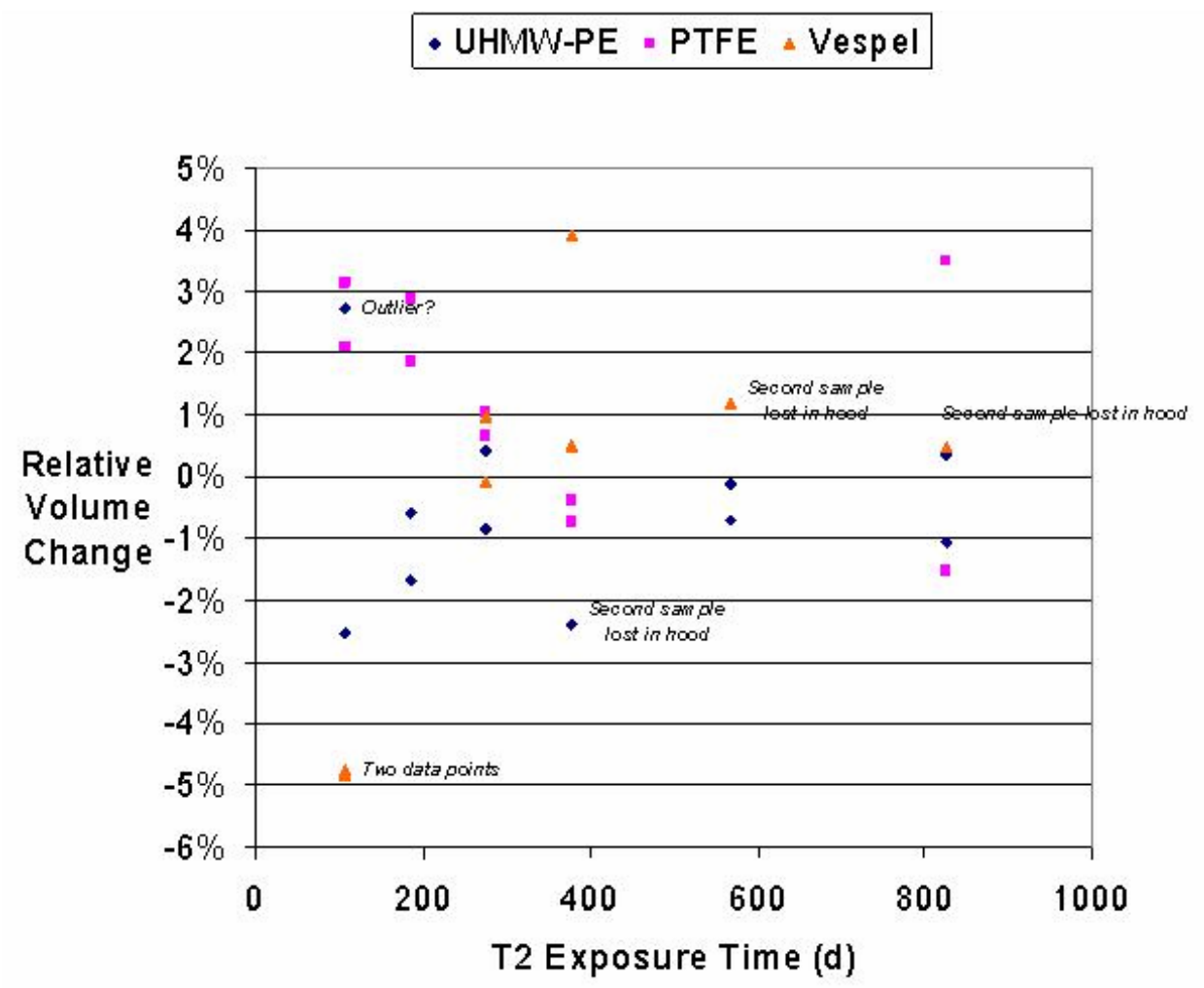

Figure 3. Relative Volume Change of Each Sample as Function of Tritium Exposure Time 


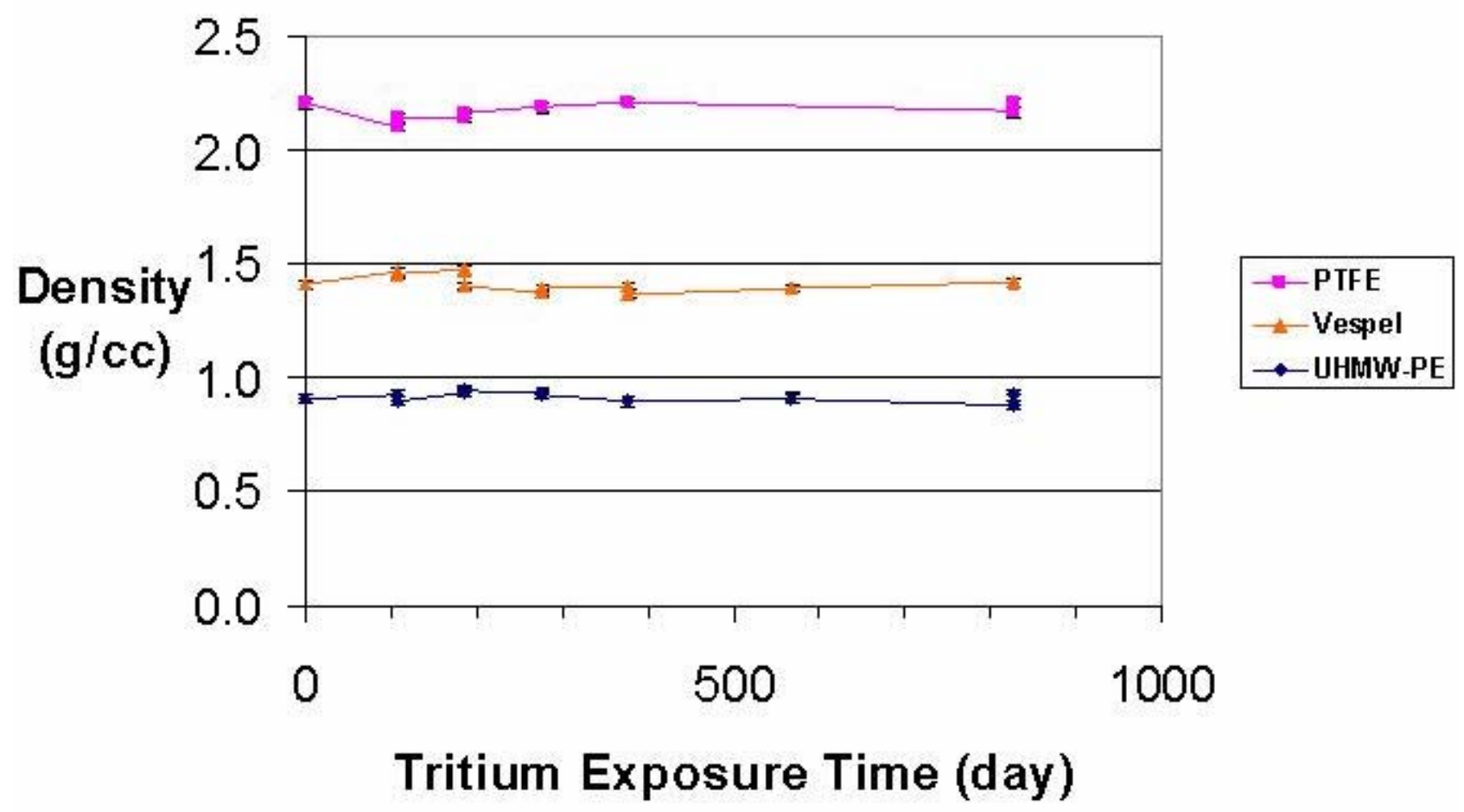

Figure 4. Sample Density as Function of Tritium Exposure Time. 


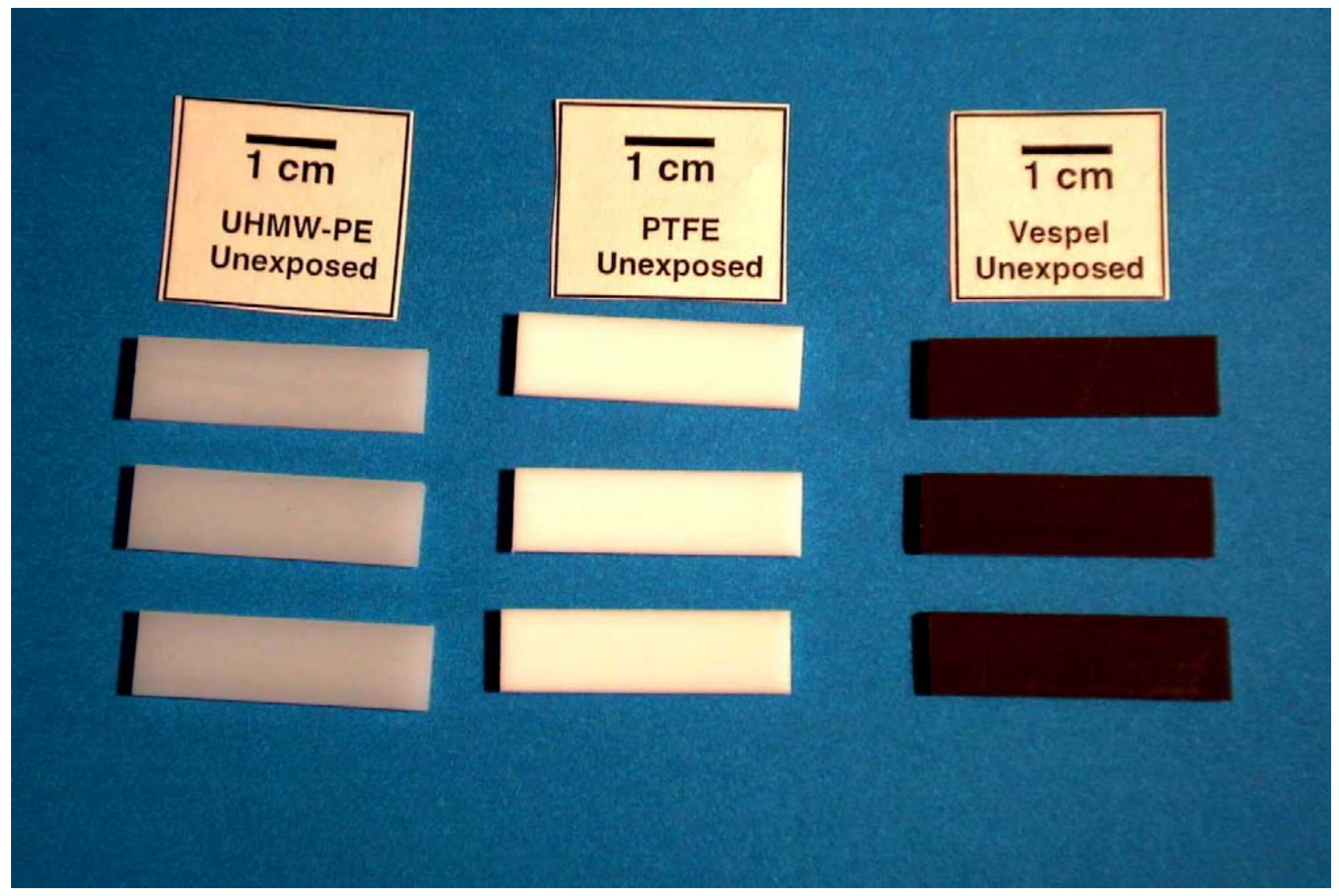

a.

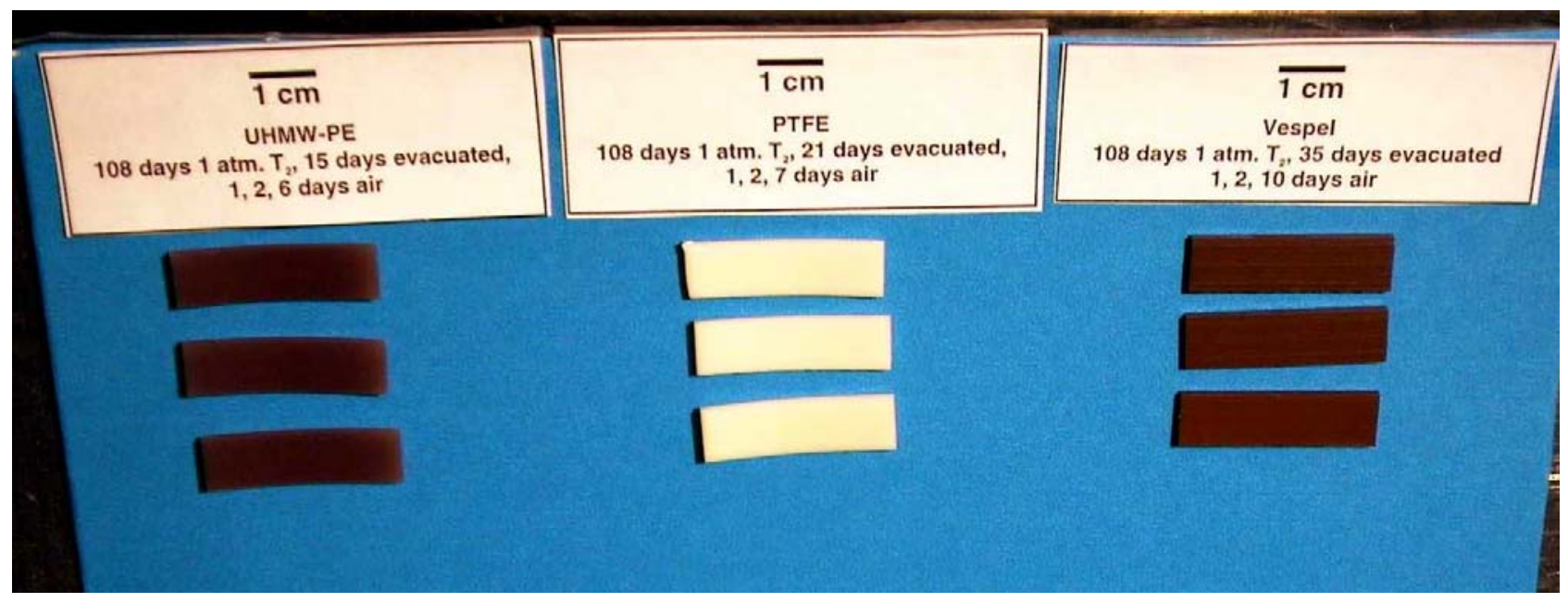

b.

Figure 5. Photographs of unexposed (top) and after 108 days tritium exposed samples (bottom). Note extreme discoloration of UHMW-PE samples. PTFE samples also discolored to the eye. Vespel ${ }^{\circledR}$ SP-1 is normally brown. Samples sized for dynamic mechanical analysis. 


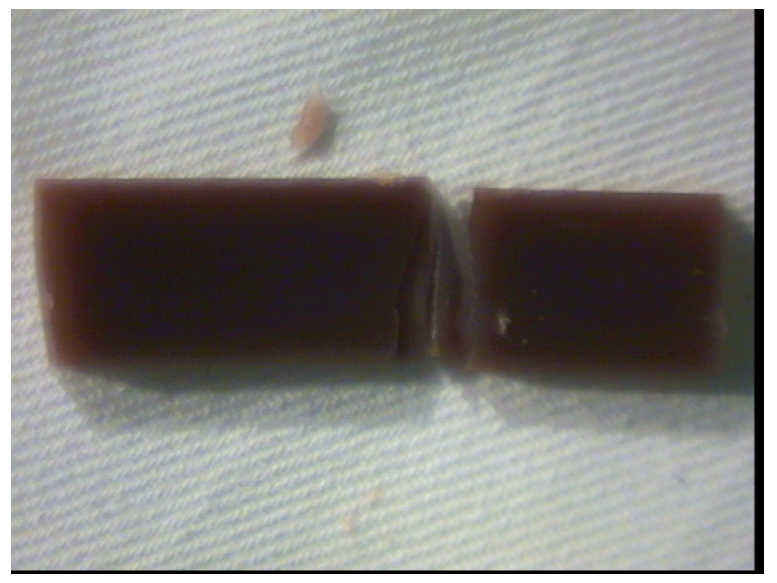

a.

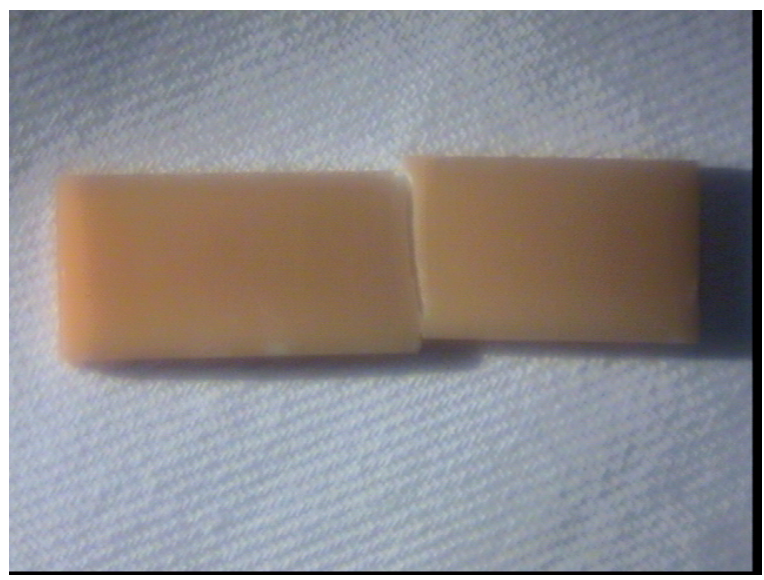

c.

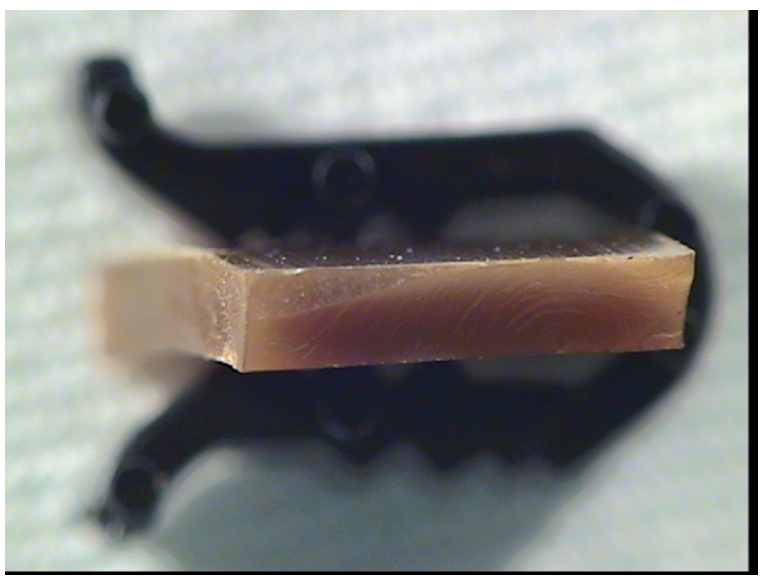

b.

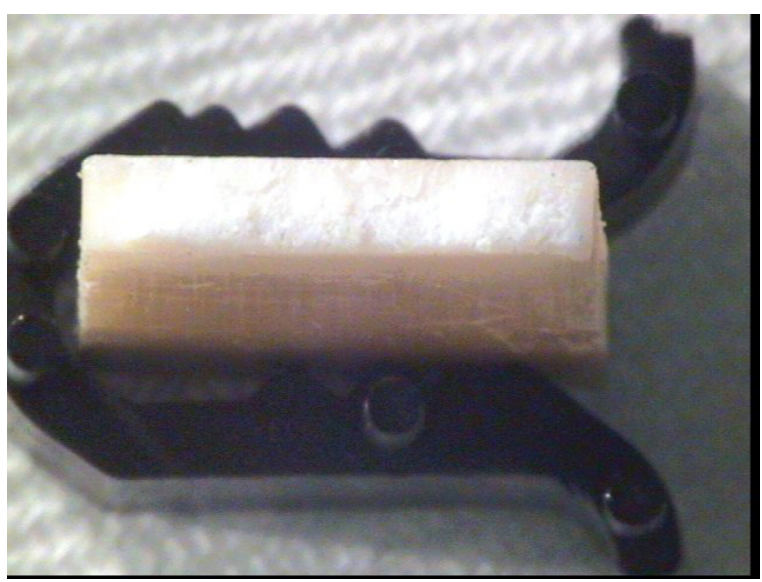

d.

Figure 6. One year (377 days) tritium exposure. UHMW-PE (top, a. and b.) cut to reveal interior, PTFE (bottom, c. and d.) sample broke during handling. Note discoloration through bulk of UHMW-PE, and only at surface of PTFE. 
$\rightarrow$ UHWM-PE

- PTFE

$\rightarrow$ VESPEL

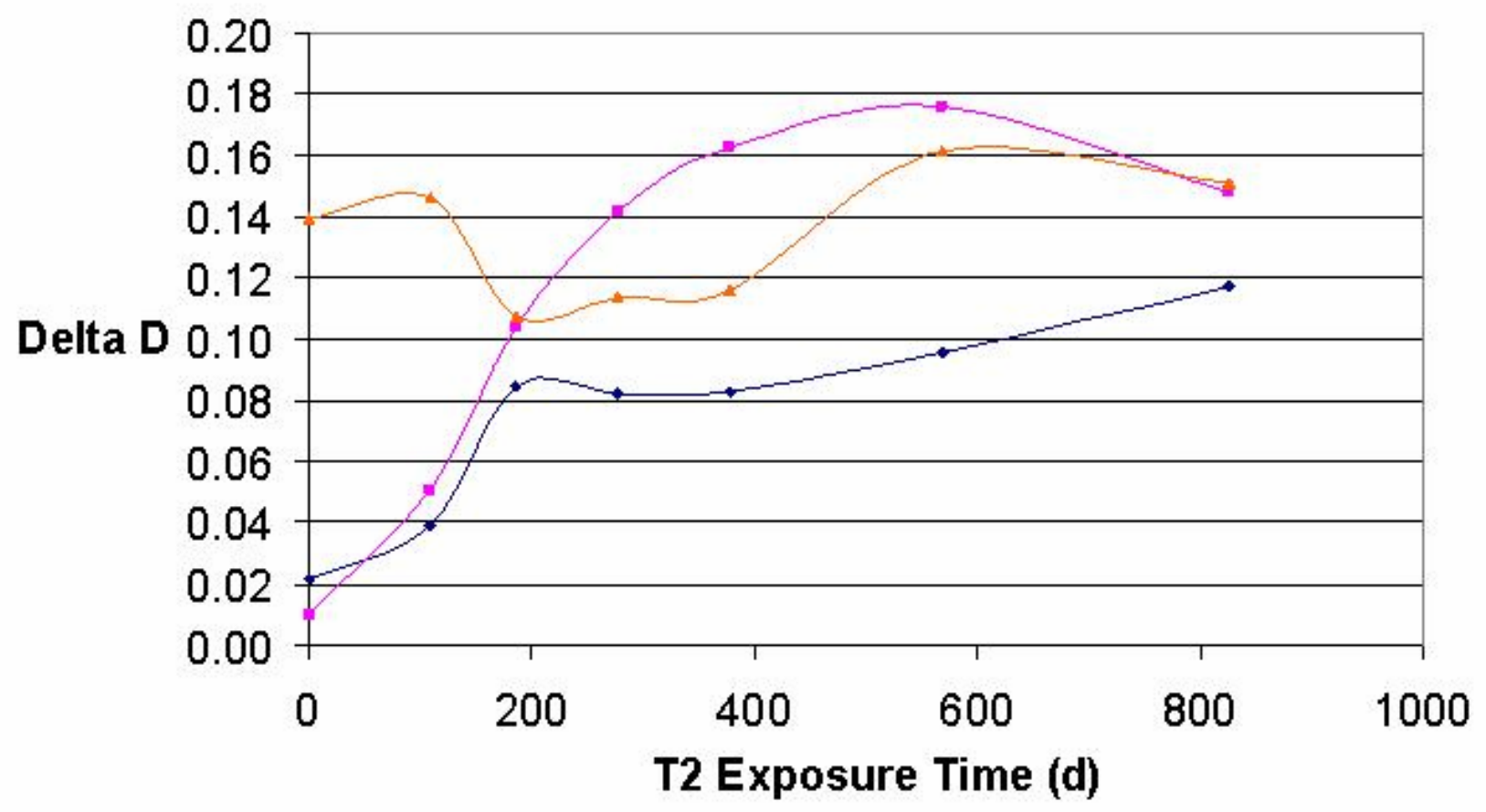

Figure 7. Colorimetric DeltaD for each polymer type as a function of tritium exposure time. DeltaD defined in text. Note initially UHMW-PE and PTFE nearly white, like standard. Vespel ${ }^{\circledR}$ is initially brown. 


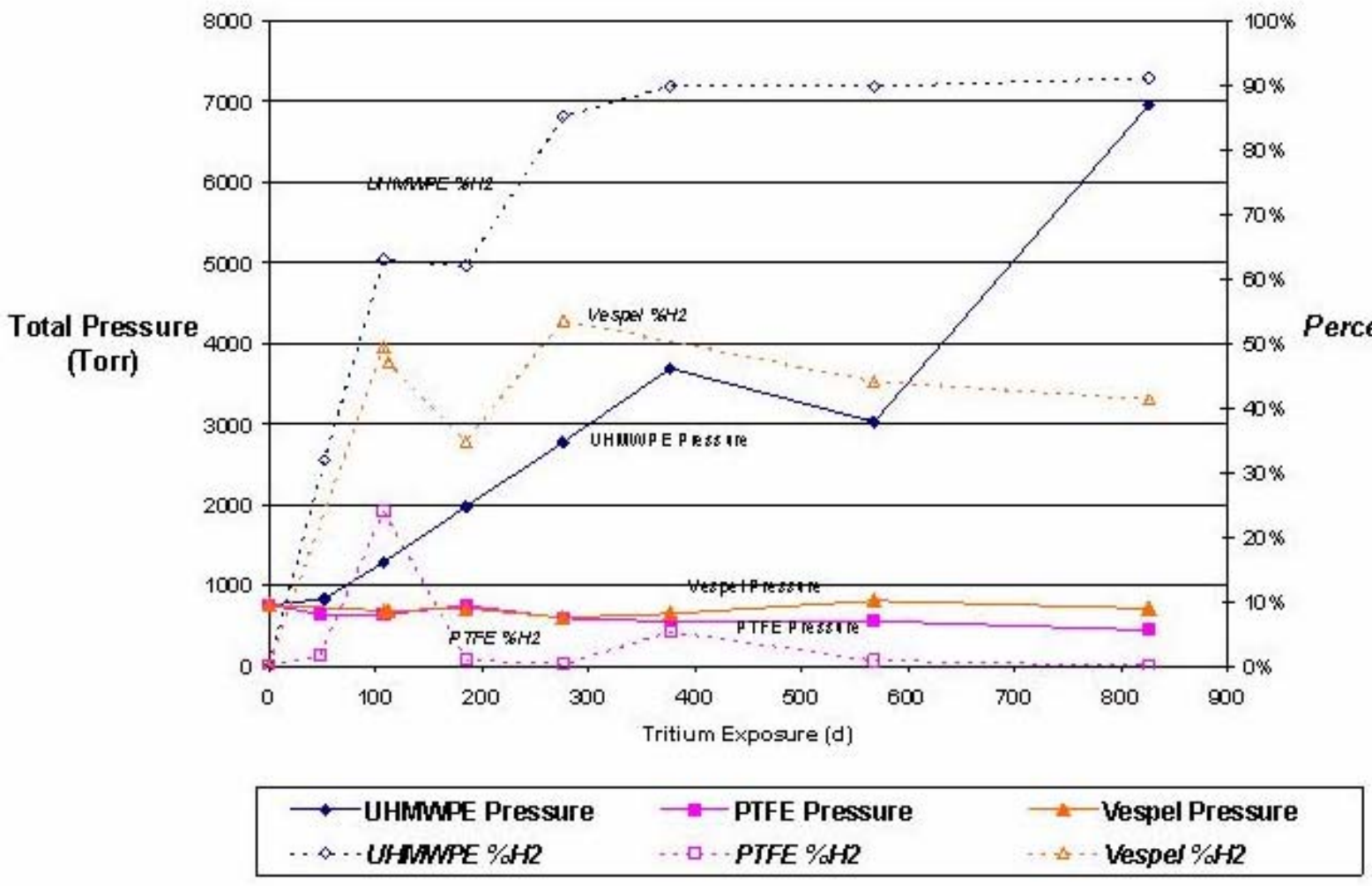

Figure 8. Total Pressure and Percent ${ }^{1} \mathrm{H}_{2}$ (protium) of Gas in Exposure Container at End of Exposure as a function of Tritium Exposure Time. Note data at about 50 days are from preliminary tests in addition to the experiments described in this report. 


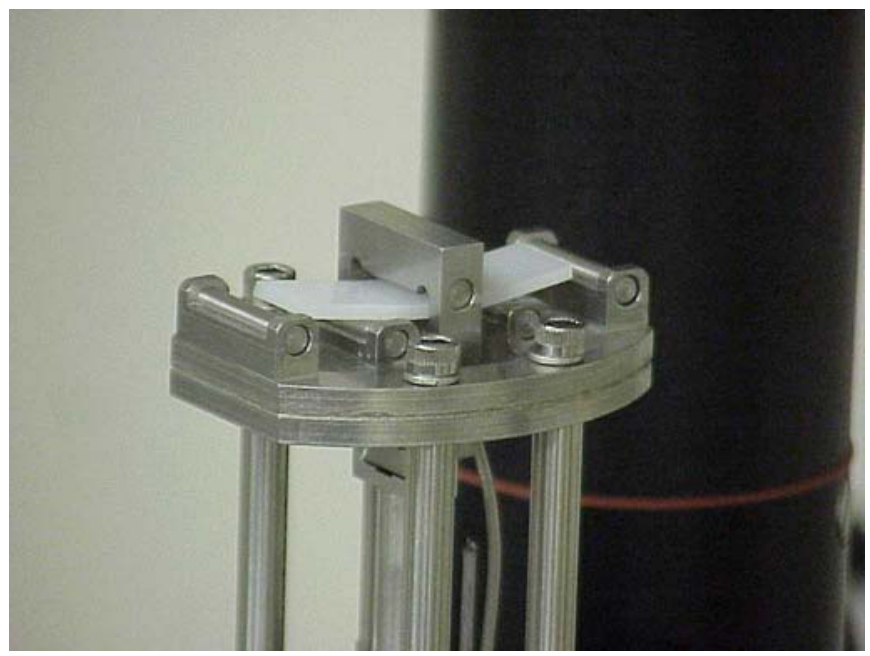

Figure 9. Photograph of Three-Point Bed sample holder (or "clamp") TA Instruments Model 2980 Dynamic Mechanical Analyzer

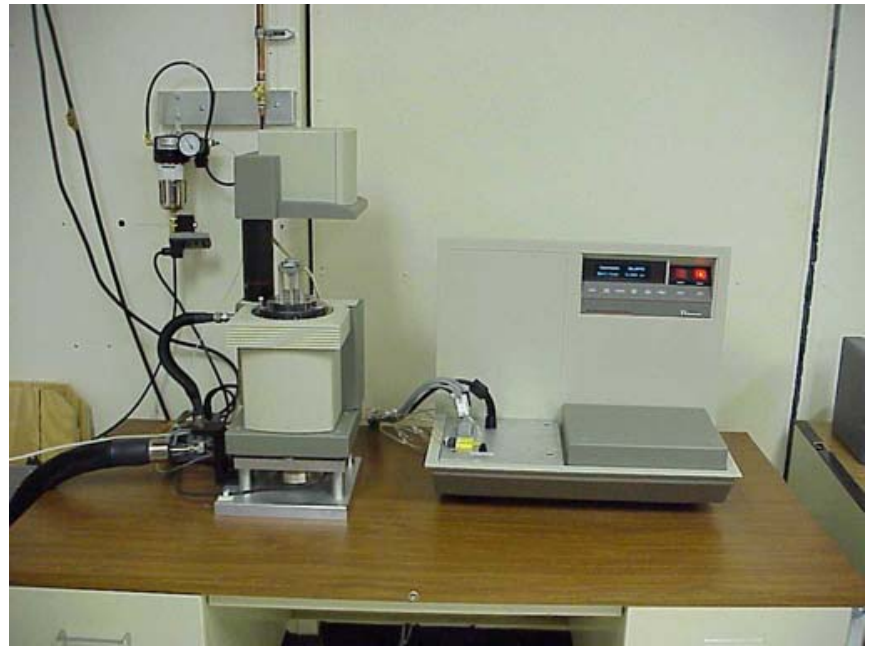

Figure 10. Photograph of TA Instruments Model 2980, showing separated mechanical and electrical assemblies. 


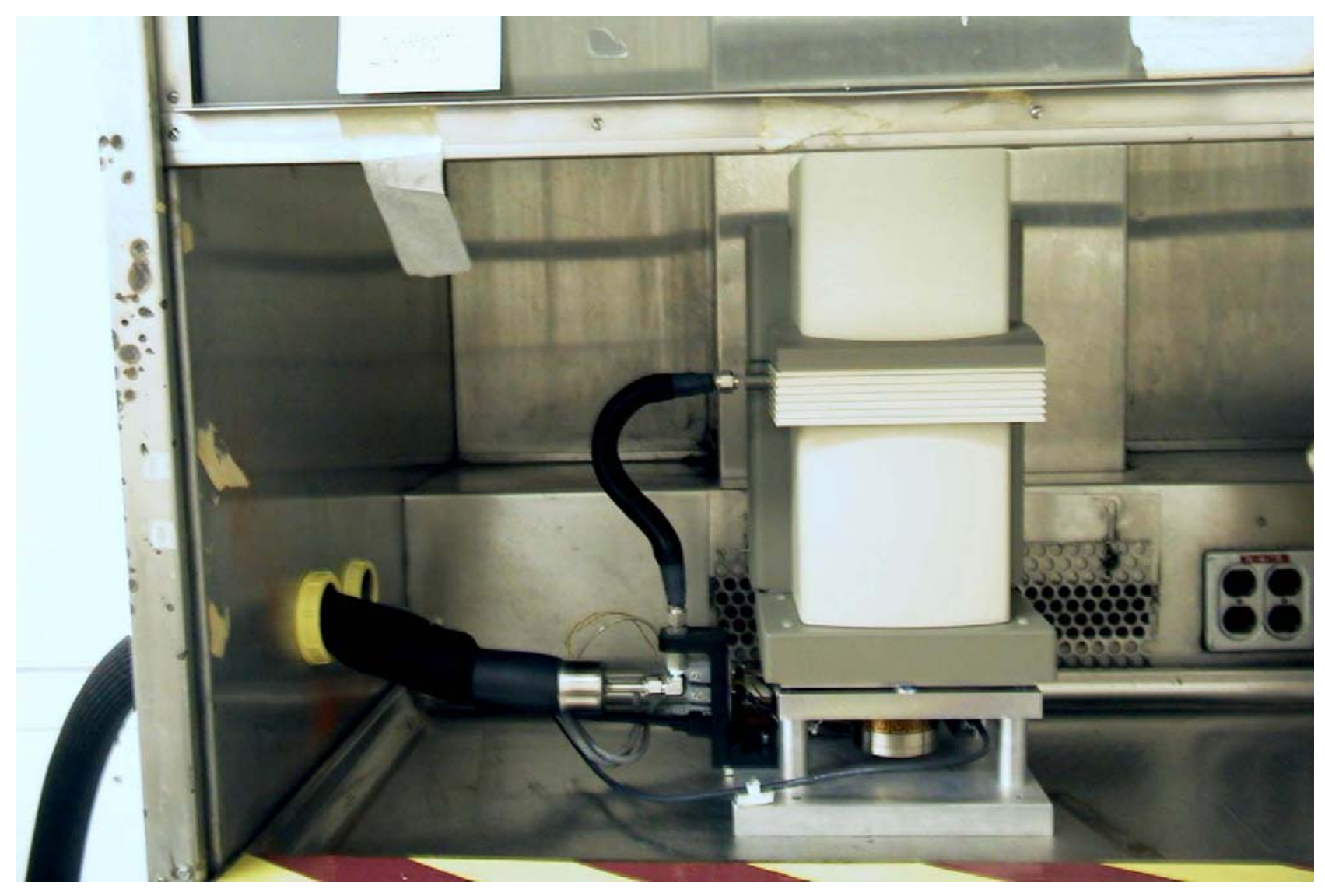

Figure 11. Photograph of mechanical part of DMA in tritium hood. 


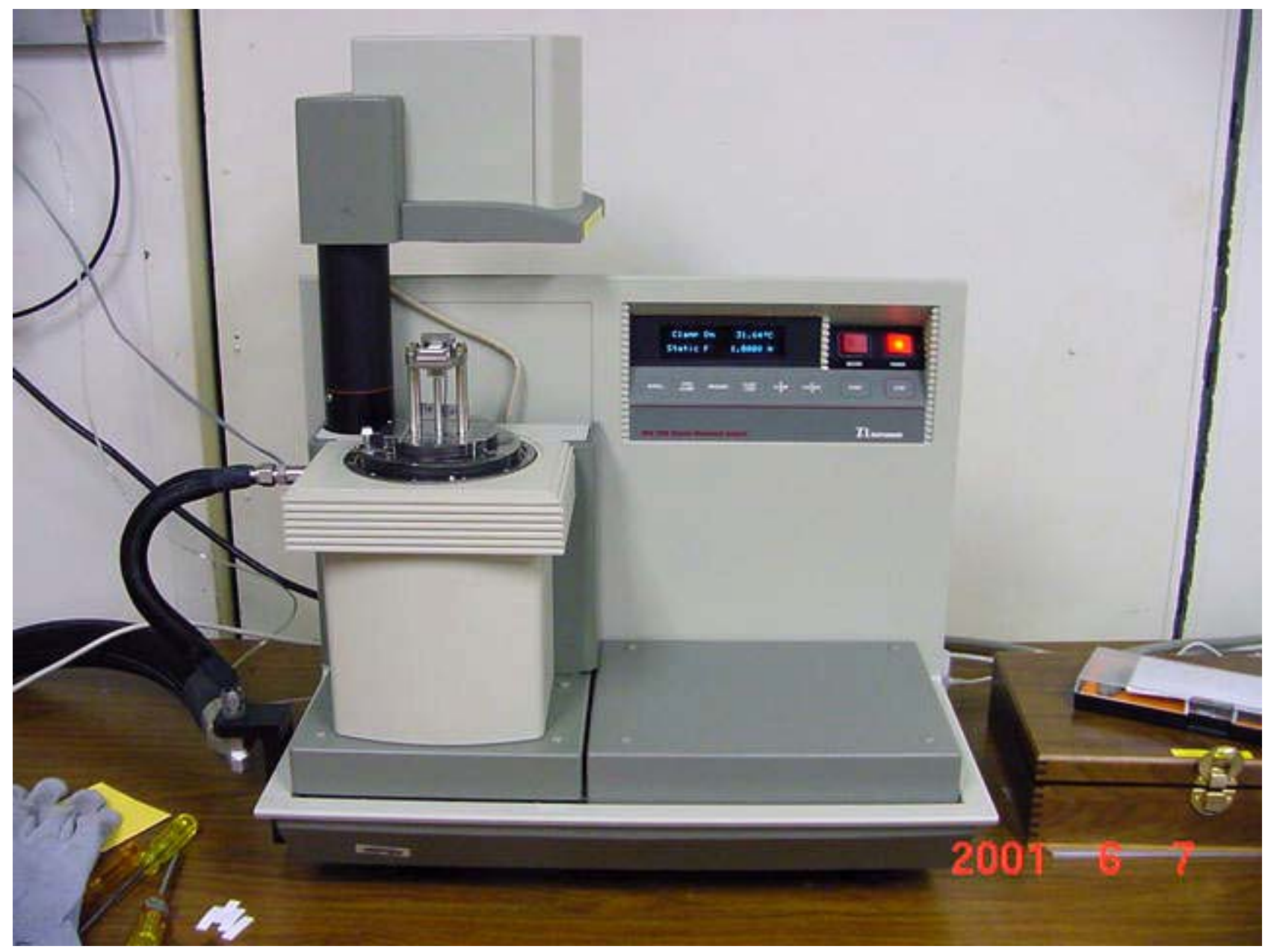

Figure 12. Photograph of second unaltered TA Instruments Model 2980 dynamic mechanical analyzer. 
Room Temperature, UHMW'PE

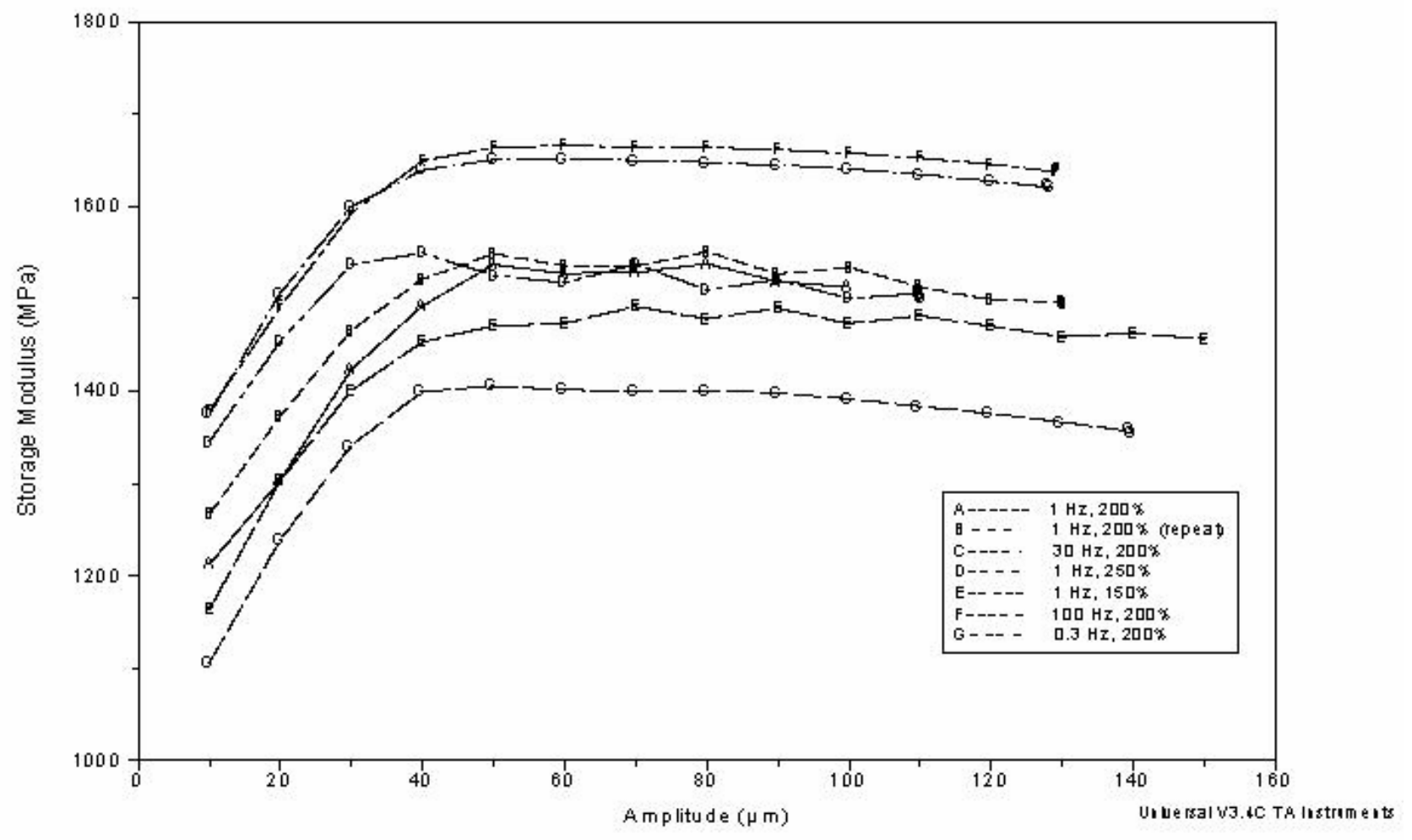

Figure 13. Storage Modulus of Unexposed UHMW-PE at Room Temperature as a Function of Applied Amplitude, for Various Applied Frequencies (Hz) and Force Track Settings (\%). Note increase at small amplitude becoming constant about 40 micron. This is an example of the preliminary data used to pick the amplitude and force track settings. 


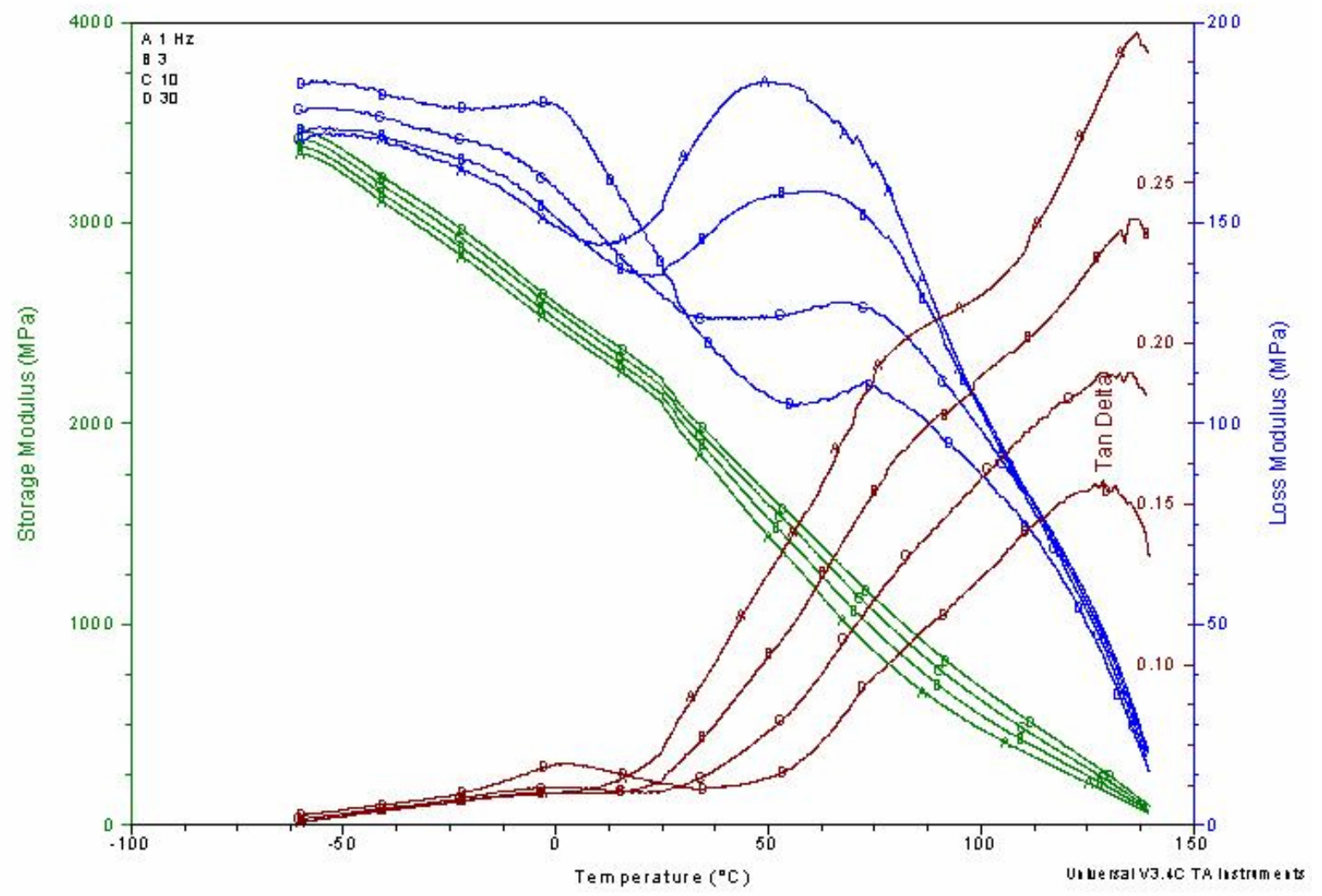

Figure 14. DMA experiment, or run, on one sample of UHMW-PE. Temperature stabilized at $-60^{\circ} \mathrm{C}$. and increased at $1^{\circ} \mathrm{C} . /$ minute to $140^{\circ} \mathrm{C}$. Note three quantities storage modulus, loss modulus, $\tan \delta$ indicated by color and axis, family of curves at four frequencies for each quantity. Frequency changed automatically during experiment. Not exposed to tritium. 
UHMW-PE exposed to $1 \mathrm{~atm}$. T2 ambient temperature time in days

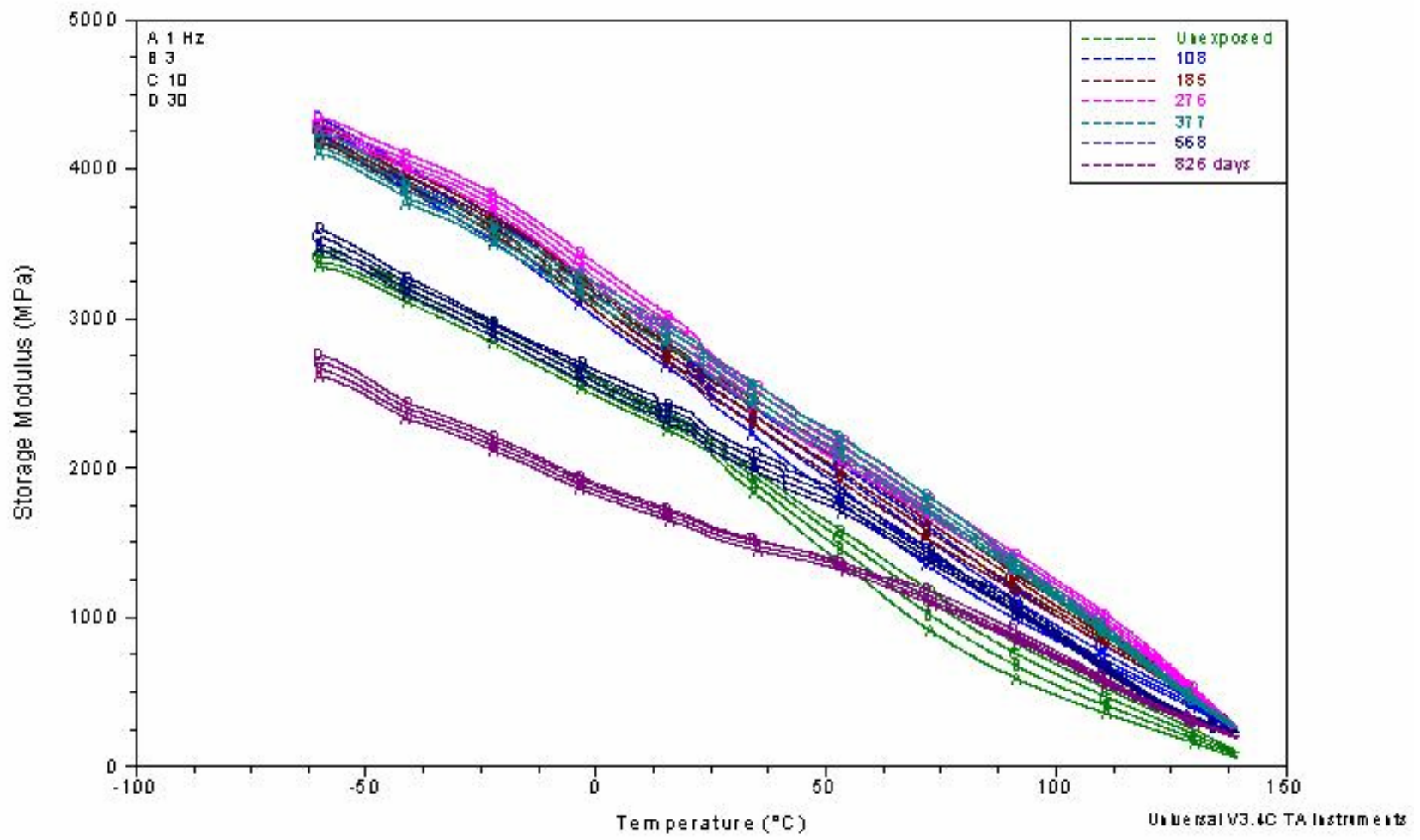

Figure 15. Storage Modulus of UHMW-PE as function of Temperature. Tritium exposure indicated by color as shown. Applied frequencies 1,3,10,30 Hz indicated by letter. 


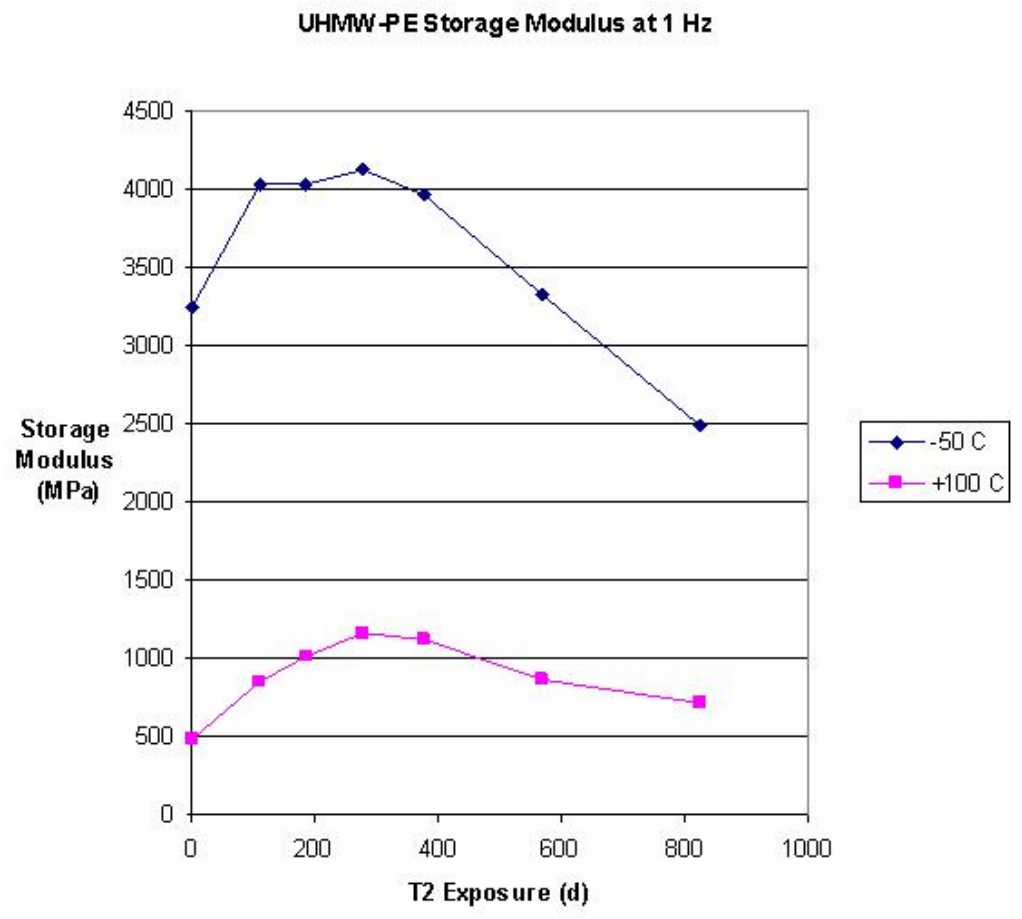

Figure 16. Variation of UHMW-PE Storage Modulus with tritium exposure at $-50^{\circ}$ and $+100^{\circ} \mathrm{C}$. Applied frequency $1 \mathrm{~Hz}$.

UHMN -PE -50 deg. C

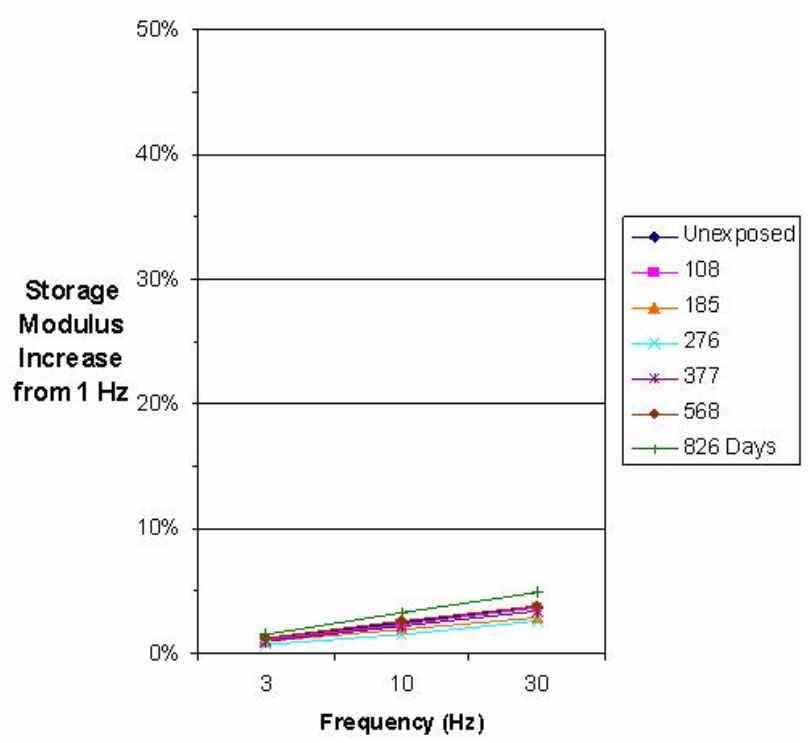

a.
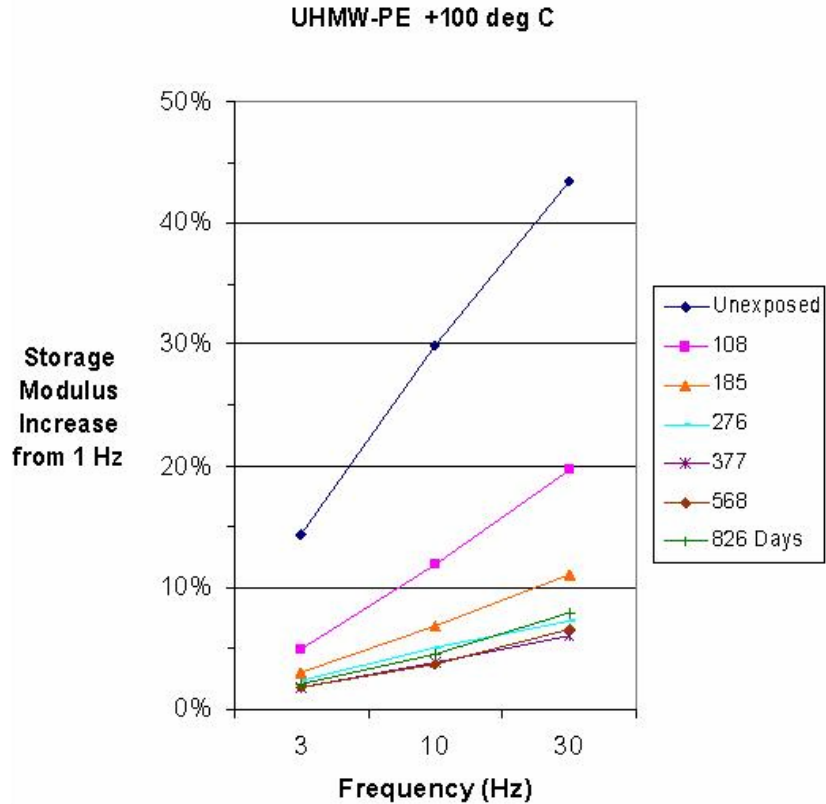

b.

Figure 17. Frequency Dependence of UHMW-PE Storage Modulus at a. $-50^{\circ}$ C. and b. $+100^{\circ}$ C. Note large frequency dependence at $100^{\circ} \mathrm{C}$. that diminishes drastically with tritium exposure. 
UHMW'PE exposed to $1 \mathrm{~atm}$. T2 ambient temperature time in days

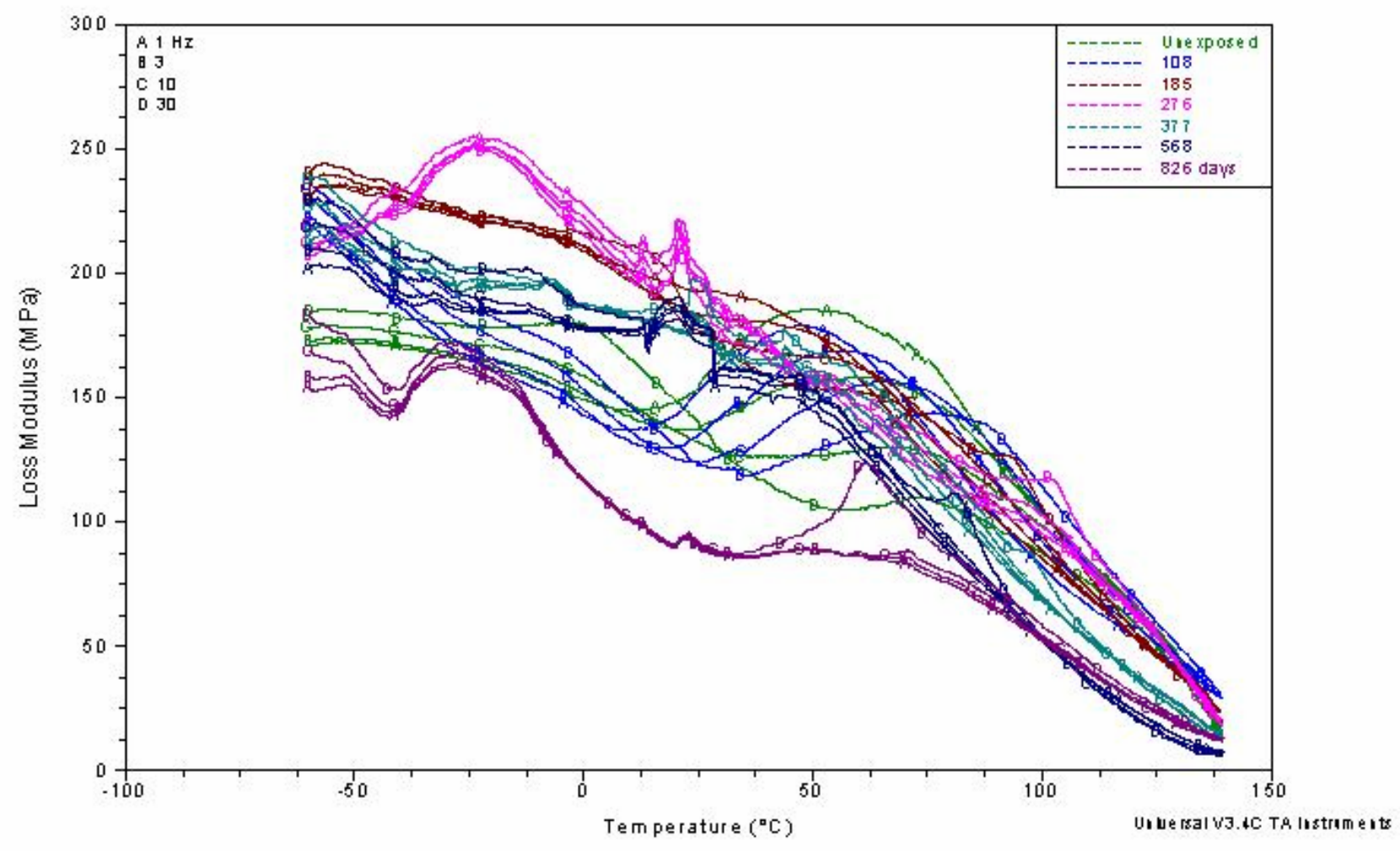

Figure 18. Loss Modulus of UHMW-PE as function of temperature. Tritium exposure in days shown by differing colors, frequency shown by letters. 
UHMW -PE exposed to 1 atm. T2 ambient temperature time in days

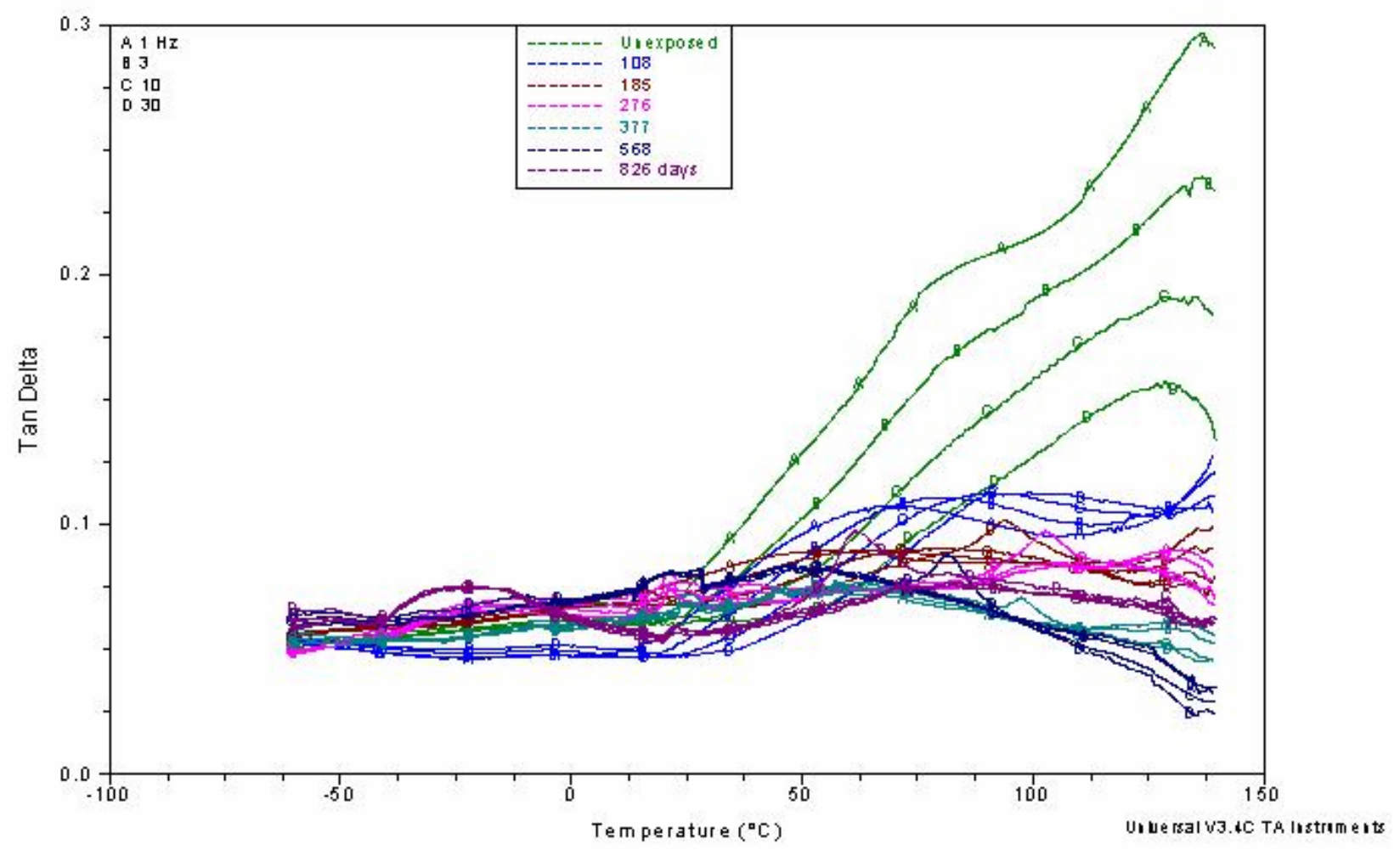

Figure 19. Tan $\delta$ of UHMW-PE as function of temperature. Exposure times shown by colors, applied frequency shown by letters. Note rapid diminishing temperature and frequency dependence above $35^{\circ} \mathrm{C}$. for tritium exposed UHMW-PE. 


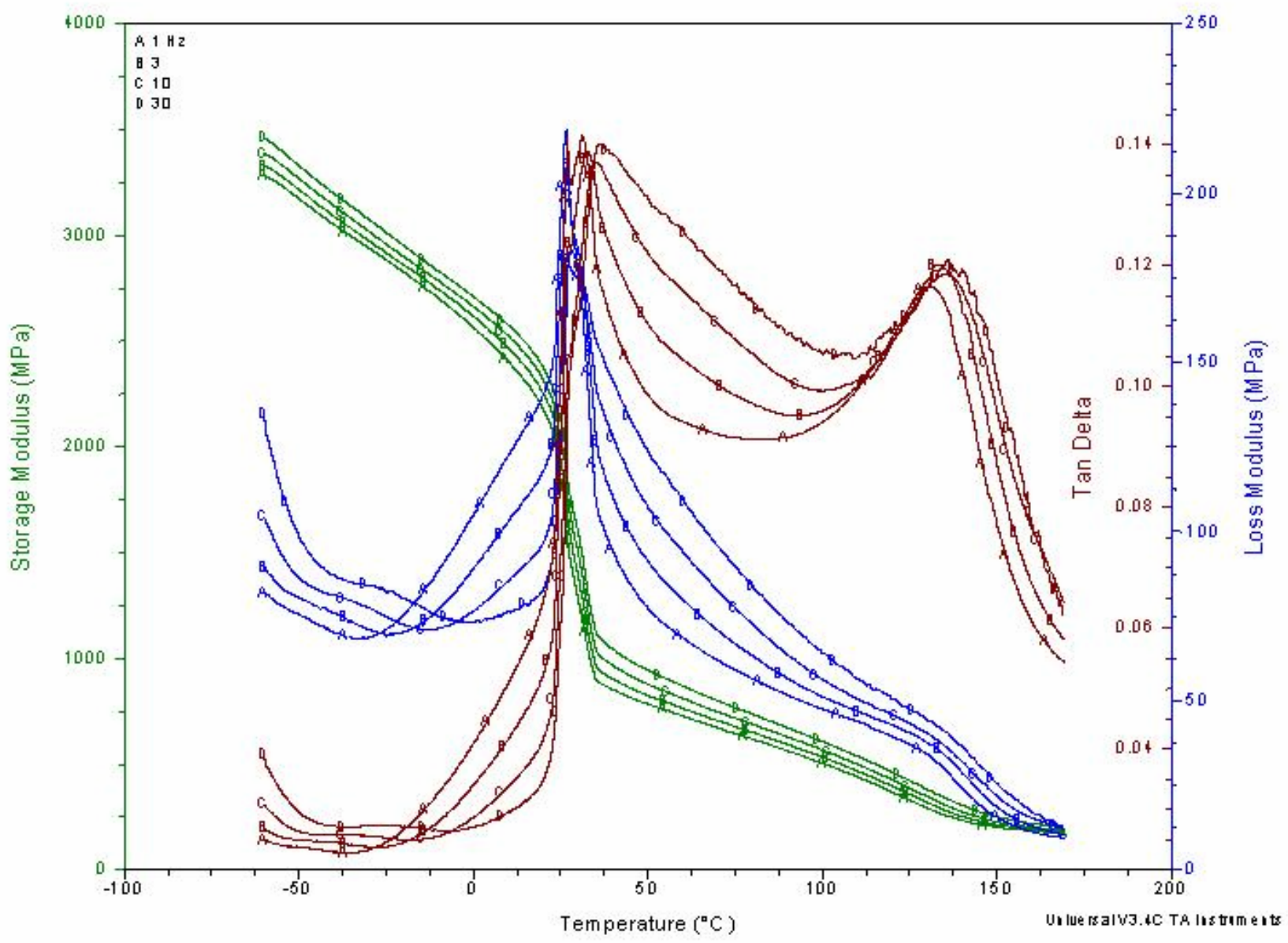

Figure 20. DMA experiment, or run, on unexposed PTFE. Temperature stabilized at $-60^{\circ} \mathrm{C}$. and increased at $1^{\circ} \mathrm{C} . /$ minute to $170^{\circ} \mathrm{C}$. Note three quantities storage modulus, loss modulus, tan $\delta$ indicated by color and axis, family of curves at four frequencies for each quantity. Frequency changed automatically during experiment. 
PTFE exposed to $1 \mathrm{~atm}$. T2 at a mbient te mperature

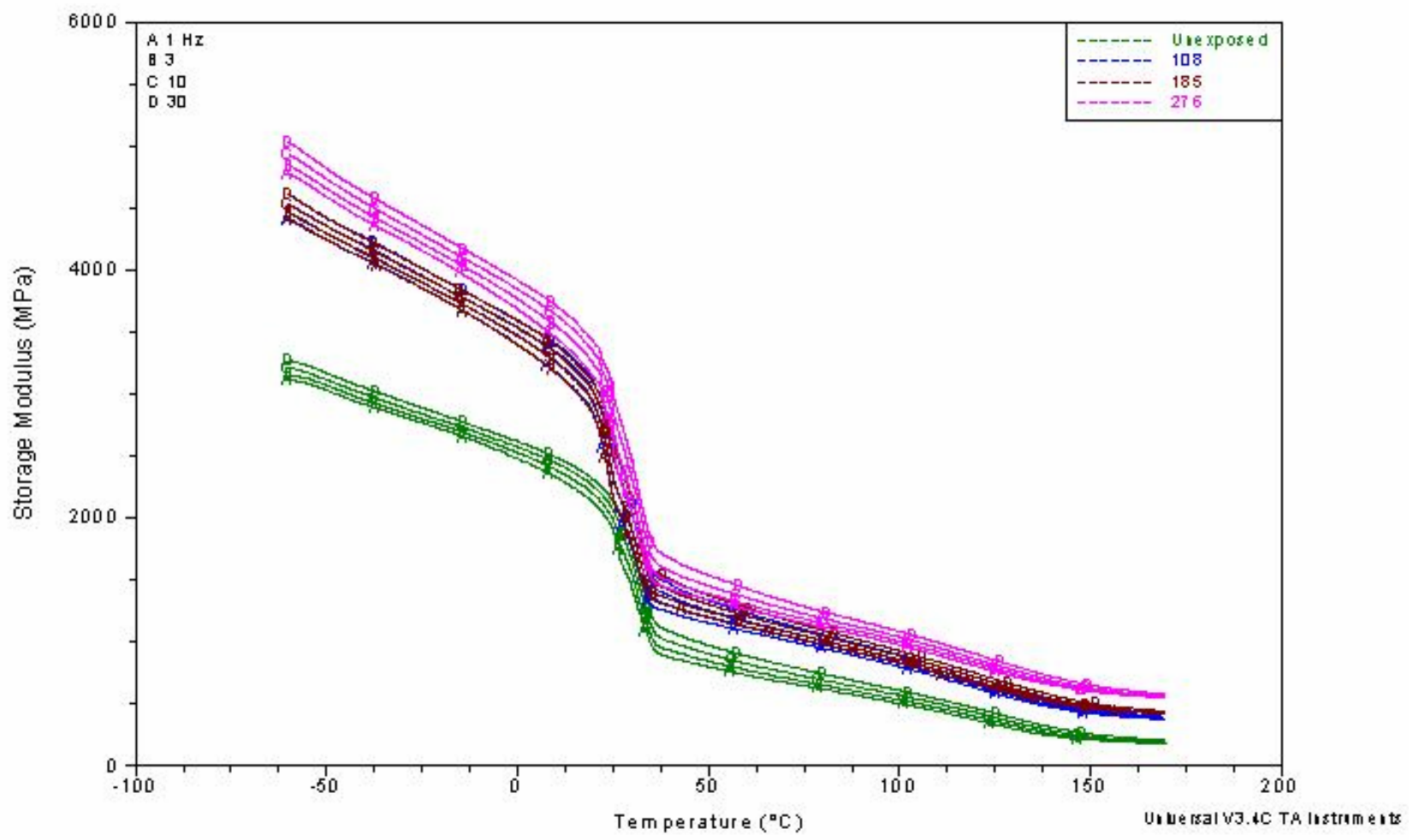

Figure 21. Storage Modulus of PTFE for various exposure times to $1 \mathrm{~atm}$ tritium (initially) as a function of temperature. Applied frequency indicated by letter, tritium exposure in days as shown. Samples exposed longer than 276 days too weak to handle or test. 
PTFE

Storage Modulus, $1 \mathrm{~Hz}$

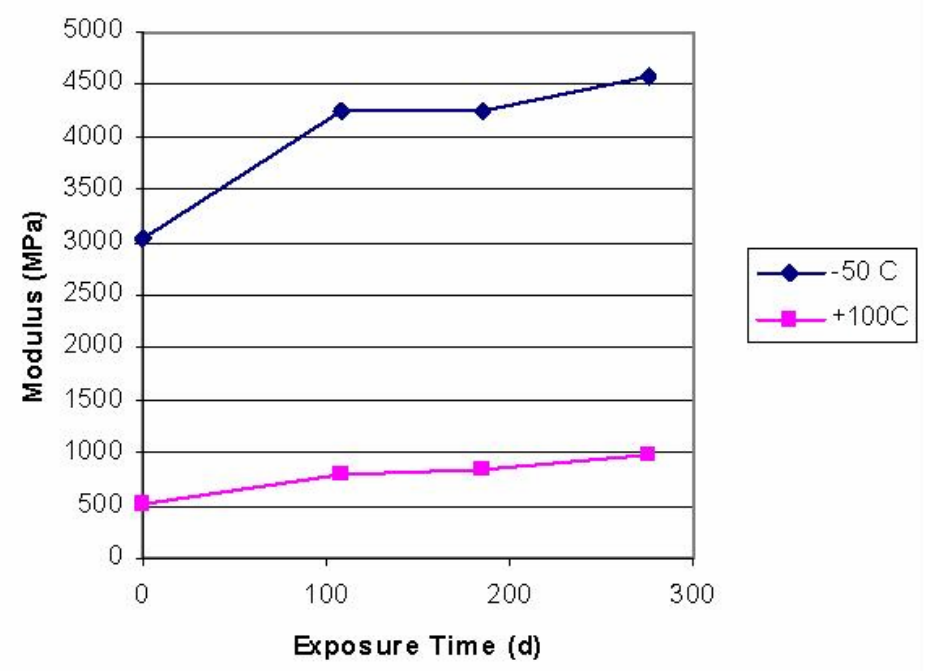

Figure 22. Storage Modulus of PTFE at $-50^{\circ} \mathrm{C}$. and $+100^{\circ} \mathrm{C}$. as a function of exposure time in days. Frequency is $1 \mathrm{~Hz}$. Samples exposed longer than 276 days too weak to handle or test.

PTFE, Frequency Dependance of Storage

Modulus, $-50 \mathrm{C}$

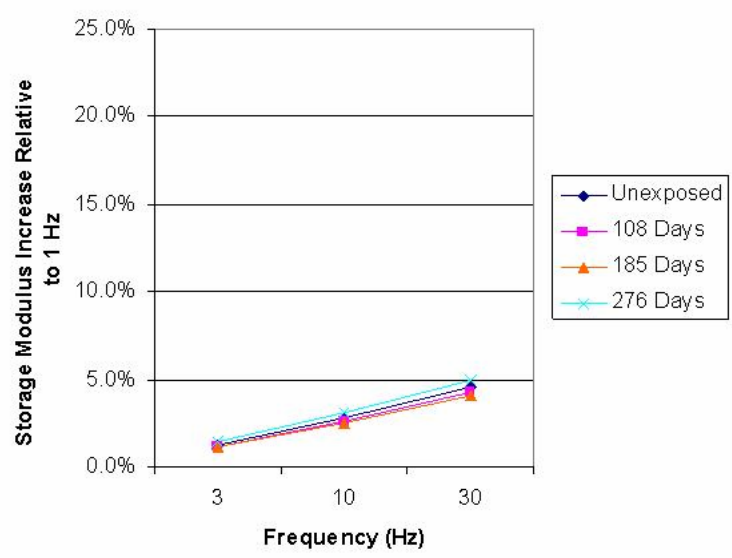

a.
PTFE, Frequency Dependance of Storage Modulus, $+100 \mathrm{C}$

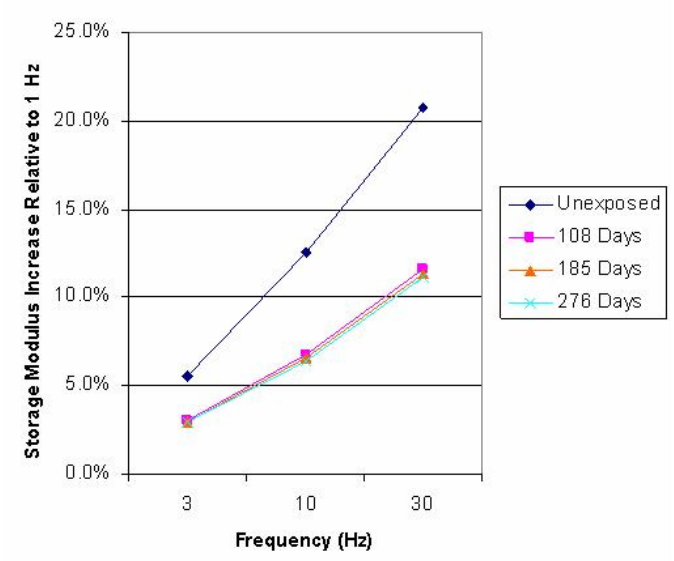

b.

Figure 23. Change of Storage Modulus Relative to $1 \mathrm{~Hz}$ as a function of Frequency, a. $-50^{\circ}$ C. b. $+100^{\circ} \mathrm{C}$. Note significant decrease of frequency change after initial exposure at $+100^{\circ} \mathrm{C}$. Little effect of frequency at $-50^{\circ} \mathrm{C}$. 
PTFE Esposed to $1 \mathrm{~atm}$ T2, ambient temperature

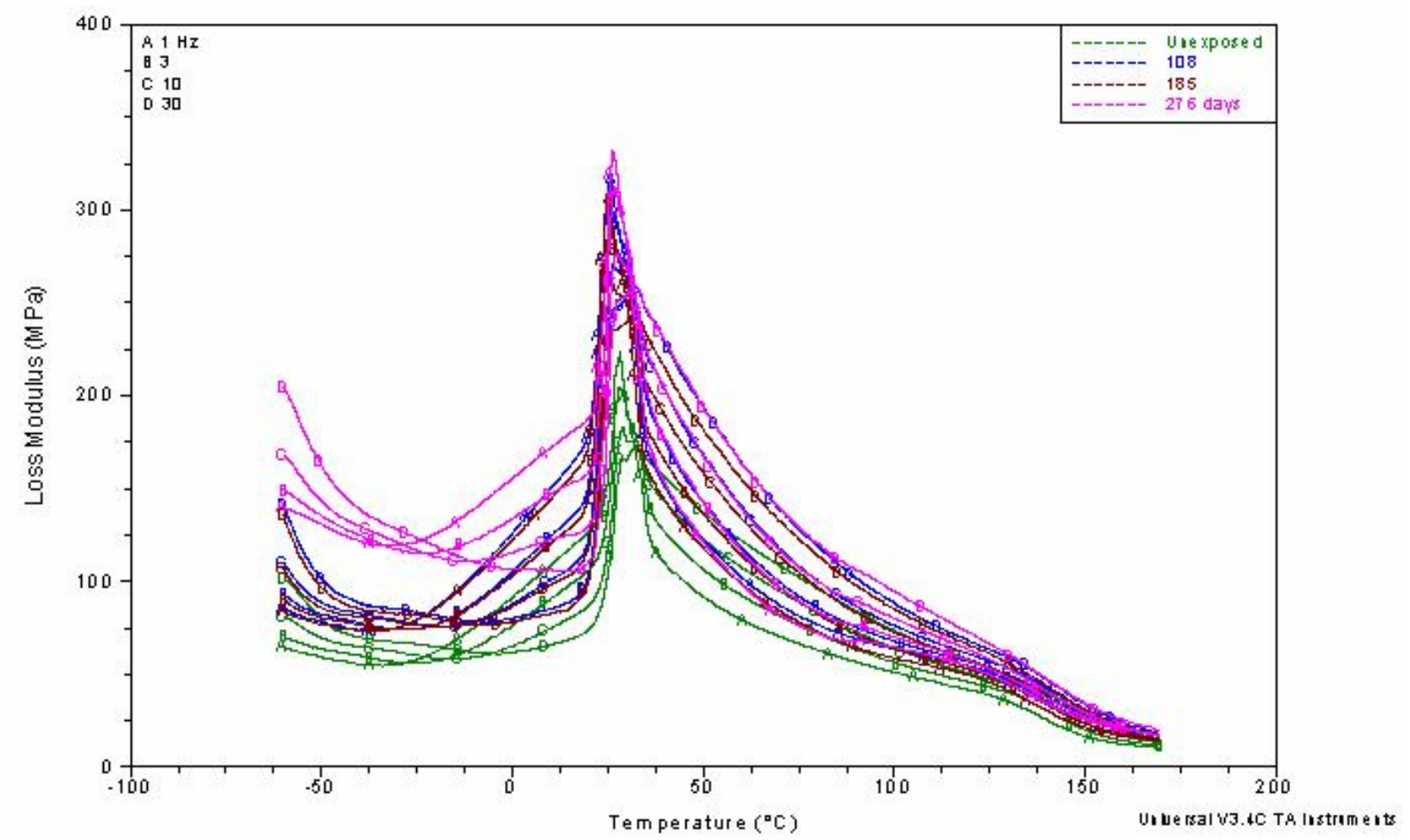

Figure 24. Loss Modulus of PTFE as a function of Temperature. Letters refer to applied frequency, different exposure times indicated by color. 
PTFE exposed to $1 \mathrm{~atm}$. T2 ambient temperature

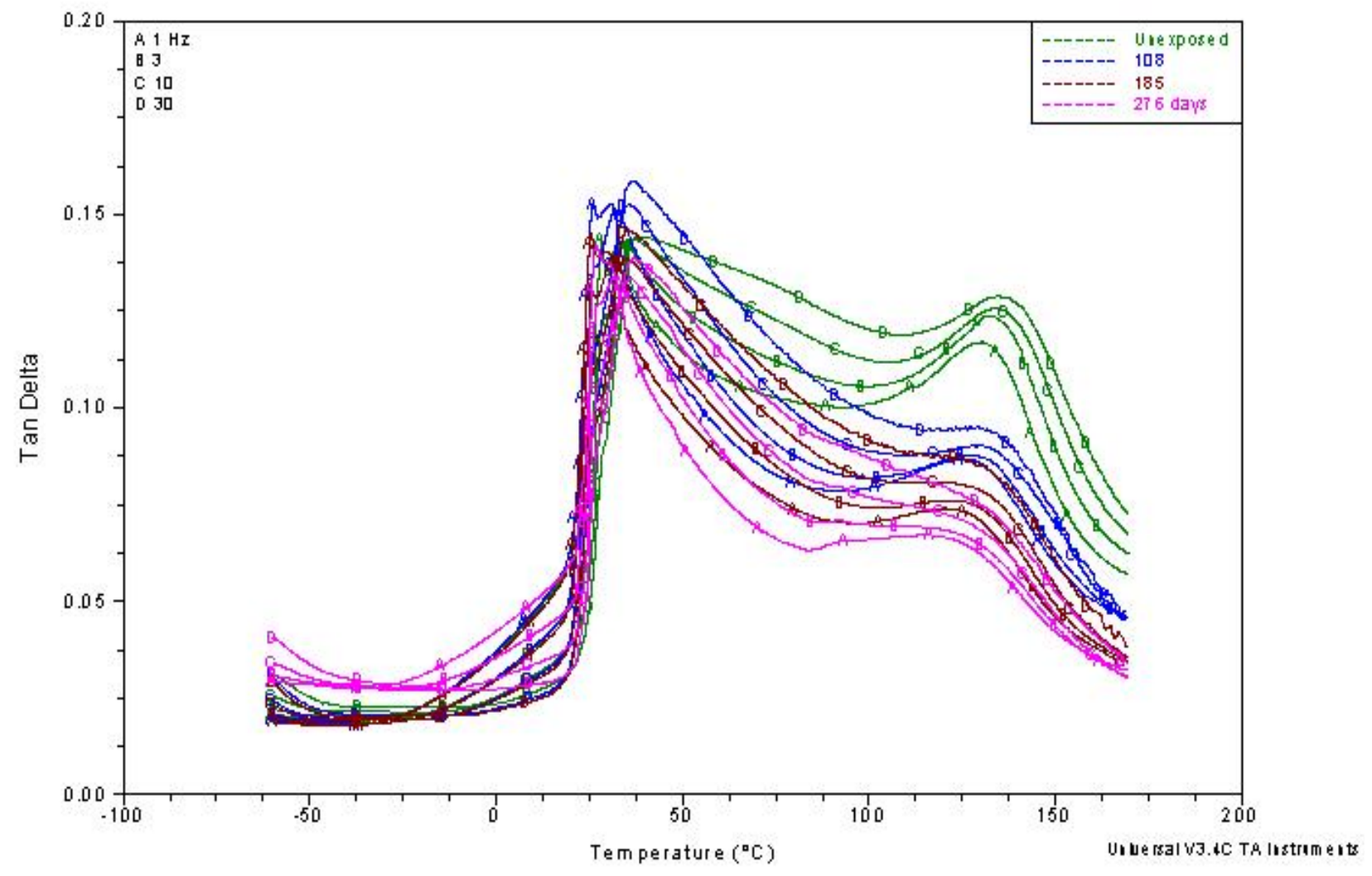

Figure 25. Tan $\delta$ of PTFE as a function of temperature. Applied frequency noted by letters, tritium exposure noted by line color. 


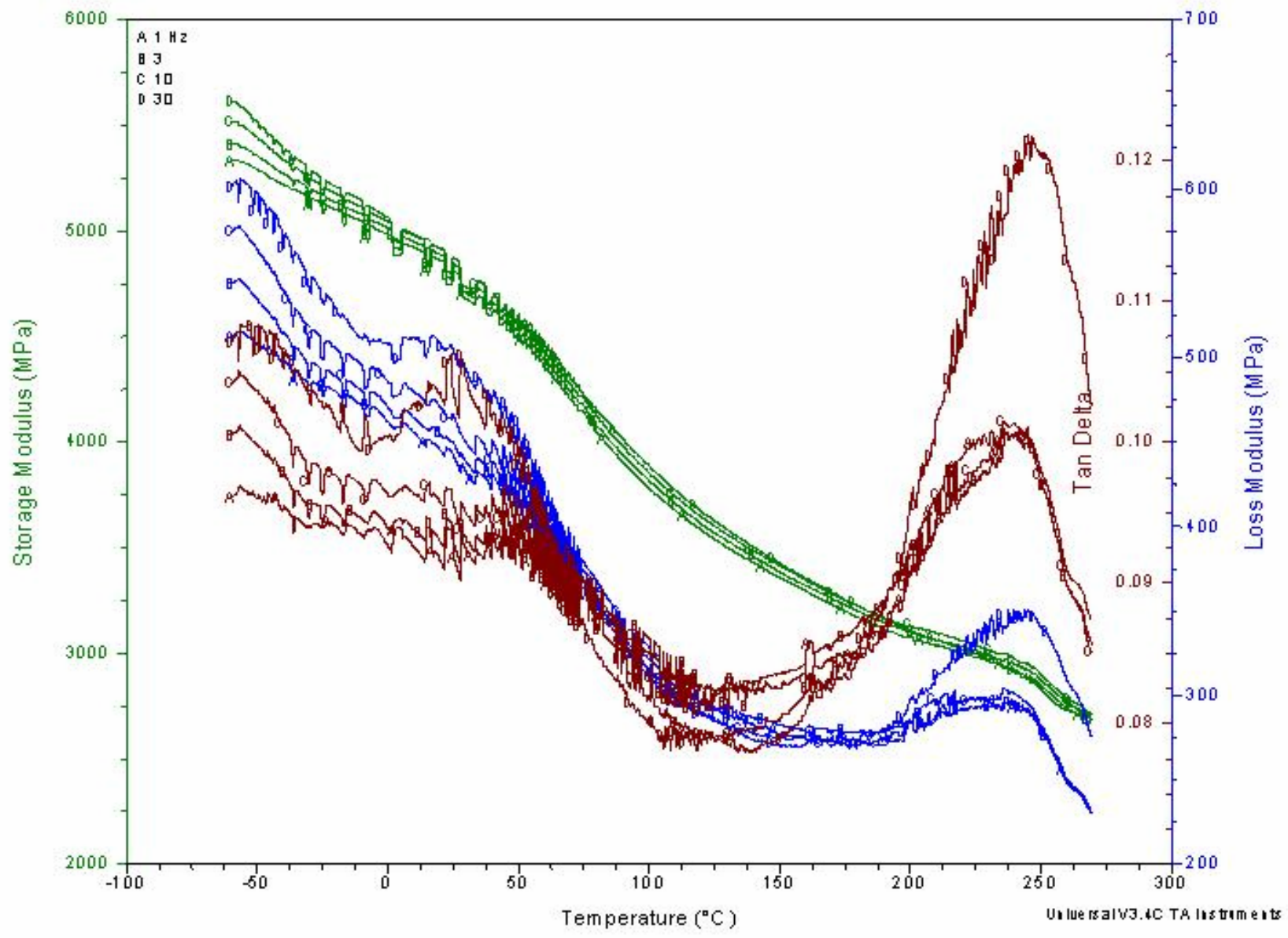

Figure 26. Storage modulus, loss modulus, $\tan \delta$ of unexposed Vespel ${ }^{\circledR}$. Temperature stabilized at $-60^{\circ} \mathrm{C}$., then increased at $1^{\circ} \mathrm{C}$./minute until $270^{\circ}$ C.- arbitrarily stopped. Applied frequency noted by letters, modulus and scale noted by color of axis. 


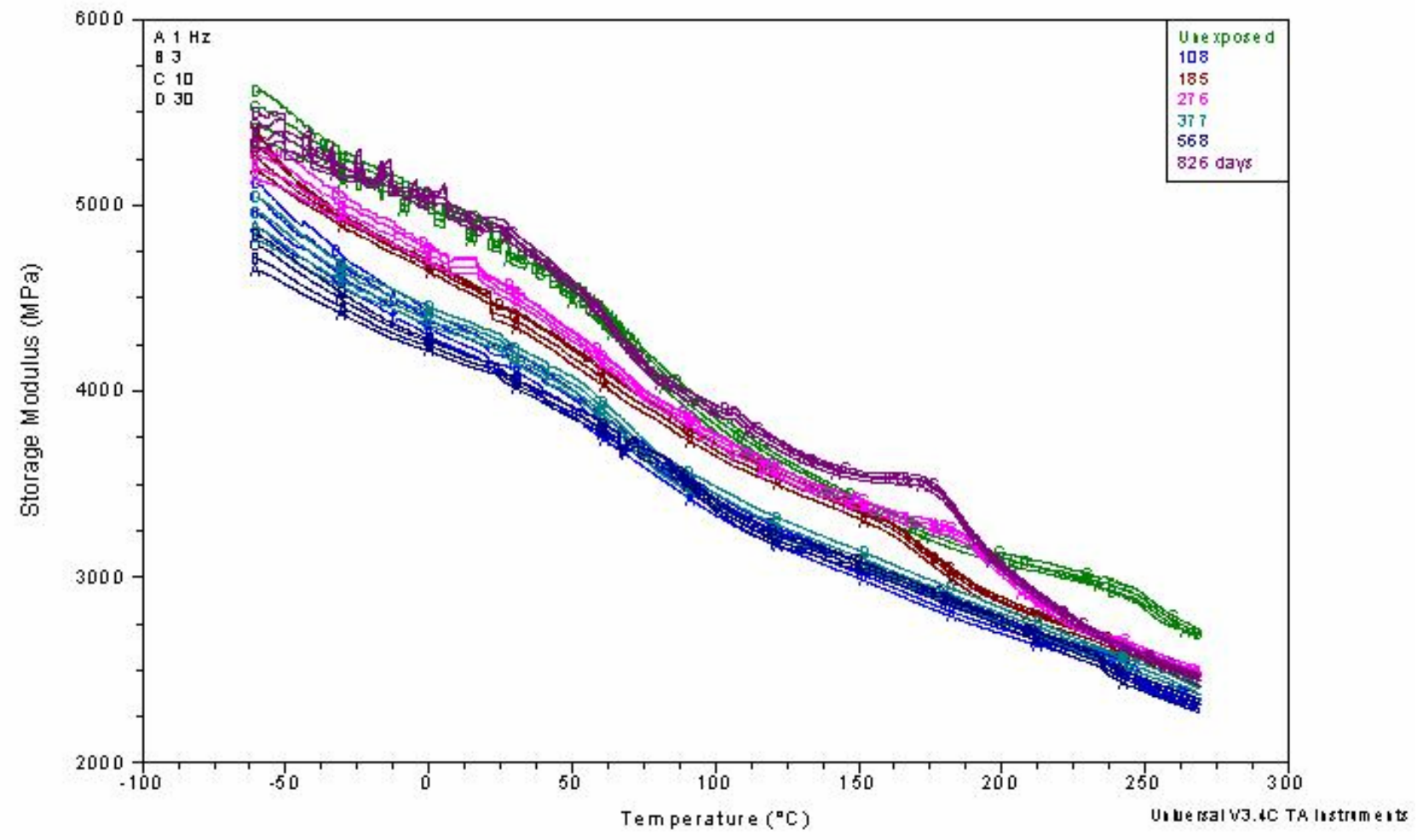

Figure 27. Storage Modulus of Vespel ${ }^{\circledR}$ SP-1 as a function of temperature for various tritium exposure times (color of line). Applied frequency noted by letter. 


\section{Vespel Storage Modulus at $1 \mathrm{~Hz}$}

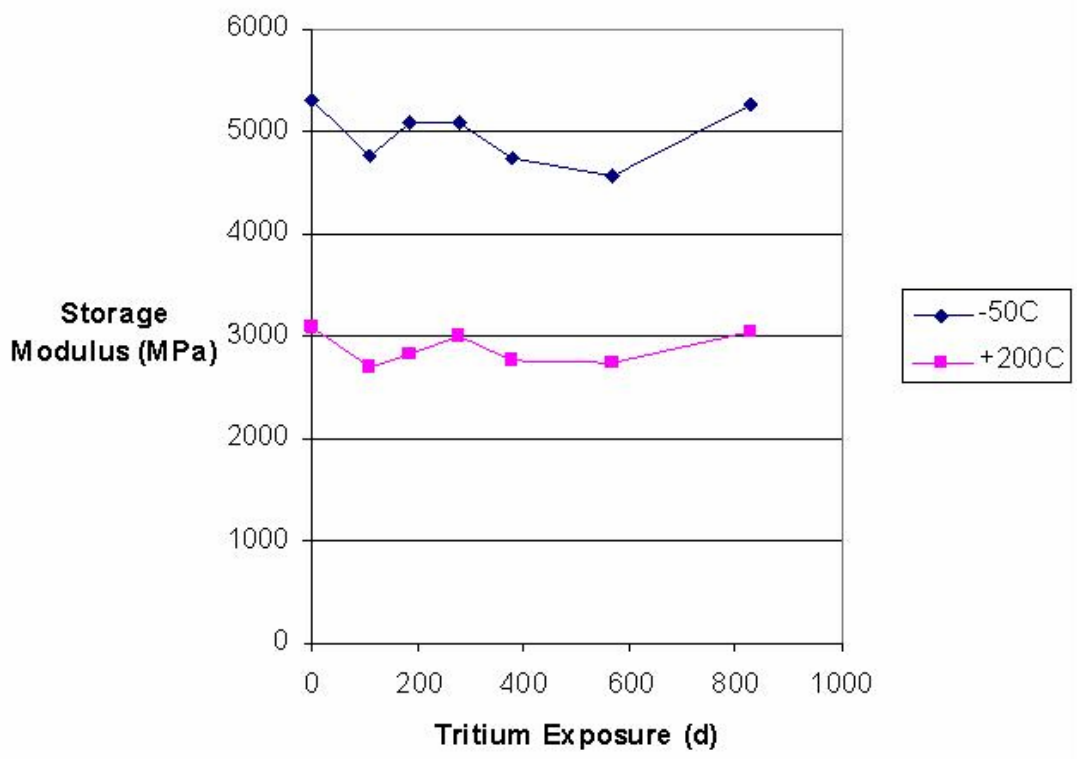

Figure 28. Storage Modulus of Vespel ${ }^{\circledR} \mathrm{SP}-1$ at $-50^{\circ} \mathrm{C}$. and $+200^{\circ} \mathrm{C}$. as function of tritium exposure in days.

Vespel, Frequency Dependance of Storage Modulus $-50 \mathrm{C}$

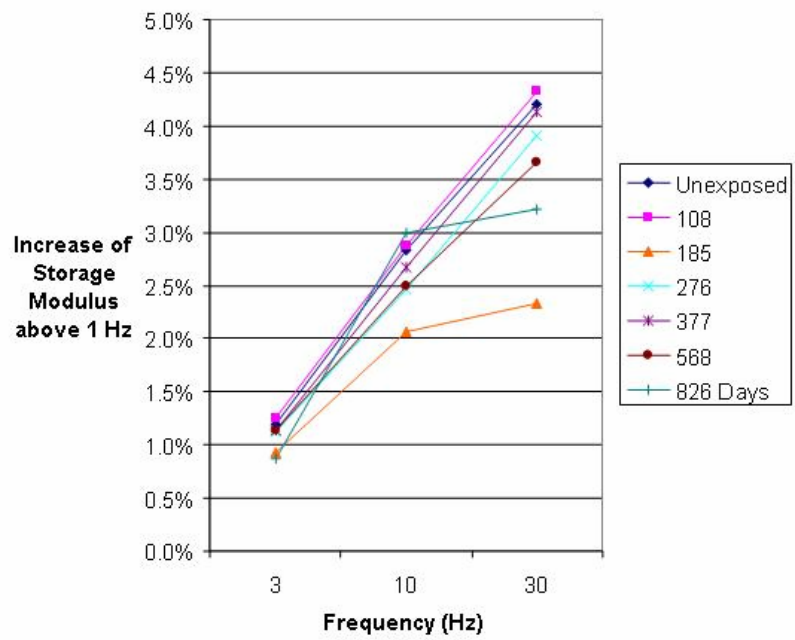

a.
Vespel, Frequency Dependance of Storage Modulus $+200 \mathrm{C}$

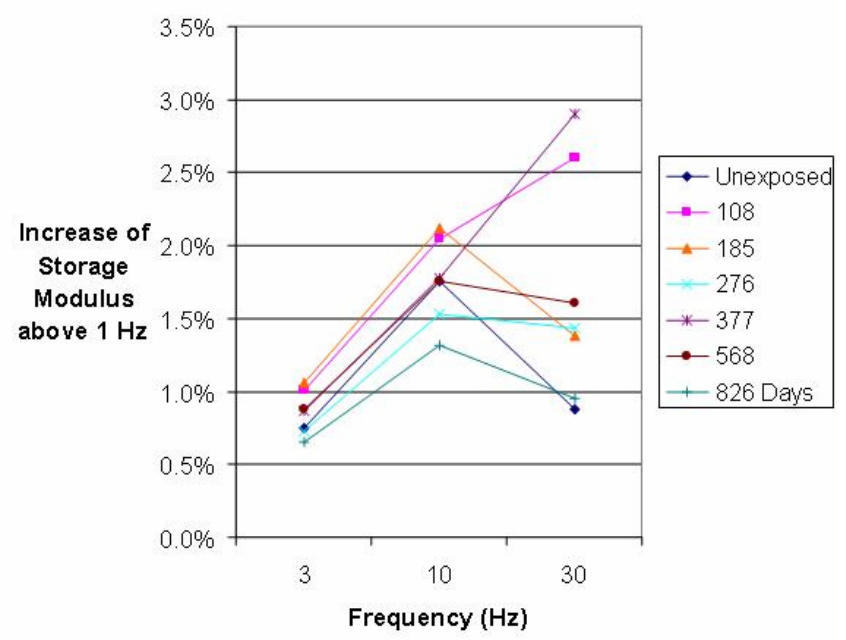

b.

Figure 29. Relative Increase of Vespel ${ }^{\circledR}$ Storage Modulus above that of $1 \mathrm{~Hz}$ as a function of frequency- a. $-50^{\circ}$ C., b. $+100^{\circ} \mathrm{C}$. 
Ve spel (R)exposed to 1 atm T2, Ambient temperature

Exposure in days

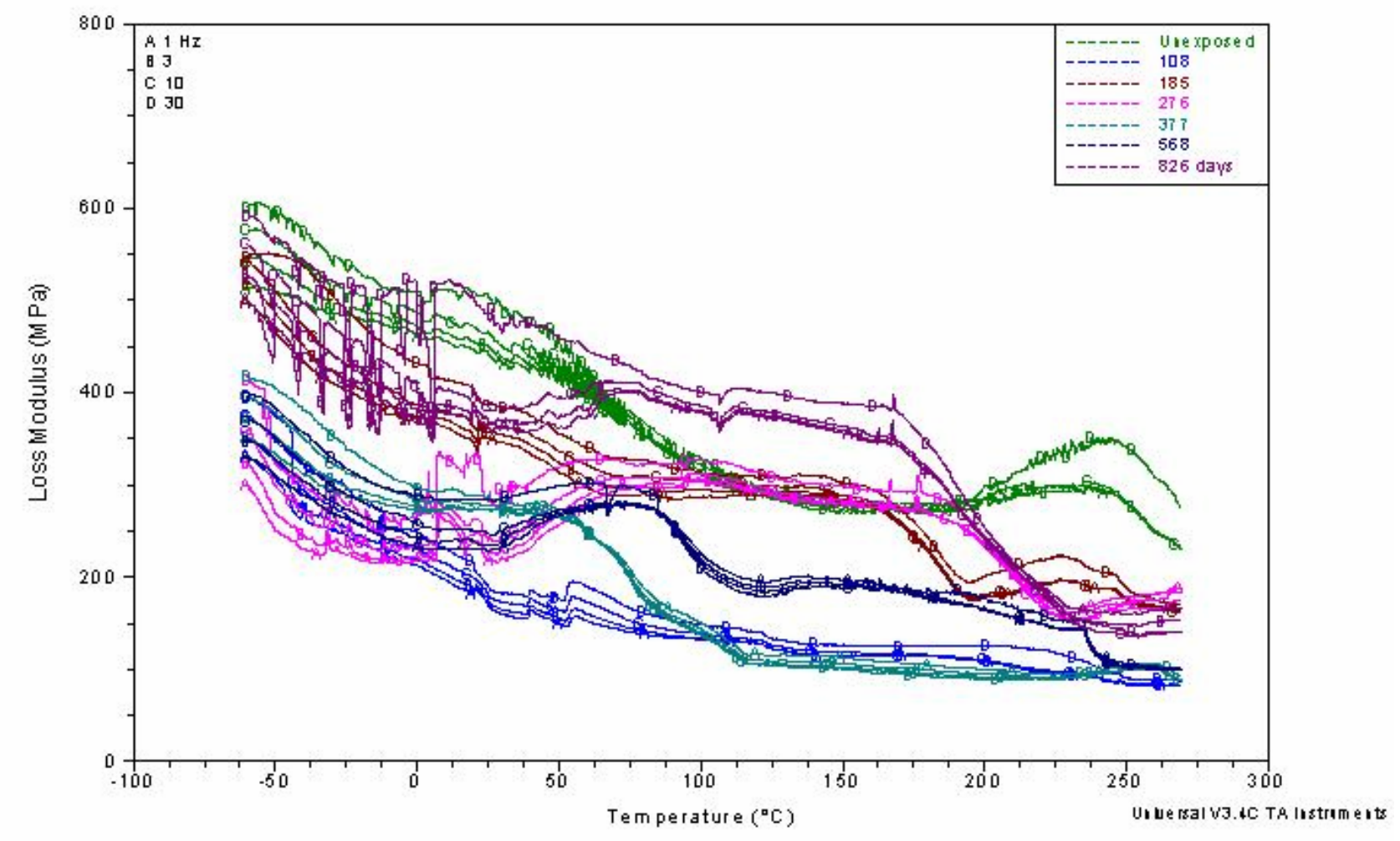

Figure 30. Loss modulus of Vespel ${ }^{\circledR}$ as function of temperature after various lengths of tritium exposure in days. Applied frequency denoted by letter, tritium exposure time by color. 


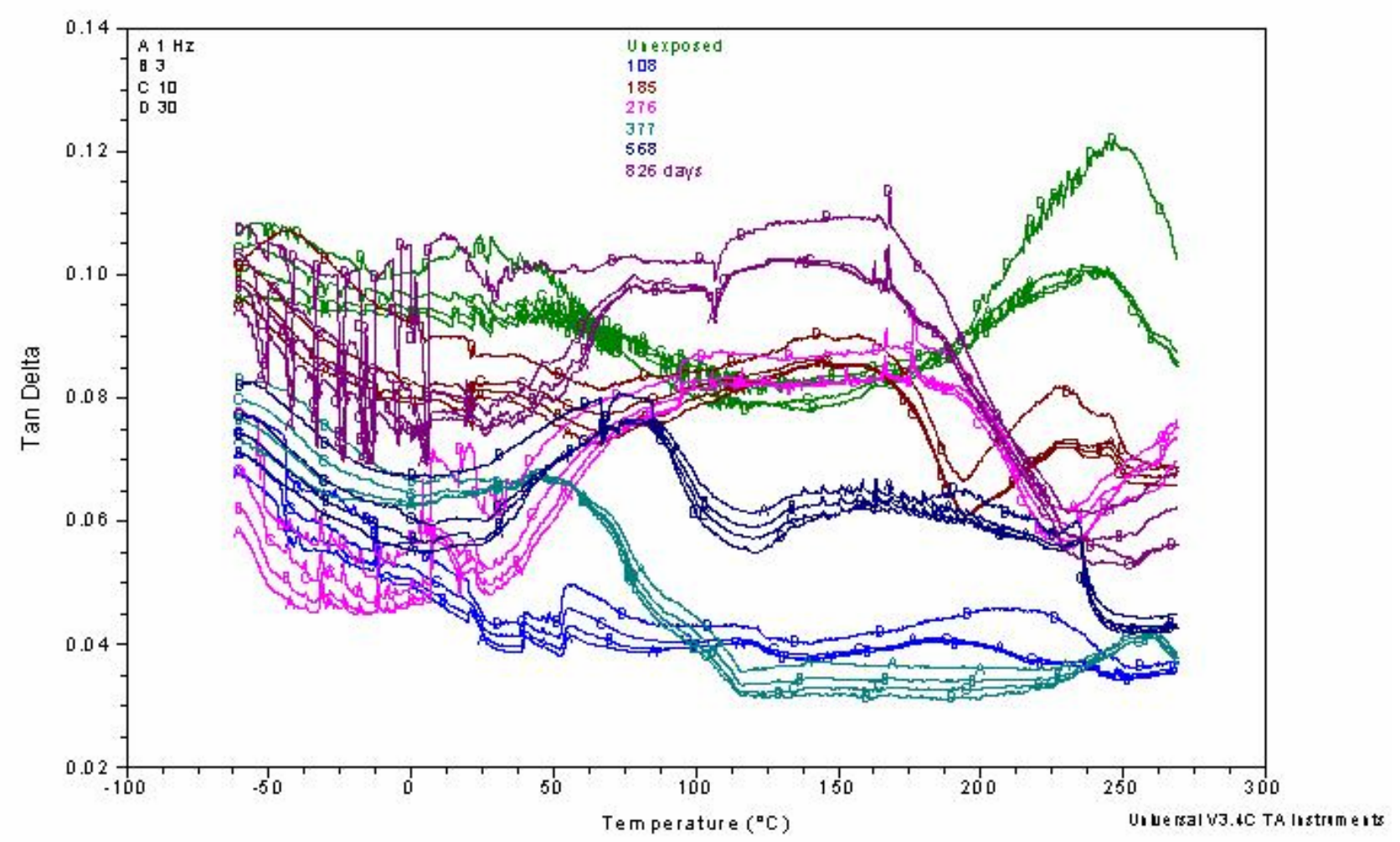

Figure 31. Tan $\delta$ of Vespel $^{\circledR}$ as function of temperature after various lengths of tritium exposure in days. Applied frequency denoted by letter, tritium exposure time by color. 


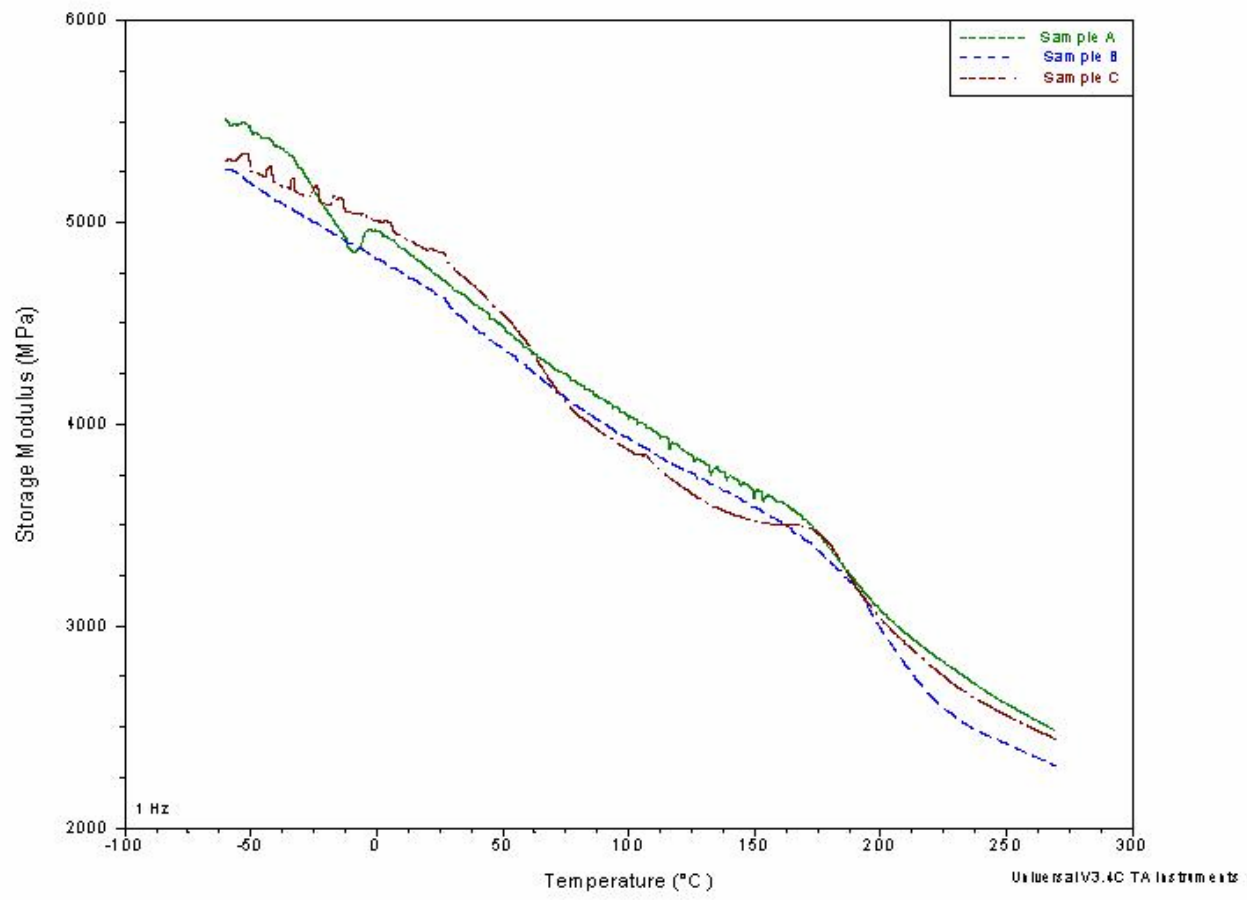

a.

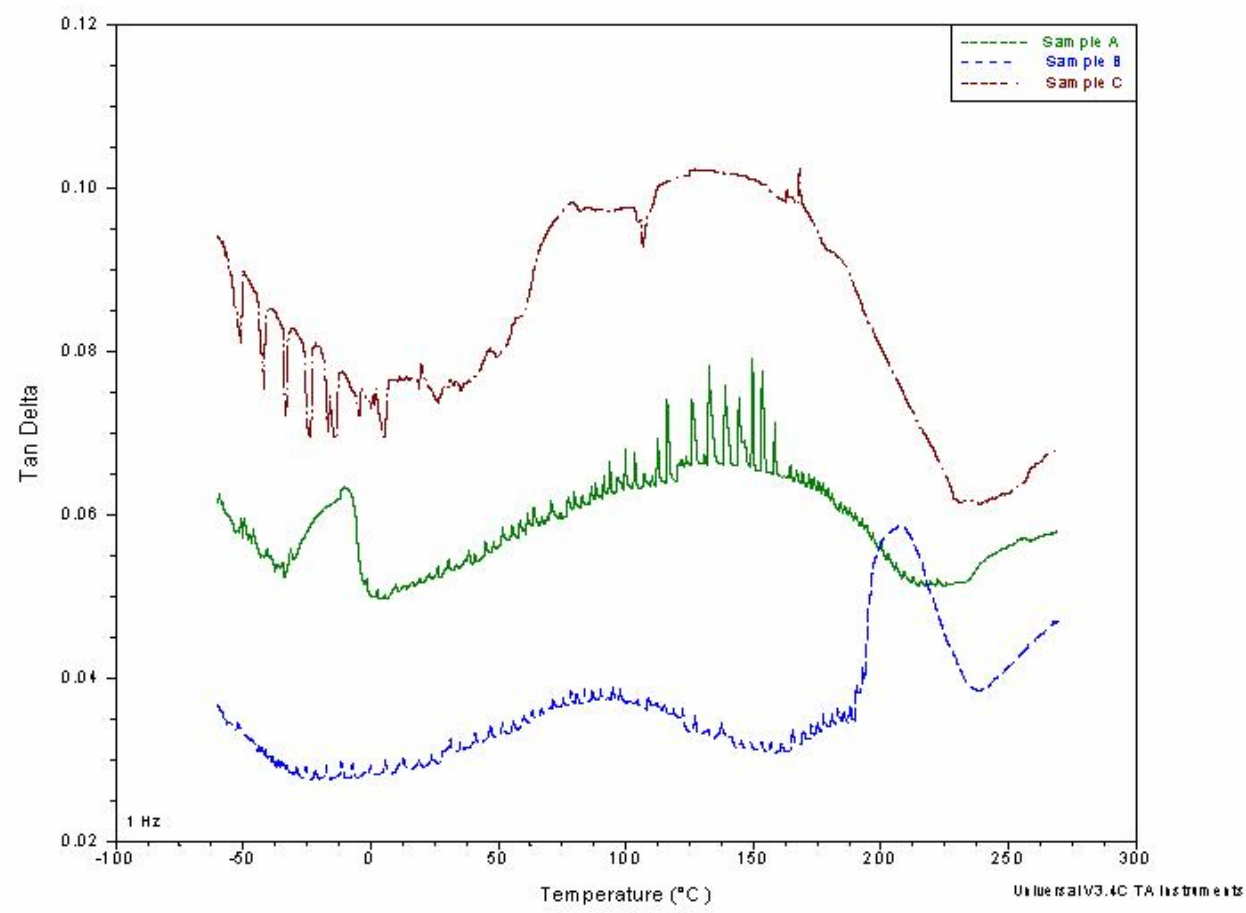

b.

Figure 32. Storage Modulus (a.) and Tan $\delta$ (b.) of three Vespel ${ }^{\circledR}$ samples exposed to tritium for 826 days. Note variation with sample- especially $\tan \delta$. 


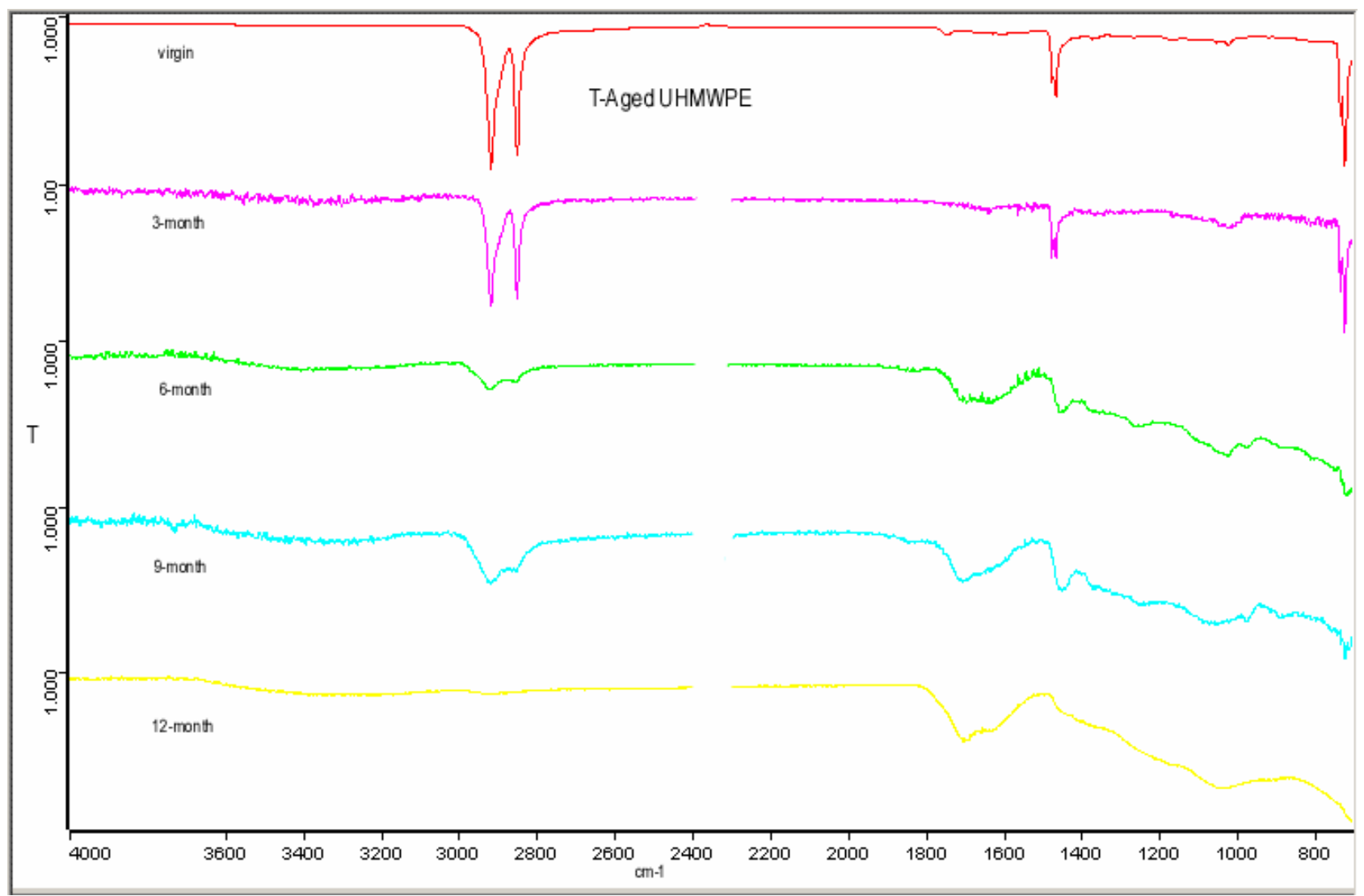

Figure 33. Series of IR Transmission Spectra - Transmittance as function of wave number for UHMWPE, samples exposed for nominal times as indicated. "Peaks" related to vibration of specific chemical bonds. "Virgin" is unexposed UHMW-PE. Note decrease of C-H stretch at $2800 \mathrm{~cm}^{-1}$ and increase of $\mathrm{C}-\mathrm{T}$ at $\sim 1700 \mathrm{~cm}^{-1}$ with increased tritium exposure time. (See Table I for exposure time in days). 


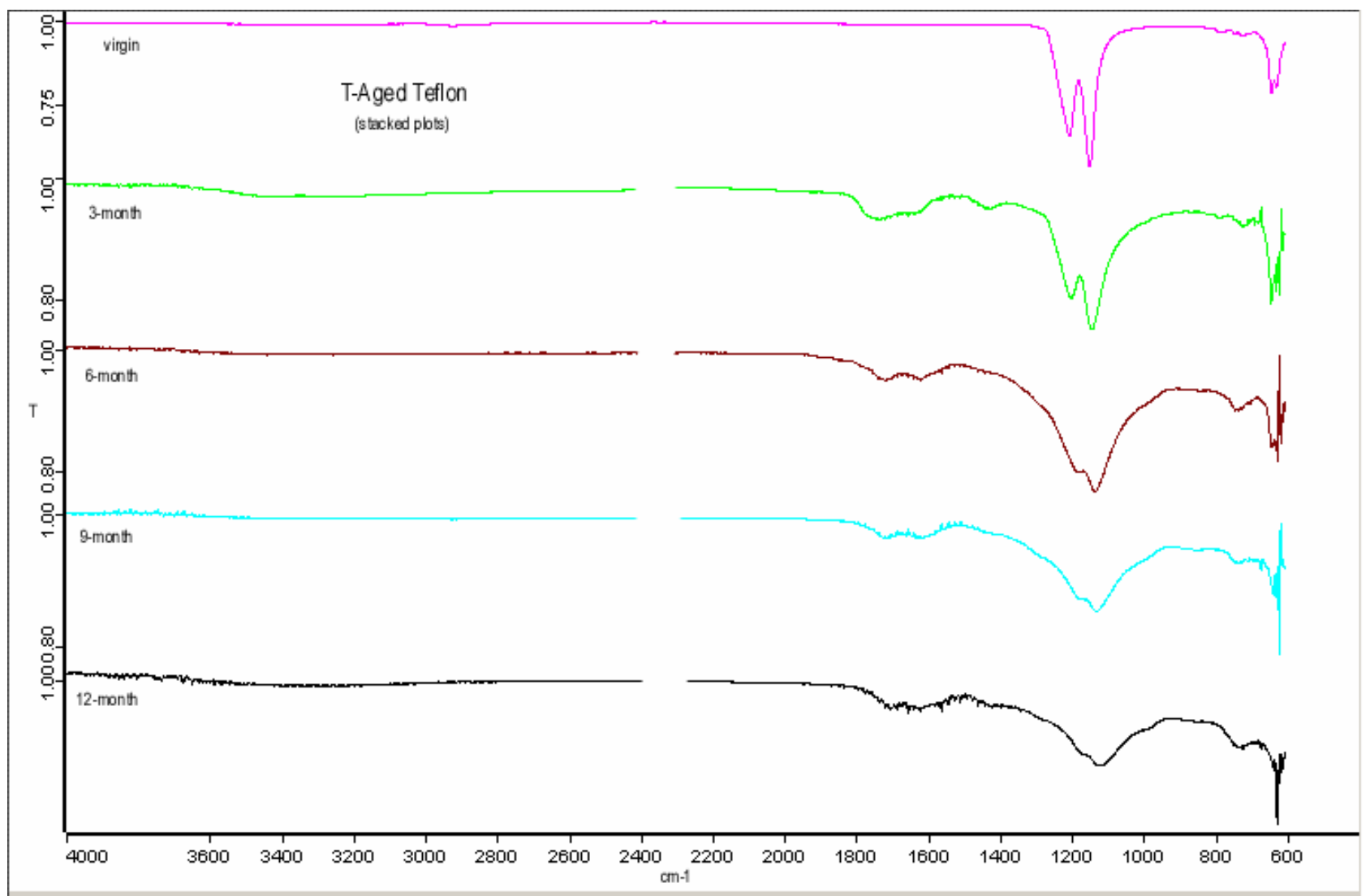

Figure 34. Series of IR Transmission Spectra - Transmittance as function of wave number for PTFE, samples exposed for nominal times as indicated. "Peaks" related to vibration of specific chemical bonds. "Virgin" is unexposed PTFE. Note decrease of C-F stretch at $1300 \mathrm{~cm}^{-1}$ and increase of C-T stretch at $\sim 1700 \mathrm{~cm}^{-1}$ with increased tritium exposure time. (See Table I for exposure time in days.) 


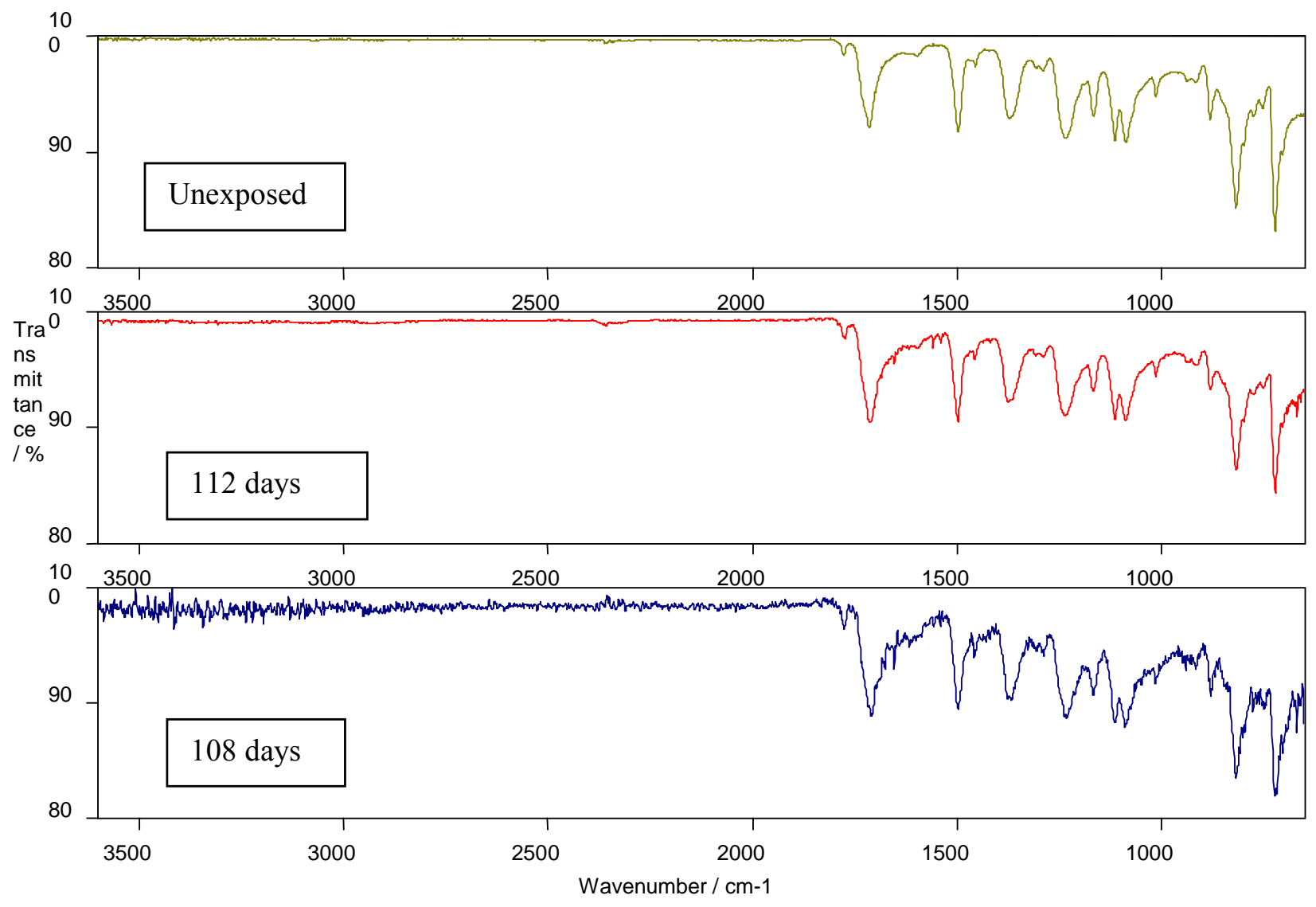

Figure 35. Series of Transmission Spectra - Transmittance as function of wave number for Vespel ${ }^{\circledR}$, samples exposed for nominal times as indicated. "Peaks" related to vibration of specific chemical bonds. Note no change of spectra with tritium exposure time. 


\section{Appendix}

\section{Gas/Solid Mass Balance Estimates}

Several estimates can be made to investigate and help explain observations of gas pressure and composition in the closed exposure containers. The internal diameter of the containers was measured with a ruler to be 1 $\mathrm{cm}$, and the internal length was $26.8 \mathrm{~cm}$ (Fig. 1). The volume of the main cylindrical part was thus $\pi^{*}(1 / 2)^{2} * 26.8=21.0 \mathrm{cc}$. The nominal density of UHMW-PE and PTFE is $0.91 \mathrm{~g} / \mathrm{cc}$. The total volume of samples in each container is estimated to be: UHMW-PE $2.28 \mathrm{cc}$ and PTFE $1.77 \mathrm{cc}$ (found by summing the calculated volume of the small and medium samples, averaged for all samples of a given type, and multiplying by 4 to account for the three DMA samples in addition to the small and medium samples).

\section{I) Pressure Increase in UHMW-PE Containers: ${ }^{1} \mathbf{H}_{2}$ Production}

During 2.3 years exposure, the pressure in the UHMW-PE containers increased from 760 torr to about 7000 torr, $90 \%$ of which was protium $\left({ }^{1} \mathrm{H}_{2}\right)$ (Fig. 8). This is a pressure increase $\Delta \mathrm{p}$ of 6240 torr, or $6240 \div 760=$ $8.2 \mathrm{~atm}$. The protium part of this increase is $90 \% * 8.2 \mathrm{~atm}=7.4 \mathrm{~atm}$. The total container volume was $21 \mathrm{cc}$ and the free volume was thus $21-2.28 \sim 19 \mathrm{cc}$, so the increase of protium in moles is

$$
\Delta \mathrm{n}=7.4 \mathrm{~atm} * 19 \mathrm{cc} \div 82.05[\mathrm{cc}-\mathrm{atm} / \mathrm{mol}-\mathrm{K}] \div 298 \mathrm{~K}=5.7 * 10^{-3} \mathrm{~mol}^{1} \mathrm{H}_{2}
$$

using the Ideal Gas Law. The protium source was the UHMW-PE. The repeat unit or mer $\left(-\left[\mathrm{CH}_{2}\right]_{\mathrm{n}^{-}}\right)$ molecular weight is $12 \mathrm{~g} / \mathrm{mol}$ carbon $+2 * 1 \mathrm{~g} / \mathrm{mol}^{1} \mathrm{H}=14 \mathrm{~g} / \mathrm{mol} \mathrm{mer}$. The total mass of UHMW-PE in the container was $0.91 \mathrm{~g} / \mathrm{cc} * 2.28 \mathrm{cc}=2.1 \mathrm{~g}$, so the moles of mer was $2.1 \mathrm{~g} \div 14 \mathrm{~g} / \mathrm{mol} \mathrm{mer}=0.15 \mathrm{~mol} \mathrm{mer}$. Each mer can provide 2 hydrogen atoms to the gas phase, so the fraction of mers needed to provide the amount of hydrogen gas in the container after 2.3 years was $5.7 * 10^{-3} \mathrm{~mol}^{1} \mathrm{H}_{2} \div 0.15 \mathrm{~mol} \mathrm{mer}=0.038$. This means that conversion of about $3.8 \%$ of the hydrogen available in the polymer to hydrogen gas would explain the pressure increase.

A typical molecular weight for UHMW-PE can be assumed to be 7,000,000 g/mol (I have seen values from 3-8 million weight-average molecular weight, not sure what was used in this study, or what this range will matter for your calcs (same order of magnitude). The number of moles polymer in a typical container in this study is $2.1 \mathrm{~g} \div 7,000,000 \mathrm{~g} / \mathrm{mol}=3 * 10^{-7} \mathrm{~mol}$. Since the moles of hydrogen produced is much greater than the moles of UHMW-PE before tritium exposure, the number of cross links is approximately equal to the amount of ${ }^{1} \mathrm{H}_{2}$ produced, or $5.7 * 10^{-3} \mathrm{~mol}$, assuming UHMW-PE cross links.

The production of gas from polymers by ionizing radiation is described in terms of the $G$ value for the reaction. The $\mathrm{G}$ value for $\mathrm{H}_{2}$ production from polyethylene is 3.1 molecules/100 ev energy deposited [5], or $0.031 \mathrm{molecule} / \mathrm{eV}$ (actual values may vary with dose rate and atmosphere). When $5.7 * 10^{-3} \mathrm{~mol}{ }^{1} \mathrm{H}_{2}$ were produced over 826 days ( 2.3 years), the total decay energy deposited was $5.7 * 10^{-3} \mathrm{~mol}^{1} \mathrm{H}_{2} * 6.02 * 10^{23}$ molecule $/ \mathrm{mol} \div 0.031$ molecule $/ \mathrm{eV}=1.1 * 10^{23} \mathrm{eV}$. The average decay energy of beta particle from tritium is $5.7 \mathrm{keV}$ (18.6 keV is the maximum decay energy) [13], so the number of disintegrations to generate the protium is $1.1 * 10^{23} \mathrm{eV} \div 5,700 \mathrm{eV} /$ disint. $=1.9 * 10^{19}$ disint.

The specific activity of $\mathrm{T}_{2}$ is $58,023 \mathrm{Ci} / \mathrm{mol}$ [14], and there are $3.7 * 10^{10}$ disintegrations/s per $\mathrm{Ci}$ (Curie); the specific activity of $\mathrm{T}_{2}$ is then $58,023 \mathrm{Ci} / \mathrm{mol} \mathrm{T}_{2} * 3.7^{*} 10^{10}$ disint. $/ \mathrm{s} / \mathrm{Ci}=2.1 * 10^{15}$ disint. $/ \mathrm{mol} \mathrm{T}_{2}$. Now during 2.3 years or 826 days $* 86400 \mathrm{~s} /$ day $=7.1 * 10^{7} \mathrm{~s}$, the total number of disintegrations is $2.1 * 10^{15} \mathrm{disint} . / \mathrm{s}-\mathrm{mol}$ $\mathrm{T}_{2} * 7.1 * 10^{7} \mathrm{~s}=1.5^{*} 10^{23}$ disint./mol $\mathrm{T}_{2}$. The actual number of disintegrations was $1.9 * 10^{19}$, so the number of moles $\mathrm{T}_{2}$ leading to the amount of hydrogen was $1.9 * 10^{19}$ disint. $\div 1.5^{*} 10^{23}$ disint. $/ \mathrm{mol} \mathrm{T}_{2}=1.3^{*} 10^{-4}$ mol $\mathrm{T}_{2}$. So over 2.3 years, the radioactive decay of $1.3^{*} 10^{-4} \mathrm{~mol} \mathrm{~T}$ resulted in $5.7^{*} 10^{-3} \mathrm{~mol}^{1} \mathrm{H}_{2}$, which implies that 
each tritium disintegration produced $5.7 * 10^{-3} \mathrm{~mol}^{1} \mathrm{H}_{2} \div 1.3 * 10^{-4}$ mol $\mathrm{T}_{2}=44$ molecules of ${ }^{1} \mathrm{H}_{2}$ produced by each tritium decay.

\section{II) Pressure reduction in PTFE containers: ${ }^{3} \mathrm{HF}$ (TF) Production}

During 2.3 years exposure, the pressure in the PTFE containers dropped from 760 torr to 443 torr (Fig. 8). This is a reduction of pressure $\Delta \mathrm{p}$ of 317 torr $\mathrm{T}_{2}$, or $317 / 760=0.42 \mathrm{~atm}$. Assuming a total container volume of $21 \mathrm{cc}$ (above) or a free volume of $21-1.77 \sim 19 \mathrm{cc}$, the reduction in moles of gas at $25^{\circ} \mathrm{C}$. or $298 \mathrm{~K}$ is

$$
\Delta \mathrm{n}=0.42 \mathrm{~atm} * 19 \mathrm{cc} \div 82.05[\mathrm{cc}-\mathrm{atm} / \mathrm{K}] \div 298 \mathrm{~K}=3.2 * 10^{-4} \mathrm{~mol} \mathrm{~T}_{2} \quad \text { A2 }
$$

using the Ideal Gas Law. If this amount of tritium all combines with fluorine from the PTFE samples in the container to form TF: since $3.2 * 10^{-4} \mathrm{~mol} \mathrm{~T}_{2}$ amounts to $6.4 * 10^{-4} \mathrm{~mol} \mathrm{~T}, 6.4^{*} 10^{-4} \mathrm{~mol} \mathrm{TF}$ is formed. This is $6^{*} 10^{-4} \mathrm{~mol} *(3 \mathrm{~g} \mathrm{~T} / \mathrm{mol}+19 \mathrm{~g} \mathrm{~F} / \mathrm{mol})=0.014 \mathrm{~g} \mathrm{TF}$ or $14 \mathrm{mg} \mathrm{TF}$. (Is only TF produced or other fluorinated compounds?)

To estimate the effect of this on the PTFE, since the atomic weight of fluorine is 19 and that of carbon is 12 ,

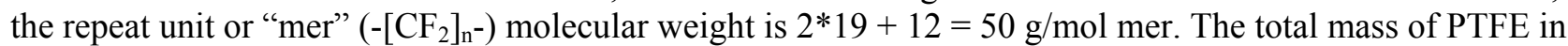
the container is $2.20 \mathrm{~g} / \mathrm{cc} * 1.77 \mathrm{cc}=3.9 \mathrm{~g}$, so the total mer mols is $3.9 \mathrm{~g} / 50 \mathrm{~g} / \mathrm{mol} \mathrm{mer}=7.8^{*} 10^{-2} \mathrm{~mol} \mathrm{mer}$. The fraction of mers that lost a fluorine atom to create the amount of TF is thus $6.4 * 10^{-4} \mathrm{~mol} \mathrm{TF} / 7.8 * 10^{-2}$ mol mer $=0.0083$, or $0.83 \%$ of the mers. 